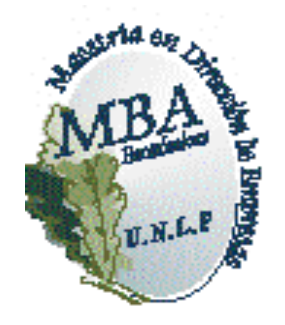

\author{
Universidad Nacional de La Plata \\ Facultad de Ciencias Económicas \\ MBA - Maestría en Dirección de Empresas
}

\title{
Calidad Educativa del Nivel Secundario de \\ La Plata
}

Autor: Basualdo, Gonzalo

Director:Legato Ana

\section{La Plata}

Diciembre 2014 


\section{Contenido}

1. Planteo del Problema.................................................................................................. 1

2. Objetivos de la investigación .......................................................................................... 4

3. Evaluación del problema .............................................................................................. 5

4. Alcances de la investigación ....................................................................................... 6

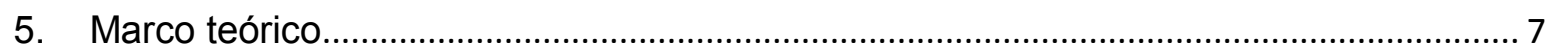

Teniendo en cuenta el objetivo del presente trabajo -analizar calidad educativa- se consideró oportuno hacer una breve referencia al concepto de calidad en general, para luego acotarlo a la calidad en educación. Descripción desarrollada en las siguientes

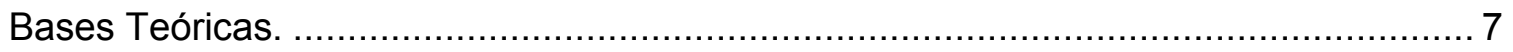

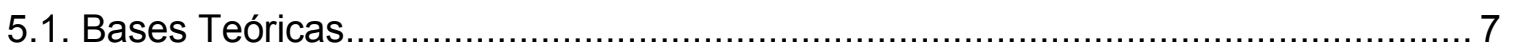

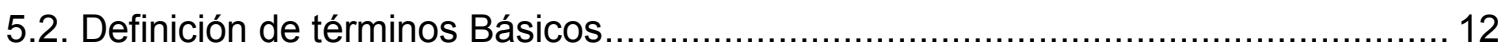

5.3. Antecedentes del problema........................................................................... 16

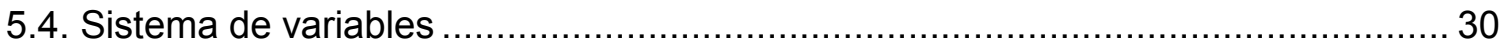

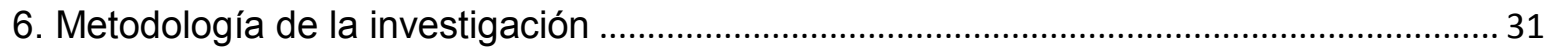

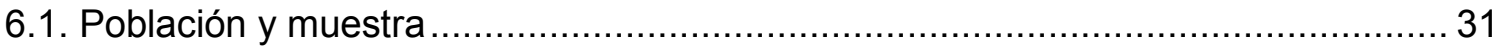

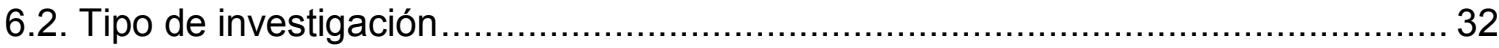

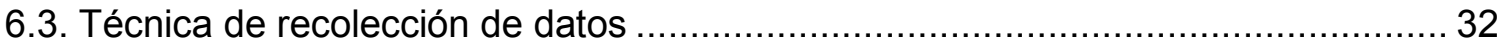

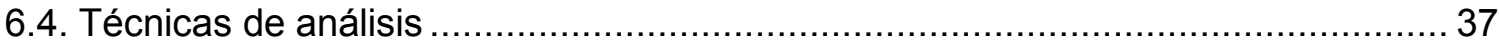

7. Resultados de la Investigación....................................................................................... 40

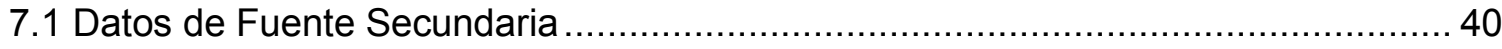

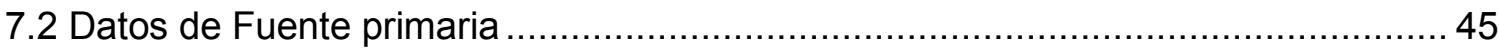

8. Conclusiones ………………………………………………………………………. 84

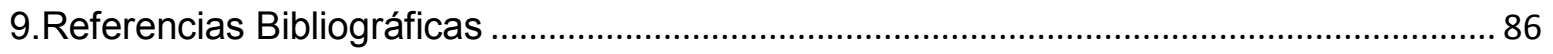

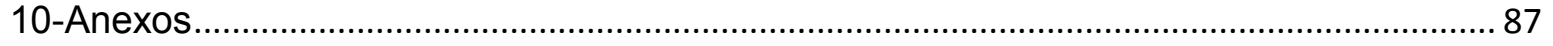

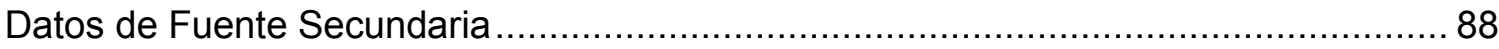




\section{Planteo del Problema}

En una sociedad democrática y participativa, los ciudadanos tienen derecho a conocer el funcionamiento de un servicio público como la educación. Sin embargo, el problema principal en Argentina radica en la falta de información acerca del nivel de calidad de la educación, tanto a escala provincial como nacional.

Los países con mayor desarrollo en educación, comunican los resultados de las evaluaciones en tiempo y forma a las escuelas, estos datos resultan creíbles y están a disposición de la comunidad de un modo transparente. En Argentina, los resultados de las evaluaciones que se realizan en el nivel secundario, en su mayoría no son devueltos a las escuelas en tiempo y forma.Son, en cambio, comunicados con gran discontinuidad, de modo poco claro, y de esta manera se deteriora su credibilidad.

"A la educación en la Argentina le falta tener normas claras y un clima apropiado para la enseñanza. (Binstock y Cerrutti, 2005) Estos problemas están relacionados con diversos factores, como el respeto por los horarios y la asistencia -tanto de profesores como de los alumnos-, con la ausencia de hábitos en cuanto al cuidado del orden en las aulas y de la metodología de trabajo, con la pérdida de días de clases por problemas gremiales, con una insuficiente capacitación para los docentes, con edificios que no están en las condiciones apropiadas de infraestructura y limpieza, y con familias que no brindan apoyo a los docentes y no participan en forma positiva en la educación de sus hijos.

(Binstock,G. y Cerrutti,M.,2005)

El nivel educativo de la sociedad siempre fue importante para el desempeño de las instituciones públicas o privadas, pero esa importancia aumenta con la complejidad de los procesos administrativos o productivos. También, con la velocidad con la que cambia la información educativa y la necesidad de actualizar la oferta educativa.

La educación cumple un papel determinante en el desarrollo económico, en generar empleos y en el resto de factores que afectan a la producción y economía del país. La buena formación de la población contribuye a mejorar el ambiente económico, pero no alcanza para generar empleos. En Argentina existen situaciones en las que los conocimientos noson utilizados o aprovechados debidamente e, incluso existe una fuga de talentos que no encuentra puestos de trabajo en el país. 
"La Argentina se rige por un sistema federal de gobierno y una organización descentralizada del sistema educativo. (...) El estado Nacional, Las provincias y la ciudad autónoma de Buenos Aires tienen la responsabilidad principal e indelegable de proveer una educación integral, permanente y de calidad para todos los habitantes de la nación, garantizando la igualdad, gratuidad y equidad en el ejercicio de este derecho, con la participación de las organizaciones sociales y las familias”.(López Armengol, M., 2011).

En 2011, el Banco Interamericano de Desarrollo,(BID) analizó las habilidades sociales de las nuevas generaciones de empleados en Argentina, estudio que arrojó que,según el $80 \%$ de las empresas, escasean cualidades importantes, como el compromiso con la actividad laboral y la capacidad de resolución ante problemas cotidianos, algo que no está incluido en los programas de la escuela secundaria como preparación al mundo del trabajo.

El citadoestudio señala que la formación académica manifiesta ser insuficiente, y que las empresas necesitan gente que asuma responsabilidades para las cuales los nuevos trabajadores no parecen estar preparados. Se expresa, además, que la falta de puntualidad y la falta de compromiso se ha convertido en algo habitual en el nuevo personal. A los jóvenes, el mundo del trabajo se les presenta lejano y extraño, la calidad de la preparación recibidaen años anteriores influye negativamente en su accionar, y cabe destacar que un promedio elevado, inclso el mejor entre sus compañeros, no los convertirá necesariamente en un buen trabajador.

Al indagar sobre las condiciones en que los jóvenes argentinos ingresan al mercado laboral, el BID concluyó lo siguiente: "Se requieren políticas educativas urgentes no sólo para abordar el problema de la calidad de la educación, sino de la pertenencia de la misma cuando se trata de facilitar las transiciones de los jóvenes al mundo del trabajo".

El economista y profesor de la Universidad de Chicago, James Heckman, apuntó a la educación como el factor más importante de generación de mejorías sociales. Heckman, J.(2000) sostuvo que, en el caso de los jóvenes, "es sólo a través del entrenamiento que se podrán reducir las desigualdades generadas por la utilización cada vez más intensa de las nuevas tecnologías".

La recomendación de Heckman es que la Argentina debe acrecentar la competitividad en las escuelas secundarias. La tasa de retorno a la educación en chicos 
que no pudieron terminar el nivel secundario $y$, aun para los que la terminan, es baja. Las capacidades innatas se forman en edad temprana.

Estas conclusiones han surgido del análisis de datos y resultados sobre el trabajo con personas, realizando un seguimiento durante 30 años, desde el momento de su nacimiento hasta la fecha en que se cumplió esa edad.

"Los conocimientos académicos no son suficientes para el desarrollo de los jóvenes en su vida adulta. La escuela tiene que cambiar y desarrollar metodologías que les permitan a los jóvenes poder desempeñarse en el mundo del trabajo. Los jóvenes no vienen preparados, no saben cumplir un horario, no saben identificar un problema ni comunicarlo a sus jefes y no saben trabajar en equipo".(Bassi, 2012).

En relación con lo citado anteriormente, la misma autora afirma que cada vez más jóvenes pueden acceder al sistema educativo, pero al mismo tiempo disminuye la cantidad de los que logran permanecer hasta el final del ciclo. A su vez, las habilidades adquiridas en la escuela secundaria son menos valoradas por los empleadores. (Bassi, 2012). En el mismo trabajo, sostiene que "el sistema educativo de la región tiene el enorme desafío de retener a los jóvenes hasta culminar su formación y de proporcionarles las destrezas que el trabajo y la sociedad les exigirán después".

El nivel secundario parece haber quedado muy atrás para ofrecer las herramientas necesarias para dar el primer paso en el mundo adulto, un mundo cada vez más competitivo perotambién que ofrece empleos cada vez más precarizados.(TentiFanfani, E., 2011).

Por su parte, Nancy Montes, investigadora del Área de Educación de la Flacso, señala que si bien en los últimos años aumentó la presencia de los jóvenes en las escuelas y disminuyó el porcentaje de los que teniendo edad para ir al colegio se encuentran trabajando, todavía subsiste un desencuentro entre lo que los jóvenes esperan de la escuela, lo que los docentes esperan de ellos y lo que efectivamente puede promover la escuela con su conformación actual. (Montes, 2013)

En un informe de 2012, la CEPAL señaló que existen fuertes distorsiones en la distribución interna de la inversión educativa en perjuicio de los escalones primarios del 
sistema. Esta forma de distribución afecta, en primer lugar, a los grupos de menores ingresos, que dependen del sistema público para su educación básica. En segundo lugar perjudica a los niveles superiores del sistema, que reciben aspirantes con formación inadecuada. Este déficit obliga a las universidades a establecer sistemas de selección o de nivelación. Si estos sistemas son estrictos impiden el ingreso de muchos aspirantes, pero si no lo son obligan a las universidades a costear la permanencia de un enorme grupo de estudiantes que abandonarán las aulas. Además de aumentar los recursos destinados a la educación, es necesario prestar atención a otros aspectos clave como la forma más adecuada de distribuir los fondos, la mejora en la calidad y la búsqueda de una mejor articulación entre sus diferentes niveles. De este modo se logrará una mejor utilización de los recursos sociales.

Uno de los puntos más resonantes de los últimos años tiene que ver con el ingreso a primer año en las carreras de la Universidad Nacional de Plata. En muchos casos no llegan a responder sobre cuestionarios preparados para alumnos de séptimo grado de la primaria, estas preguntas son sobre matemáticas, química y física, y solo aprueban el examen de ingreso entre el 10 y el $30 \%$ de los alumnos (Ver Anexos).(Nuevos aplazos masivos en el ingreso a IngenieríaRevisarán un examen que nadie aprobó)

Con respecto a la región conformada por los partidos de La Plata, Berisso y Ensenada, se da una carencia y desorden significativo de datos e información oportuna y útil para la toma de decisiones e iniciativas de proyectos, y propósitos. En la región no existe una base de datos e información fidedigna, que permita conocer con certeza el estado o nivel de situación real de la educación, es por ello que el objetivo del trabajo se basa en efectuar una investigación acerca del nivel de calidad de la educación secundaria.

\section{Objetivos de la investigación}

\section{Objetivo General}

Analizar el nivel de calidad de la educación secundaria en la ciudad de La Plata . 


\section{Objetivos específicos}

Los objetivos específicosplanteados en esta investigación son:

- Identificar parámetros de eficiencia del sector educativo en la ciudad de la Plata.

- Generar información acerca de la calidad educativa en el nivel secundario de la ciudad de la Plata.

- Comparar los parámetros de eficiencia obtenidos para La Plata con los obtenidos con el resto de la región, Berisso y Ensenada.

\section{Evaluación del problema}

La educación se ha convertido en uno de los principales caminos para el desarrollo económico de un país. De allí que los países avanzados hagan fuertes inversiones para aumentar el volumen y la calidad de la educación. En el mundo industrializado, la adecuación de los estándares educativos a lo que cada país o grupo de interés considera estratégico son motivos de análisis y discusión permanentes.

En Argentinase percibe un sistema educativo en el cual la calidad está sumamente deteriorada y cuestionada. "Resulta lamentable tener que afirmar que el deterioro de los insumos del proceso educativo (caída del gasto, deterioro del salario docente, disminución del tiempo de aprendizaje, etc.) no puede menos que producir un empobrecimiento de los procesos de producción del aprendizaje y por lo tanto, una pérdida de calidad de los productos educativos". (La escuela vacía. TentiFanfani, E.(2011).

En educación básica, la escuela secundaria es considerada como etapa propedéutica para el alumno(a)ya que al término de tres ciclos escolares debe decidir hacia qué área productiva enfocarse. La educación secundaria es entonces concebida comofundamental para el desarrollo sano e integral del adolescente. Sin embargo, es sabido que la escuela secundariasufre una marcada crisis porque las adecuaciones que debieran formularse en este nivel para lograrla calidad requerida al egresar el 
alumno(a), no se han puesto en marcha, por ende,no se logra hacer tangible en esta etapa, su calidad y pertinencia.

Los jóvenes de hoy, desde su propia perspectiva, ven una escasez de expectativas en su futuro inmediato, tanto en su formación y estudios como en su calidad de vida y futuro profesional aún cuando éste no sea tan inmediato. Por eso, todos los esfuerzos que el conjunto de la sociedad pueda realizar en educación, y en particular en este nivel de nuestra escuela pública, pueden parecer insuficientes para atender una demanda creciente que hasta hoy, no ha logrado el nivel de cobertura y calidad que se requieren para dar certidumbre a los futuros profesionales que el país demanda.

Defender, reformar y fortalecer a la escuela secundaria pública es importante para el desarrollo nacional no sólo por sus características de gratuidad y laicidad que redunda en accesibilidad para todos, sino porque representa el espacio más importante de influencia para la estructuración del perfil de la juventud.

La segmentación y la exclusión aparecen como fenómenos sociales importantes pero ahora se observa que desde la relación con el mercado laboral acompañan la expansión de la economía en conocimiento. (TentiFanfani; E. (2011).

Recrudecen así problemas como el desempleo, la pobreza y distintas formas de manifiesto la situación que afecta directamente a los trabajadores: la reducción de puestos de trabajo estables y la utilización total de las personas que ocupan dichos puestos, así las empresas solo garantizan puestos estables a una reducida parte del personal dando lugar a la precarización de los demás trabajadores. Las empresas se orientan hacia formas flexibles de contratación tanto externa como interna. La flexibilidad externa se refiere a la subcontratación de partes del proceso productivo hacia otras empresas, mientras que la flexibilidad interna se refiere a la polivalencia de su personal que debe adaptarse a condiciones cambiantes de trabajo. Esta exigencia de polivalencia y de adaptación permanente, unida a las exigencias de trabajo en equipo de creatividad en la solución de problemas cambiantes genera, potencialmente, un clima desestabilizador muy fuerte, tanto en el plano individual como en el institucional.

\section{Alcances de la investigación}


El alcance geográfico de esta investigación abarca a la ciudad de La Plata. Cabe aclarar que existen limitaciones relacionadas con la falta de datos estadísticos sobre las personas que terminan el secundario y su seguimiento correspondiente.

Esta es una investigación enmarcada en el proyecto del MBA, que será realizadasobre un área común que incluye la zona de influencia de las ciudades de La Plata, Berisso y Ensenada, y que a medida que avance dicha investigación los datos serán divididos y especificados en cada una de esas áreas menores.

Además, es necesario detallar que para trabajar con los indicadores y los cálculos que éstos arrojarán, se utilizará información concerniente al año 2011.

\section{Marco teórico}

Teniendo en cuenta el objetivo del presente trabajo -analizar calidad educativa- se consideró oportuno hacer una breve referencia al concepto de calidad en general, para luego acotarlo a la calidad en educación. Descripción desarrollada en las siguientes Bases Teóricas.

\subsection{Bases Teóricas}

\section{Calidad Total}

La Gestión de Calidad Total (abreviada TQM, del inglés Total Quality Management) es una estrategia de gestión creada por Deming, W.(1956)en la década de 1980 y orientada a crear conciencia de calidad en todos los procesos organizacionales. La TQM ha sido ampliamente utilizada en manufactura, educación, gobierno e industrias de servicio. Se le denomina «total» porque en ella queda concernida la organización de la empresa globalmente considerada y las personas que trabajan en ella.

El concepto de la calidad total es una alusión a la mejora continua, con el objetivo de lograr la calidad óptima en la totalidad de las áreas.

Kaoru Ishikawa un autor reconocido de la gestión de la calidad, proporcionó la siguiente definición respecto a la Calidad Total: "Filosofía, cultura, estrategia o estilo de gerencia de una empresa según la cual todas las personas en la misma, estudian, practican, participan y fomentan la mejora continua de la calidad".

La calidad total puede entenderse como la satisfacción global aplicada a la actividad empresarial. 


\section{Concepto de percepción de la calidad}

El concepto de calidad total está relacionado con otro concepto: el de la "percepción de la calidad", que es la percepción que se tiene de la calidad de un producto o de como ve la gente a una empresa o una marca (su forma de vender, el trato hacía los clientes, su implicación en proyectos sociales o con el medio ambiente).

\section{Satisfacción global}

La satisfacción global, como su nombre indica, no solo atañe a los clientes de cada empresa, sino a todo el "universo" de la empresa, es decir: a los propios empleados y a otras empresas que le venden sus productos/servicios (lo que se denomina clientes internos).

\section{Calidad total en la educación}

En el sector educativo la cultura de la Calidad Total pareciera ser de dificultosa implementación toda vez que se trata de estructuras burocráticas y no resulta sencillo definir quien es el cliente final y la detección de sus requerimientos.

Esto implica asumir que la Calidad Total solamente está destinada a satisfacer las necesidades del cliente, sin embargo, Calidad Total es mucho más que eso: es reducir costos, es incrementar la productividad y es lograr una mejor calidad de vida.

Son estas últimas consideraciones las que permiten afirmar que en el ámbito educativo también es aplicable la Calidad Total.

El proceso de implantación de un sistema de calidad en un centro docente considera las siguientes fases:

- Toma de conciencia de la situación actual del centro, de los problemas, de la necesidad de cambio

- Decisión de empezar que se concreta en dos momentos: ¿qué se va a hacer? (se formará a la dirección y parte del personal sobre el tema de la calidad y los instrumentos que se utilizan en los sistemas de calidad), ¿dónde se está posicionado? (se hará un diagnóstico de la situación actual del centro).

- Declaración de un plan para la mejora del centro y aceptación por todo el colectivo.

- Actuación de todo el personal según los acuerdos 
- Seguimiento y control del proceso, con el fin de comprobar el logro de los objetivos, analizar las desviaciones y sus posibles causas; establecer mecanismos de corrección...

- Establecimiento de un sistema de mejora continúa de la calidad. Comprenderá: una estructura organizativa y el empleo de herramientas adecuadas.

\section{Calidad en Educación}

La OCDE (Organización para la Cooperación y Desarrollo Económico) define la educación de calidad como aquella que "asegura a todos los jóvenes la adquisición de los conocimientos, capacidades destrezas y actitudes necesarias para equipararles para la vida adulta".

"La escuela de calidad es la que promueve el progreso de sus estudiantes en una amplia gama de logros intelectuales, sociales, morales y emocionales, teniendo en cuenta su nivel socioeconómico, su medio familiar y su aprendizaje previo. Un sistema escolar eficaz es el que maximiza la capacidad de las escuelas para alcanzar esos resultados". (Mortimore,J,1995)

La eficacia no estará en conseguir un buen producto a partir de unas buenas condiciones de entrada, sino en hacer progresar a todos los alumnos a partir de sus circunstancias personales. En este sentido conviene enfatizar en la calidad de los procesos escolares, y evitar dar un valor absoluto a los productos obtenidos.

\section{La calidad desde la esfera de los valores}

Un sistema educativo de calidad se caracteriza por su capacidad para:

- Ser accesible a todos los individuos.

- Facilitar los recursos personales, organizativos y materiales, ajustados a las necesidades de cada alumno para que todos puedan tener las oportunidades que promoverán lo más posible su progreso académico y personal.

- Promover el cambio yla innovación en la institución escolar y en las aulas (lo que se conseguirá, entre otros medios, posibilitando la reflexión compartida sobre la propia práctica docente y el trabajo colaborativo del profesorado)

- Promover la participación activa del alumnado, tanto en el aprendizaje como en la vida de la institución, en un marco de valores donde TODOS se sientan respetados y valorados como personas. 
- Lograr la participación de las familias e insertarse en la comunidad

- Estimular y facilitar el desarrollo y el bienestar del profesorado y de los demás profesionales del centro.

\section{Características de los centros docentes eficaces:}

Ciertas características deben estar presentes en la formación docente para garantizar un nivel cualitativo suficiente. Entre ellas, se destacan las siguientes:

- Compromiso con normas y metas compartidas y claras. Los fines generales de la educación deben considerar tres categorías básicas:

1. En primer lugar, la atención permanente sobre la competencia académica y personal.

2. En segundo término, no menos importante, el grado de socialización de los estudiantes

3. Y, finalmente, apuntar a la formación integral de los estudiantes.

- Búsqueda y reconocimiento de unos valores propios.

- Liderazgo profesional de la dirección. La actividad directiva se centra en el desarrollo de actividades de información, organización, gestión, coordinación y control. Supone una continua toma de decisiones en aspectos: administrativos y burocráticos, jefatura del personal, disciplina de los alumnos, relaciones externas, asignación de recursos y resolución de problemas. Debe conocer bien lo que pasa en el centro, mediar en la negociación de los conflictos y ver de tomar decisiones compartidas.

- Estabilidad laboral y estrategias para el desarrollo del personal, acorde con las necesidades pedagógicas de cada centro. Procurar el aprendizaje continuo del profesorado y la actualización de los contenidos, recursos y métodos.

- Currículum bien planeado y estructurado, con sistemas de coordinación y actualización periódica.

- Clima de aprendizaje. La enseñanza y el aprendizaje deben constituir el centro de la organización y la actividad escolar. Se debe cuidar el ambiente de aprendizaje buscando el aprovechamiento del estudiante y el empleo eficiente de los tiempos de aprendizaje. La motivación y los logros de cada estudiante están muy influidos por la cultura o clima de cada escuela. 
- Profesionalidad de la docencia: organización eficiente del profesorado, conocimiento claro de los propósitos por los alumnos, actividades docentes estructuradas, tratamiento de la diversidad, seguimiento de los avances de los estudiantes, uso de refuerzos positivos, claras normas de disciplina, en fin, eficacia docente

- Expectativas elevadas sobre los alumnos y sus posibilidades, comunicación de estas expectativas, proponer desafíos intelectuales a los estudiantes.

- Atención a los derechos y responsabilidades de los estudiantes, darles una cierta responsabilidad en actividades del centro, control de su trabajo, atender a su autoestima...

- Elevado nivel de implicación y apoyo de los padres. Participación de la comunidad educativa

- Apoyo activo y sustancial de la administración educativa

Con todo hay que tener en cuenta que según la perspectiva sobre la noción de calidad que se adopte variará lo que se considere una escuela eficaz; sólo se puede hablar de eficacia en función del logro de unos fines específicos.

\section{Principios de la calidad total en educación}

A lo largo del tiempo ha ido variando la consideración de lo que resulta fundamental en la calidad. Primero fue el "producto", más tarde el "proceso", luego los "trabajadores". Actualmente la calidad total se fundamenta en la idea de la satisfacción del cliente (en el ámbito educativo esto puede considerarse la superación de los principios de las "escuelas eficaces")

- Lo más importante es la satisfacción del cliente, con el costo más bajo posible. La empresa de éxito será la que identifique y satisfaga las expectativas de sus clientes.

- El proceso de calidad total se inicia con la detección de problemas y deficiencias y la propuesta de determinadas soluciones.

- La gestión de la calidad se fundamenta en el desarrollo continuo de planes integrales, no en la ejecución de simples acciones aisladas o puntuales.

- La toma de decisiones se debe realizar como consecuencia de datos y evidencias, no a partir de suposiciones y opiniones. Por lo tanto es preciso evaluar.

- La calidad depende básicamente de las personas, por ello resulta fundamental atender a aspectos como: 
- La participación

- El compromiso

- La implicación voluntaria

- La colaboración

- El trabajo en equipo

- La formación de las personas

- Propiciar el desarrollo/crecimiento personal de cada individuo como clave del crecimiento y enriquecimiento de la organización

- La calidad total implica a toda la organización

Una educación de calidad es aquella que promueve:

- La construcción de conocimientos psicológica, social y científicamente significativos.

- El desarrollo de procesos de pensamiento y estrategias cognitivas que le permitan al sujeto "aprender a aprender".

- La apropiación de instrumentos para participar en la vida económica, política y social, contribuyendo a la construcción de un modelo social democrático.

- El desarrollo de habilidades básicas que posibiliten al educando, la inserción en condiciones adecuadas en el nivel siguiente del sistema educativo o la incorporación a la vida activa.

- La aplicación del conocimiento para operar sobre la realidad.

- La posibilidad de la duda y la discusión.

- La consideración de las características propias del sujeto de aprendizaje, en sus aspectos cognitivos, socio-afectivos y psicomotrices.

- El crecimiento profesional del docente.

\subsection{Definición de términos Básicos}

A efectos de la investigación y de los objetivos propuestos se hace necesario definir ciertos conceptos básicos que serán utilizados de modo recurrente, entre ellos:

\section{Educación}

La educación, (del latíneducere "sacar, extraer" o educare "formar, instruir") puede definirse como: 
- El proceso multidireccional mediante el cual se transmiten conocimientos, valores, costumbres y formas de actuar. La educación no sólo se produce a través de la palabra, pues está presente en todas las acciones, sentimientos y actitudes. Por lo tanto, no sólo tiene lugar en las aulas de las instituciones educativas, sino que es un proceso que se comparte entre las personas por medio de las ideas, la trasmisión cultural y de conocimientos, etc.

- El proceso de vinculación y concientizacióncultural, moral y conductual. Así, a través de la educación, las nuevas generaciones asimilan y aprenden los conocimientos, normas de conducta, modos de ser y formas de ver el mundo de generaciones anteriores, creando además otros nuevos.

- Proceso de socialización formal de los individuos de una sociedad.

Existen tres tipos de educación: la educación formal, la educación no formal y la educación informal. La educación formal hace referencia a los ámbitos de las escuelas, institutos, universidades, módulos, mientras que la no formal se refiere a los cursos, academias, e instituciones, que no se rigen por un particular currículo de estudios, y la educación informal es aquella que fundamentalmente se recibe en los ámbitos sociales, pues es la educación que se adquiere progresivamente a lo largo de toda la vida.

\section{Educación básica}

Preescolar, educación primaria y secundaria es la etapa de formación de los individuos en la que se desarrollan las habilidades del pensamiento y las competencias básicas para favorecer el aprendizaje sistemático y continuo, así como las disposiciones y actitudes que regirán sus respectivas vidas (educación en valores). Lograr que todos los niños, las niñas, y los adolescentes del país tengan las mismas o similares oportunidades de cursar y concluir con éxito la educación básica, para así lograr los aprendizajes que se establecen para cada grado y nivel, son factores fundamentales para sostener el desarrollo de la nación.

En una educación básica de buena calidad el desarrollo de las competencias básicas y el logro de los aprendizajes de los alumnos son los propósitos centrales, son las metas a las cuales los profesores, la escuela y el sistema dirigen sus esfuerzos.

Permiten valorar los procesos personales de construcción individual de conocimiento por lo que, en esta perspectiva, son poco importantes los aprendizajes 
basados en el procesamiento superficial de la información y aquellos orientados a la recuperación de información en el corto plazo.

Una de las definiciones más interesantes la propone uno de los más grandes pensadores, Aristóteles: "La educación consiste en dirigir los sentimientos de placer y dolor hacia el orden ético."

También se denomina educación al resultado de este proceso, que se materializa en la serie de habilidades, conocimientos, actitudes y valores adquiridos, produciendo cambios de carácter social, intelectual, emocional, etc. en la persona que, dependiendo del grado de concientización, será para toda su vida o por un periodo determinado, pasando a formar parte del recuerdo en el último de los casos.

\section{Objetivos}

- Incentivar el proceso de estructuración del pensamiento, de la imaginación creadora, las formas de expresión personal y de comunicación verbal y gráfica.

- Favorecer el proceso de maduración de los niños en lo sensorio-motor, la manifestación lúdica y estética, la iniciación deportiva y artística, el crecimiento socio afectivo, y los valores éticos.

- Estimular hábitos de integración social, de convivencia grupal, de solidaridad y cooperación y de conservación del medio ambiente.

- Desarrollar la creatividad del individuo.

- Fortalecer la vinculación entre la institución educativa y la familia.

- Prevenir y atender las desigualdades físicas, psíquicas y sociales originadas en diferencias de orden biológico, nutricional, familiar y ambiental mediante programas especiales y acciones articuladas con otras instituciones comunitarias.

\section{Educación Secundaria}

La educación secundaria, -objeto de la investigación- incluida dentro de la educación básica, es la que tiene como objetivo capacitar al alumno para proseguir estudios superiores o bien para incorporarse al mundo laboral. Al terminar la educación secundaria se pretende que el alumno desarrolle las suficientes habilidades, valores y actitudes para lograr un buen desenvolvimiento en la sociedad. En particular, la 
enseñanza secundaria debe brindar formación básica para responder al fenómeno de la universalización de la matrícula; preparar para la universidad pensando en quienes aspiran y pueden continuar sus estudios; preparar para el mundo del trabajo a los que no siguen estudiando y desean o necesitan incorporarse a la vida laboral; y formar la personalidad integral de los jóvenes, con especial atención en los aspectos relacionados con el desempeño ciudadano.

Dentro de la educación secundaria pueden encontrarse diferentes factores relacionados con las vías formativas de los alumnos y según las salidas laborales posteriores con las que ellos se encuentran. Las modalidades, a la vez, pueden tener diversas especializaciones y orientaciones que permiten formarse en temas específicos. Por ejemplo, en la educación técnico profesional se prepara mayoritariamente para el trabajo después de abandonar la escuela secundaria, en esta modalidad se entrena al alumno para que aprenda una carrera técnica o industrial.

En muchos países, este nivel educativo no es obligatorio y las edades en las que los estudiantes lo transitan varían significativamente de una nación a otra. Sin embargo, es común que la educación secundaria cubra la etapa de la adolescencia, y en general se comienza con 12 o 13 años y se termina con 17 o 18años.

\section{La Educación Secundaria en Argentina}

A través del tiempo, el sistema de educación secundaria en Argentina ha sido modificado varias veces.

La ciudad de Buenos Aires y algunas otras provincias aún conservan el sistema de siete años de Primaria y cinco años de Secundaria (Ley 26.206). En el 4to año, los alumnos deben escoger una orientación, cada una de las cuales tiene sus materias específicas y diferencias en los horarios:

- Ciencias Sociales: Psicología, Sociología, Filosofía, Economía, Cultura, Historia, Geografía (en las otras hasta 5to)

- Ciencias Naturales: Genética, Biología, Astronomía, Física, Química (en las otras Física y Biología 4to, Química en 5to) 
- Economía y Administración: Contabilidad, Derecho, Informática, Teoría del desarrollo, Elementos de la Microeconomía y Macroeconomía, Gestión Organizacional, Filosofía, Cultura, Política y Ciudadanía.

- Artes Visuales y Escénicas: Arte, Música, Danza, Teatro, Expresión Corporal, Historia del arte

- Arte y Diseño: Arte, Producción De Imágenes, Informática

- Salud y Deporte: Salud y Adolescencia, Deportes, Gimnasia, Biología, higiene, nutrición

- Lenguas Extranjeras: Ingles, Italiano, Francés, Alemán, Latín, Portugués

Para la Educación Secundaria Técnica se definen las siguientes tecnicaturas:

- Técnico en Electromecánica

- Técnico en Administración de las Organizaciones

- Técnico Químico

- Técnico en Tecnología de los Alimentos

- Técnico en Electrónica

- Técnico en Informática Personal y Profesional

- Maestro Mayor de Obras

- Técnico en Aeronáutica

- Técnico en Automotores

- Técnico en Servicios Turísticos

- Técnico en Multimedios

- Técnico Constructor Naval

\subsection{Antecedentes del problema}

\section{Situación en algunos países de América Latina}

En la región latinoamericana, la actualidad presenta señales de progreso en cuanto al nivel educativo, en especial en la enseñanza básica; tal es el caso de Brasil, que avanzó a una velocidad récord en los últimos quince años en la tabla de clasificaciones mundiales de educación según el The Wall Street JournalAmérica. Además, Chile y México han registrado un mejor desempeño en las pruebas estandarizadas. Algunos expertos también detectan señales de que el crecimiento económico de los últimos años 
no sólo generó demanda por más y mejores cursos universitarios, sino que también aportó un nuevo empuje para la mejora de la enseñanza básica.

El estudio menciona la reconocida prueba estandarizada Pisa, llamado así por sus siglas en inglés(Programmefor International StudentAssessment) que se basa en el análisis del rendimiento de estudiantes a partir de unos exámenes que se realizan cada tres años en varios países con el fin de determinar la valoración internacional de los alumnos. Este informe es elaborado por la Organización para la Cooperación y el Desarrollo Económico (OCDE), incluye más de 70 países, y en 2009 mostró que Brasil subió de 368 a 401 puntos, un progreso notable aunque el país sigue por debajo del promedio de la OCDE.

Bárbara Bruns, líder del grupo que llevó a cabo el estudio, afirmó que "Brasil consiguió poner en marcha una reforma continua desde el gobierno de Cardoso". La investigadora menciona iniciativas como la "Bolsa Escuela", un programa donde el gobierno les paga a las familias de escasos recursos por mantener a sus hijos en el colegio, iniciado durante el gobierno de Fernando Henrique Cardoso y ampliado en el de Luizlgnácio Lula da Silva, cuando fue rebautizado como "Bolsa Familia".

"En América Latina, el cuerpo docente ha decaído en las últimas décadas, y el orgullo de ser profesor perdió valor socialmente", apunta Furman, M. profesora adjunta de la Facultad de Educación de la Universidad de San Andrés, en Argentina. Furman resaltó que, mientras los países de la región "están luchando" para mejorar las condiciones de trabajo de los maestros, en los países desarrollados "ya es así desde hace mucho tiempo".

"No estamos preparando a la próxima generación. Los profesores de hoy no fueron bien capacitados", lamenta LuanneZurlo, fundadora y presidenta de WorldFund, una organización sin fines de lucro con sede en Estados Unidos concentrada en la educación en América Latina y que tiene programas para la preparación de profesores.

La capacitación del profesorado forma parte de una serie de problemas que aún deben ser resueltos en la región, concuerdan los especialistas.

En Brasil, por ejemplo, $42 \%$ de los estudiantes de secundaria aún asisten a cursos nocturnos, destaca el informe del Banco Mundial. Esos jóvenes reciben 4 horas de escuela diarias, en promedio, "en comparación con las 7 horas o más en la mayoría de 
países de la OCDE e incluso más en los países líderes de Asia del Este", especifica el estudio. "La infraestructura es deplorable: faltan bibliotecas, laboratorios de ciencias, instalaciones para el aprendizaje de idiomas y computadoras de las que disfruta la mayoríade estudiantes de la OCDE", añade.

\section{SISTEMAS DE EVALUACIÓN INTERNACIONALES}

\section{Programa para la Evaluación Internacional de Alumnos}

A continuación se hace referencia a determinados Programas internacionales utilizados para la evaluación de los alumnos en el nivel secundario. Ellos son PISA, LLECE, ICILS, TIMSS y SIMCE.

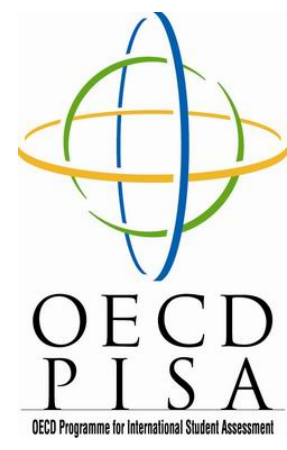

\section{PISA (OCDE)}

El nombre PISA corresponde con las siglas del programa según se enuncia en inglés: Programmefor International StudentAssessment, es decir, Programa para la Evaluación Internacional de Alumnos. Se trata de un proyecto de la OCDE (Organización para la Cooperación y el Desarrollo Económicos), cuyo objetivo es evaluar la formación de los alumnos cuando llegan al final de la etapa de enseñanza obligatoria, hacia los 15 años.

Se trata de una población que se encuentra a punto de iniciar la educación postsecundaria o que está a punto de integrarse a la vida laboral. Es muy importante destacar que el Programa ha sido concebido como un recurso para ofrecer información abundante y detallada que permita a los países miembros adoptar las decisiones y políticas públicas necesarias para mejorar los niveles educativos.

La evaluación cubre las áreas de lengua, matemáticas y competencia científica. El énfasis de la evaluación está puesto en el dominio de los procesos, el entendimiento de los conceptos y la habilidad de actuar o funcionar en varias situaciones dentro de cada dominio.

\section{Los exámenes}

Los exámenes utilizados en el proceso de evaluación no requieren otra cosa que papel y lápiz y cada estudiante cuenta con dos horas para responderlo. Cada examen es una combinación de preguntas directas con una única respuesta correcta (preguntas que sólo admiten algunas palabras o algunas frases breves por respuesta, o que ofrecen 
múltiples opciones para que el alumno marque alguna o algunas), y preguntas que requieren que los estudiantes elaboren sus propias respuestas. Las preguntas del primer tipo sólo pueden ser correctas o incorrectas, y las del segundo tipo son de evaluación más compleja y admiten respuestas parcialmente correctas. Es importante destacar que si bien PISA utiliza la herramienta de las preguntas de opción múltiple, una porción importante de los reactivos, particularmente los más complejos, requieren del alumno la redacción de textos e incluso la elaboración de diagramas.

No todos los alumnos tienen el mismo examen sobre la mesa el día de la prueba; a diferentes alumnos les tocan cuadernillos distintos. Tal como se aplicó la prueba en 2006, había 13 cuadernillos de examen diferentes, cada uno de ellos con cuatro capítulos o grupos de actividades de evaluación.

Además del examen propiamente dicho, los estudiantes deben responder un cuestionario en el que se les hacen preguntas sobre sí mismos y sobre sus hogares. Este cuestionario de contexto es una herramienta muy importante para el aprovechamiento de la prueba de PISA, y se hará una referencia a este más adelante.

\section{La muestra}

Para la realización de PISA se utilizan muestras representativas de entre 4,500 y 10,000 estudiantes por país. Este tamaño de muestra permite realizar inferencias del país en su totalidad pero no permite inferencias por regiones o estados. Algunos países solicitan sobre muestras para utilizar la prueba también en la exploración de las diferencias regionales. Tal fue el caso de México, que en el ciclo de evaluación de 2003 condujo una evaluación con 29,983 estudiantes y en el ciclo 2006 con 30,971 estudiantes.

\section{Los resultados}

Con los resultados PISA propone ofrecer un perfil de las capacidades de los estudiantes de 15 años de todos los países donde se aplica el examen. Además, provee información sobre el contexto personal, familiar y escolar de los participantes en la muestra.

El carácter cíclico (trienal) de la evaluación permite tener indicadores sobre las tendencias en cada país y en el conjunto de los países involucrados en el proyecto. En última instancia, la calidad y riqueza de los datos arrojados en el proceso de evaluación pretende constituirse en la base para la investigación y análisis destinados a mejores políticas en el campo de la educación. 


\section{¿Qué evalúa PISA?}

A diferencia de otros exámenes que se han utilizado en el pasado, PISA está diseñado para conocer las competencias, o, dicho en otros términos, las habilidades, la pericia y las aptitudes de los estudiantes para analizar y resolver problemas, para manejar información y para enfrentar situaciones que se les presentarán en la vida adulta y que requerirán de tales habilidades.

PISA se concentra en la evaluación de tres áreas: competencia lectora, competencia matemática y competencia científica. Si bien la adquisición de conocimientos específicos es importante en el aprendizaje escolar, la aplicación de esos conocimientos en la vida adulta depende rigurosamente de la adquisición de conceptos y habilidades más amplios. En ciencia, tener conocimientos específicos, como los nombres de las plantas y los animales, tiene menor valor que comprender temas más amplios, como el consumo de energía, la biodiversidad y la salud humana, cuando se trata de pensar en los grandes problemas en debate dentro de la comunidad adulta.

\section{Evaluación cíclica}

La evaluación a través del PISA se realiza cada tres años, con el objeto de permitir a los países supervisar adecuadamente su desempeño y valorar el alcance de las metas educativas propuestas. Cada año de su realización el proyecto se ha concentrado en alguna de las tres áreas evaluadas: en la evaluación del año 2000 se dio especial atención a la competencia en lectura, en el 2003 a la competencia en matemáticas y en 2006 a la competencia en el área de ciencias.

Esto quiere decir que la parte más extensa del examen se refiere al área de concentración correspondiente a ese año (Los porcentajes son aproximadamente 66\% para el área de concentración y $17 \%$ para cada una de las otras áreas).

\section{Contexto}

La universalidad que le da a PISA el hecho de no estar ligado a currículos y planes de estudio específicos no implica una indiferencia frente al contexto.

Un cuestionario dirigido al responsable de cada escuela permite recabar información sobre el contexto del estudiante: las condiciones de su entorno, su familia, sus hábitos de estudio, las condiciones de su escuela. 


\section{Lo que evalúa PISA}

PISA no está diseñado para evaluar el aprendizaje de los contenidos específicos fijados en los programas de las escuelas o de los distritos o regiones correspondientes. Tampoco está pensado para evaluar el desempeño de los docentes ni los programas vigentes. PISA se centra en el reconocimiento y valoración de las destrezas y conocimientos adquiridos por los alumnos al llegar a sus quince años. La adquisición de tales destrezas y conocimientos es fruto de numerosas circunstancias familiares, sociales, culturales y escolares. PISA trata de recoger información sobre esas circunstancias para que las políticas que pudieran desprenderse del análisis de los resultados de la prueba atiendan a los diferentes factores involucrados.

Los resultados de la prueba describen el grado en el que se presentan las competencias estudiadas y permiten observar la ubicación de los resultados de cada país en el contexto internacional.

\section{Evaluar las competencias}

La evaluación de competencias no se dirige a la verificación de contenidos; no pone la atención en el hecho de que ciertos datos o conocimientos hayan sido adquiridos. Se trata de una evaluación que busca identificar la existencia de ciertas capacidades, habilidades y aptitudes que, en conjunto, permiten a la persona resolver problemas y situaciones de la vida. No interesa, pues, en el enfoque de la evaluación de competencias, sólo si una persona lee y cuánto lee, por ejemplo, sino más bien qué competencia tiene en la lectura: qué capacidad para identificar ideas y argumentos en el texto, qué destreza para reconocer problemas y planteamientos distintos.

Hay competencias muy generales, que preceden a la formación escolar, como la competencia comunicativa, o las competencias de colaboración o de creatividad. Algunas competencias básicas ligadas a la enseñanza escolar son, por ejemplo, la lectura, la escritura y el cálculo. La exploración del proyecto PISA se refiere a competencias específicas (lectura, matemáticas, ciencia), detalladas y divididas en sub-competencias, dentro de cada área.

La definición de competencia utilizada en México por el Instituto Nacional para la Evaluación de la Educación es la siguiente: "un sistema de acción complejo que abarca 
las habilidades intelectuales, las actitudes y otros elementos no cognitivos, como motivación, valores y emociones, que son adquiridos y desarrollados por los individuos a lo largo de su vida y son indispensables para participar eficazmente en diferentes contextos sociales". La clave del concepto de competencia, tal como se utiliza para el PISA y lo ha explicado el INEE, está en valorar la capacidad del estudiante para poner en práctica sus habilidades y conocimientos en diferentes circunstancias de la vida.

Al examinar los conocimientos y habilidades cerca del final de la enseñanza básica, PISA examina el grado de preparación de los jóvenes para la vida adulta y, hasta cierto punto, la efectividad de los sistemas educativos. Su ambición es evaluar el éxito con relación a los objetivos subyacentes (definidos por la sociedad) del sistema educativo, y no con relación a la enseñanza de un cuerpo de conocimientos determinado.

\section{Laboratorio Latinoamericano de Evaluación de la Calidad de la Educación LLECE (UNESCO)}

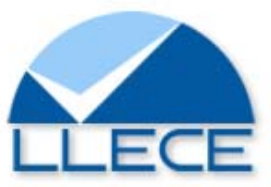

Es una red de sistemas de evaluación de la calidad de la educación de los países de América Latina y el Caribe. Lo coordina la Oficina Regional de Educación de la UNESCO para América Latina y el Caribe.

Constituye un ámbito de discusión técnico-político sobre el aprendizaje, variables relativas al desarrollo personal de los estudiantes y de los factores asociados a estas.

Creado en Ciudad de México en noviembre de 1994, el LLECE marcó un Hito en el desarrollo de nuevas formas de cooperación entre los países. Su objetivo principal es generar conocimientos que contribuyan a que los Ministerios de Educación de la región tomen decisiones informadas en materia de políticas educativas a partir del análisis de los resultados de las investigaciones evaluativas que el LLECE realiza.

En el Laboratorio participa Argentina, Brasil, Chile, Colombia, Costa Rica, Ecuador, Guatemala, Honduras, México, Nicaragua, Panamá, Paraguay, Perú, República Dominicana y Uruguay, junto al estado mexicano de Nuevo León. El LLECE realiza permanentes gestiones para que se integre a sus actividades el resto de los países de la región. 
Las prioridades del LLECE son:

- Diseñar, implementar y asegurar el financiamiento del Tercer Estudio Regional Comparativo y Explicativo (TERCE).

- Diseñar y ejecutar un estudio cualitativo de escuelas con resultados destacables en el Segundo Estudio Regional Comparativo y Explicativo (SERCE).

- Realizar y fomentar la realización de estudios sobre factores asociados, a partir del SERCE.

- Fortalecer el apoyo técnico a los sistemas de evaluación de los países miembros del LLECE y el trabajo en red.

- Generar información sobre evaluación docente.

- Favorecer la generación de conocimientos sobre modelos de evaluación de la calidad educativa que tengan un enfoque holístico.

- Favorecer el debate y la reflexión sobre nuevos modelos de evaluación: sistemas integrales, donde se considere el desarrollo global del estudiante, sus diferencias, etc. en coherencia con el concepto de calidad de la educación de la OREALC/UNESCO Santiago.

- Apoyar las diversas acciones de la UNESCO en materia de evaluación.

\section{Estudio Internacional de Alfabetización Computacional y Manejo de Información \\ ICILS (IEA)}

En la actualidad no hay quien niegue el papel transformador que tienen las Tecnologías de la Información y la Comunicación (TIC),

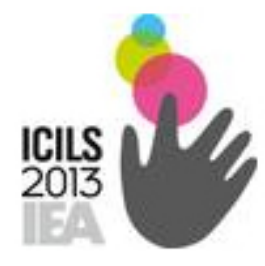
prácticamente en todos los campos de la actividad humana. Precisamente, esos cambios acelerados y revolucionarios de las TIC en la sociedad, están demandando de las personas competencia en su uso para poder insertarse efectivamente tanto en el mundo académico como laboral. Estas demandas, las deben atender los sistemas escolares contemporáneos

A pesar de la urgencia manifiesta, la competencia en TIC y el manejo de información, históricamente han estado desatendidos por los sistemas educativos latinoamericanos. Si a esta situación se le agrega la falta de estándares educativos en 
TIC, la baja penetración de infraestructura TIC en las Instituciones Educativas y el muy desigual desarrollo de competencias en TIC que demuestran los estudiantes Latinoamericanos cuando terminan su último grado escolar, el panorama no resulta alentador.

Sin embargo, dado que tanto el desarrollo de competencia en TIC, como el enriquecimiento de ambientes de aprendizaje con estas, son un proceso gradual, un factor importante de la ecuación es medir el nivel actual en el que se encuentran los estudiantes de la región en su uso efectivo. Medición esta que debe hacerse con total seriedad y de manera periódica, para determinar así, avances o retrocesos.

EI ICILS evaluará los resultados que obtengan los estudiantes, de diferentes países. El alfabetismo en el uso del computador y en información (CIL por su sigla en inglés), hace referencia a la habilidad individual de las personas en el uso de computadores para investigar, crear y comunicarse de manera que puedan participar efectivamente en el hogar, la Institución Educativa, el sitio de trabajo y la comunidad.

La evaluación de CIL no solo será auténtica sino hecha directamente en el computador. Incluirá preguntas de respuesta múltiple y temas en los que se deben construir las respuestas en base a material de estímulo realista; esto es, simulaciones de software de aplicaciones genéricas en los que se pide al estudiante completar una acción como respuesta a una instrucción dada; además de realizar tareas auténticas que requieren del estudiante modificar y generar productos de información usando aplicaciones de software de computador en "vivo".

El cuestionario que se aplique a los estudiantes recopilará información sobre el uso de computadores dentro y fuera de la Institución Educativa, las actitudes hacia las Tecnologías de la Información y la Comunicación (TIC), autoevaluación de la competencia en el uso de computadores y características del contexto particular de los estudiantes. Los cuestionarios a docentes e Instituciones, preguntarán sobre el uso de computadores, los recursos de cómputo y las políticas y prácticas relevantes. Un número de temas enlazarán a SITES 2006.

La encuesta, en el contexto nacional, recopilará datos sistémicos de políticas y prácticas educativas para el desarrollo del alfabetismo en el uso del computador y en información, idoneidad de los docentes y recursos de las tecnologías digitales (TIC) existentes en las instituciones.

\section{Instrumentos}


- Pruebas realizadas en CIL, directamente en el computador, que ofrecerán un rango amplio de módulos de evaluación auténticos en un ambiente coherente.

- Cuestionario para el estudiante

- Cuestionario para el docente (incluyendo enlaces a IEA SITES 2006)

- Cuestionario para la Institución Educativa (incluyendo enlaces a IEA SITES 2006)

- Encuesta nacional de contexto

\section{Programación}

ICILS se inició en el encuentro Nacional de Coordinadores de Investigación, en junio 21 de 2010, en Ámsterdam. El proyecto pretendía elaborar la evaluación marco en el 2010 y terminarla en el 2011, desarrollar y hacer pilotos de esos instrumentos durante el 2011, hacer una prueba de campo en la primera mitad del 2012 y recolectar los datos a principios del 2013 en el Hemisferio Norte y a fines del mismo año en el Hemisferio Sur, para entregar resultados en Noviembre de 2014.

\section{Participantes}

Los sistemas educativos que están considerando participar en ICILS-2013 son: Canadá, Chile, Croacia, Chipre, República Checa, Dinamarca, Alemania, Hong KongChina, Israel, Holanda, Noruega, Polonia, la Federación Rusa, Arabia Saudita, Eslovaquia, Eslovenia, España (Cataluña), Tailandia y los Estados Unidos.

\section{Población objetivo}

El foco de la población a la que se aplicará la encuesta, incluirá a todos los estudiantes matriculados en el grado correspondiente a ocho (8) años de escolarización, contados a partir del primer año de ISCED Nivel 1; siempre y cuando, el promedio de edad en el momento de tomar la prueba sea por lo menos de 13.5 años. Para muchos países correspondería al grado $8^{\circ}$. Además, esta evaluación se ofrecerá como una opción, con un conjunto de temas modificados, para el grado $4^{\circ}$.

\section{Estudio Internacional de Tendencias en Matemática y Ciencias TIMSS (IEA)}

Es un proyecto de la Asociación Internacional para la Evaluación Educativa (IEA). La IEA es una institución independiente que coopera con

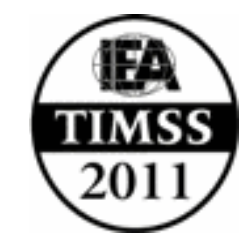


las instituciones nacionales de investigación en la realización estudios de evaluación desde 1959.

El estudio TIMSS se realiza cada cuatro años y proporciona a los países una oportunidad única para medir el progreso en la enseñanza de Matemáticas y Ciencias.

TIMSS por medio de cuestionarios pregunta a estudiantes, profesorado y miembros de los equipos directivos acerca de los contextos para aprender Matemáticas y Ciencias. Los datos de estos cuestionarios proporcionan un retrato dinámico de los cambios en las prácticas educativas y son una ayuda para mejorar dichas prácticas e implementar normas.

El modelo curricular de TIMSS tiene tres aspectos:

- El curriculum diseñado.

- El curriculum aplicado.

- El curriculum logrado.

Estos representan, por una parte, lo que la sociedad piensa que los estudiantes tienen que aprender de las Matemáticas y las Ciencias, y por otra parte, cómo el sistema educativo se ha de organizar para facilitar dicho aprendizaje.

- Las pruebas de TIMSS se elaboran mediante un consenso internacional contando con expertos en Didáctica, en Matemáticas, en Ciencias y en Estadística.

- Los diseñadores de la prueba e investigadores, así como la comunidad educativa pueden esperar que los resultados en Matemáticas y en Ciencias:

- Informen sobre comparaciones de los resultados obtenidos por cada país y entre países y, en unión con otros datos de TIMSS, sugieran las razones para establecer diferencias entre ellos.

- Mejoren la evaluación de la eficacia de la enseñanza y el aprendizaje en Matemáticas y en Ciencias dentro de cada país.

- Descubran los aspectos más relevantes del progreso en el conocimiento y habilidades matemáticas y científicas en $2^{\circ}$ curso de la E.S.O.

- Proporcionen datos complementarios acerca de los resultados en distintos sistemas educativos y centros escolares, así como en la mejora de la práctica docente. 


\section{Sistema Nacional de Evacuación de Resultados de aprendizaje del Ministerio de Educación de Chile \\ SIMCE}

EI SIMCE es el Sistema Nacional de Evaluación de resultados de aprendizaje del Ministerio de Educación de Chile. Su propósito

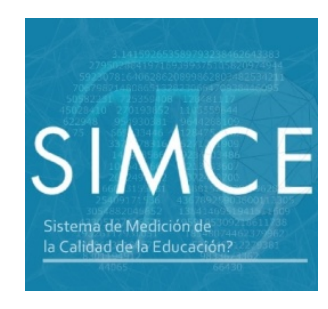
principal es contribuir al mejoramiento de la calidad y equidad de la educación, informando sobre el desempeño de los estudiantes en diferentes áreas de aprendizaje del Currículum Nacional, y relacionando estos desempeños con el contexto escolar y social en que aprenden.

Las pruebas SIMCE evalúan el logro de los Objetivos Fundamentales y Contenidos Mínimos Obligatorios (OF-CMO) del Marco Curricular vigente en diferentes sectores de aprendizaje, a través de una medición que se aplica a nivel nacional, una vez al año, a los estudiantes que cursan un determinado nivel educacional. Hasta el año 2005, la aplicación de las pruebas se alternó entre $4^{\circ}$ Básico, $8^{\circ}$ Básico y $2^{\circ}$ Medio. A partir del año 2006, se evalúa todos los años a $4^{\circ}$ Básico y se alternan $8^{\circ}$ Básico y $2^{\circ}$ Medio. Desde el año 2010 se aplica cada dos años la evaluación del sector Inglés en $3^{\circ}$ Medio, y todos los años una evaluación muestral del sector de Educación Física en $8^{\circ}$ Básico, con el objetivo de diagnosticar la condición física de los estudiantes.

Además de las pruebas asociadas al currículum, el SIMCE también recoge información sobre docentes, estudiantes y padres y apoderados a través de cuestionarios de contexto. Esta información se utiliza para contextualizar y analizar los resultados de los estudiantes en las pruebas SIMCE.

\section{Propósito}

EI propósito principal de SIMCE es contribuir al mejoramiento de la calidad y equidad de la educación, informando sobre el desempeño de los estudiantes en distintas áreas de aprendizaje y del Currículum Nacional y relacionando estos desempeños con el contexto escolar y social en que aprenden. Para cumplir con este propósito, SIMCE fomenta el uso de la información de las pruebas nacionales e internacionales por parte de distintos usuarios.

1- A los profesores, directivos y sostenedores la información entregada por el SIMCE les sirve para: 
- Conocer cómo le fue a sus estudiantes en comparación con aquellos del mismo curso evaluado en años anteriores. Los profesores pueden saber, por ejemplo, si al $4^{\circ}$ Básico de este año le fue mejor, peor o similar que al $4^{\circ}$ Básico del año pasado. Esto es importante para saber si las nuevas generaciones de estudiantes alcanzan mejores desempeños en comparación con las generaciones más antiguas.

- Conocer si sus estudiantes obtienen un puntaje promedio mejor, peor o similar que otros alumnos del país, de su comuna, o de establecimientos que atienden a estudiantes con similares características socioeconómicas. Cuando dos establecimientos con similares características socioeconómicas obtienen puntajes promedios significativamente distintos, es más probable que estas diferencias se deban a que una escuela ofrece una educación de mejor calidad que la otra.

- Evaluar si las iniciativas implementadas en la escuela tuvieron un efecto positivo en el nivel de desempeño de los alumnos. Por ejemplo, en una escuela los resultados SIMCE podrían haber subido como consecuencia de un cambio planificado en los énfasis de contenidos que los profesores tratan en clases.

- Conocer qué porcentaje de los estudiantes de $4^{\circ}$ y $8^{\circ}$ Básico del establecimiento se encuentra en el nivel avanzado, intermedio e inicial de los Niveles de Logro. Estos resultados deben ayudar a que los profesores tomen conciencia de la diversidad de rendimientos que presentan sus alumnos.

- Conocer el tipo de problemas que se espera que los alumnos puedan resolver. Al analizar los Niveles de Logro y las preguntas publicadas del SIMCE, los profesores pueden revisar en qué medida los estudiantes han tenido oportunidades de aprender los contenidos y habilidades evaluados. Es importante que esta pregunta se la hagan todos los profesores del ciclo de enseñanza, y no solo los profesores del curso evaluado. También pueden revisar si el nivel de exigencia de sus evaluaciones de aula se adecua al nivel de exigencia señalado en el currículo oficial y en las pruebas SIMCE.

- Pensar cómo ofrecer clases más estimulantes y provechosas para estudiantes con distintos Niveles de Logro. Por ejemplo, en clases los profesores podrían armar grupos de alumnos del nivel avanzado, intermedio e inicial; y dar a cada grupo actividades acordes con sus necesidades de aprendizaje.

- Ponerse metas. Por ejemplo, sostenedores, directivos y docentes podrían proponerse disminuir en 10 puntos porcentuales la proporción de estudiantes en el 
nivel inicial de los Niveles de Logro, junto con aumentar significativamente el puntaje promedio del establecimiento.

- A través de las evaluaciones internacionales, conocer las competencias que manejan los estudiantes chilenos en comparación con los estudiantes de otros países. Los estudiantes en cada país merecen aprender y desarrollarse tanto como los estudiantes de cualquier otro país. El que lo hagan es importante para su desarrollo personal y para el desarrollo económico y social del país.

2- A los padres y apoderados, la información entregada por el SIMCE les sirve para:

- Conocer cómo le fue a su escuela en comparación con otras escuelas de la misma comuna o dependencia. Los padres pueden preguntarle al director del establecimiento por qué la escuela obtuvo estos resultados, y qué pueden hacer para que mejore.

- Conocer qué porcentaje de los estudiantes de $4^{\circ}$ y $8^{\circ}$ Básico del establecimiento se encuentra en el nivel avanzado, intermedio e inicial de los Niveles de Logro. Conocer qué se espera que sean capaces de hacer los alumnos en el curso evaluado. Los padres pueden consultar al profesor si su hijo maneja las competencias de cada Nivel de Logro, y qué pueden hacer para ayudarlo a alcanzarlas.

- Complementar la información sobre las notas. Con las notas, los padres pueden saber cómo es el rendimiento de su hijo en comparación con el de sus compañeros de curso. Con el SIMCE pueden saber cómo es el rendimiento de su escuela en comparación con otras escuelas del país.

3- Al Ministerio de Educación, la información entregada por el SIMCE le sirve para:

- Realizar el seguimiento de la calidad y equidad de la educación desde la perspectiva de los logros de aprendizaje que alcanzan los estudiantes en distintas áreas curriculares. El Ministerio de Educación puede saber en qué medida los estudiantes están logrando los objetivos curriculares y si ha habido progreso en el logro de estos objetivos a través de los años. También puede monitorear en qué medida distintos grupos de estudiantes (ej. estudiantes de distinto nivel socioeconómico) están alcanzando estos objetivos. 
- Identificar establecimientos que presentan sistemáticamente bajos resultados en el SIMCE y que necesitan apoyo externo para mejorar el desempeño de sus estudiantes.

- Evaluar la efectividad de programas de intervención cuyo objetivo es mejorar el desempeño de los estudiantes en distintas áreas curriculares.

- Asignar incentivos a las escuelas que logran mantener altos puntajes en el SIMCE o que los suben sistemáticamente.

- Aprender de la experiencia de países que alcanzan altos estándares de calidad y equidad en educación, a partir de los resultados de las evaluaciones internacionales.

- Conocer las principales características del entorno escolar y familiar en el que estudian los alumnos chilenos y de otros países del mundo. Esta información de contexto puede ser muy valiosa para comprender mejor los resultados.

\subsection{Sistema de variables}

A continuación se detalla las variables que afectan la calidad de educación en la zona para el nivel secundario.

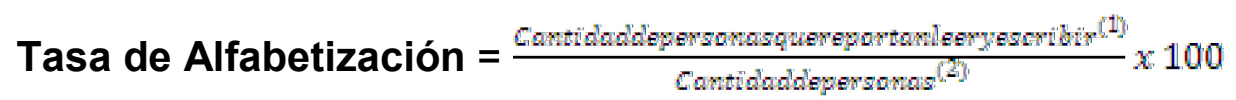

(1) Alumnos de Nivel secundario mayores de 11 (12) años y menores de 17 (18) años.

(2) Población general de la región mayores de 11 (12) años y menores de 17 (18) años.

Mediante esta fórmula se evalúa el nivel de alfabetización, esto es la habilidad que tiene la persona de utilizar texto para comunicarse a través del espacio y el tiempo. Esto se reduce a la habilidad de leer y escribir.

Tasa de Matriculación Bruta Combinada $=\frac{\text { Contidadilealumasmatriculados }}{\text { Tataldepoblaciónemlaedadearrespondiemte }} \times 100$

Se calcula esta tasa para cada curso, luego para cada nivel Educativo y luego se hace un Promedio simple de la Tasa Bruta de Matriculación por Niveles. Esta tasa, particularmente en los primeros cursos de la educación formal puede ser superior al 100\% 
ya que calcula la proporción entre los matriculados y la población con la edad correspondiente para cada año de la educación formal. En países o regiones en los cuales la sobre-edad es un fenómeno de relevancia, esto se ve con frecuencia.

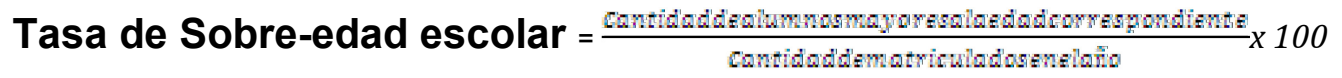

Esta tasa hace referencia a la cantidad de alumnos que se encuentran cursando el secundario y tienen una edad mayor a la correspondiente, de acuerdo con el nivel que debería cursar.

Tasa de Analfabetismo $=\frac{\text { Cantidad de alumnos que reportar no leser ni escribir" }}{\text { Total de alumnos }} \cdot 100$

Es justamente lo contrario a la tasa de albabetizaciòn. El analfabetismo es la incapacidad de leer y escribir, lo cual se debe generalmente a la falta de aprendizaje.

\section{Metodología de la investigación}

\subsection{Población y muestra}

La técnica de investigación utilizada fue la de "Panel de Expertos", entendiendo por expertos a personas especialistas independientes y reputadas que conocen en profundidad la temática del campo al que concierne el objeto que se pretende evaluar, a quienes se recurre para que emitan un juicio sobre dicho objeto.

La población, objeto de análisis, está compuesta por docentes de nivel terciario y empresarios de la ciudad de La Plata. De la misma se seleccionó una muestra para la formación del panel de expertos compuesta pordoce docentes de distintos establecimientos educativos terciarios y universitarios, y doce empresarios de diferentes rubros y actividades.

Se tuvieron en cuenta algunas características esenciales al seleccionar la muestra bajo estudio. Entre éstas se pueden contar las siguientes:

- Homogeneidad: todos los consultados debían contar con similares conocimientos acerca del nivel de educación presentado por los egresados del secundario.

- Tiempo: para el cálculo de los indicadores se utilizó información del año 2011, la cual fue proporcionada por el Ministerio de Educación. 
- Espacio: el estudio se basa en especialistas de la región de La Plata, Berisso y Ensenada; provincia de Buenos Aires.

- Cantidad: El tamaño de la población de los especialistas a consultar se limitó a dos grupos de paneles de expertos que brindaron respuestas, luego de comprender la metodología y consigna propuesta. Uno de los paneles está compuesto por profesores de universidades y escuelas terciarias, debido a que son quienes reciben a los egresados del secundario, y son capaces de evaluar el nivel de educación que estos presentan. El otro panel está conformado por empresarios, ya que saben acerca de las capacidades, habilidades y conocimiento que poseen los egresados, y su respectivo desempeño en el mercado laboral.

\subsection{Tipo de investigación}

La investigación que se llevó a cabo es de tipo exploratoria y descriptiva.

Es exploratoria debido a que la investigación se efectúa sobre un tema poco estudiado y los resultados constituyen una visión aproximada de dicho objeto, es decir, un nivel superficial de conocimiento.

Y es también descriptiva ya que pretende dar a conocer situaciones, costumbres y actitudes predominantes en educación, a través de la descripción exacta de las actividades, objetos, procesos y personas que en ella intervienen.

\subsection{Técnica de recolección de datos}

Los datos secundarios serán recabados principalmente del Ministerio de Educación y los datos primarios se obtendrán mediante la realización de encuestas a un panel de expertos. Tal, como se expresó en el apartado anterior, los estudios que se realizan utilizando un "Panel de Expertos" tienen por finalidad obtener ideas o confirmar planteamientos por la experiencia de las personas seleccionadas representando más bien una consulta o una técnica proyectiva que una investigación cuantitativa de mercados propiamente dicha.

Un panel es una técnica de investigación de mercados cuantitativa que obtiene información de una muestra de la población. La muestra está formada por personas (físicas o jurídicas) que colaboran libre y voluntariamente en el estudio; se comprometen a 
permanecer en el panel durante un tiempo mínimo (variable según el tipo de panel de que se trate).

Ventajas del uso de paneles de expertos:

Las ventajas de esta herramienta radican fundamentalmente en el profundo conocimiento que tienen los expertos sobre los temas objeto de evaluación. Entre ellos:

- Un ahorro de tiempo considerable.

- Un costo reducido.

- Una gran credibilidad de las conclusiones.

- Una gran capacidad de adaptación a las diferentes situaciones.

Desventajas del uso de paneles de expertos

- El funcionamiento del panel puede tender por estructura a omitir las opiniones minoritarias y a suavizar las conclusiones.

- La opinión de determinados expertos puede llegar a primar sobre el resto, a costa de otras opiniones.

- La tendencia de los expertos a exceder el campo de sus competencias reconocidas.

La realización de la encuesta, se basó en la metodología de PISA (Programa para la Evaluación Internacional de Alumnos), debido a que es un programa de evaluación internacional ya utilizado en varios países, que permite la comparación de los resultados obtenidos. Este se trata de un programa de evaluación continuada que a largo plazo, conduce al desarrollo de una información que sirve para llevar un control de las tendencias que marca la evolución de los conocimientos y las habilidades de los alumnos de varios países, así como de diversos subgrupos poblacionales dentro de cada país.

Se analizaron los conocimientos, las habilidades, capacidades y otros atributos pertenecientes a los individuos que influyen de forma significativa en el bienestar personal, social y económico. Esta forma de enfocar el rendimiento educativo se hace necesaria si se desea fomentar que los centros de enseñanza y los sistemas educativos se centren en los desafíos que plantea la sociedad contemporánea.

Las áreas o capacidades a evaluar son las cuatro siguientes Competencia matemática: La capacidad que tiene un individuo de identificar y comprender el papel que desempeñan las matemáticas en el mundo, emitir juicios bien fundados y utilizar e implicarse en las matemáticas de una manera que satisfaga sus necesidades vitales como un ciudadano 
constructivo, comprometido y reflexivo.Las cualidades a evaluar se describen en la tabla siguiente.

Tabla 1: Capacidades a evaluar para competencia matemática

\begin{tabular}{|c|c|c|c|c|c|}
\hline El individuo... & 1 & 2 & 3 & 4 & 5 \\
\hline \multicolumn{6}{|l|}{ 1.1.- Realización de cuentas básicas sin uso de tecnología... } \\
\hline \multicolumn{6}{|l|}{ 1.2.- Ante un cálculo de porcentajes simples, responde... } \\
\hline \multicolumn{6}{|l|}{ 1.3.- Realiza conversiones con unidades de medidas... } \\
\hline \multicolumn{6}{|l|}{ 1.4.- Conocimiento de los tipos de triángulos existentes... } \\
\hline \multicolumn{6}{|l|}{ 1.5.- Distingue los distintos tipos de figuras geométricas... } \\
\hline \multicolumn{6}{|l|}{ 1.6.- En caso de fracciones, realiza las operaciones básicas... } \\
\hline \multicolumn{6}{|l|}{ 1.7.- Cálculo de la superficie de un objeto ... } \\
\hline \multicolumn{6}{|l|}{ 1.8.- Cálculo del volumen de un cuerpo... } \\
\hline \multicolumn{6}{|l|}{$\begin{array}{l}\text { 1.9.- Conocimiento acerca de los sistemas monetarios utilizados en } \\
\text { Argentina (tipos de cambio más utilizados y conversión)... }\end{array}$} \\
\hline \multicolumn{6}{|l|}{ 1.10.- Tiene noción sobre patrones de medida... } \\
\hline \multicolumn{6}{|l|}{ 1.11.- Conoce y comprende los distintos tipos de gráficos... } \\
\hline \multicolumn{6}{|l|}{ 1.12.-Comprendedatosestadísticos... } \\
\hline 1.13.- Capacidad para realizar un cálculo financiero elemental... & & & & & \\
\hline
\end{tabular}

- $\quad$ Competencia lectora: La capacidad que tiene un individuo de comprender, utilizar y analizar textos escritos con objeto de alcanzar sus propias metas, desarrollar sus conocimientos y posibilidades de participar en la sociedad.

Tabla 2: Capacidades a evaluar para competencia lectora

\begin{tabular}{|c|c|c|c|c|c|}
\hline El individuo... & 1 & 2 & 3 & 4 & 5 \\
\hline 2.1.- La comprensión de textos es... & & & & & \\
\hline
\end{tabular}




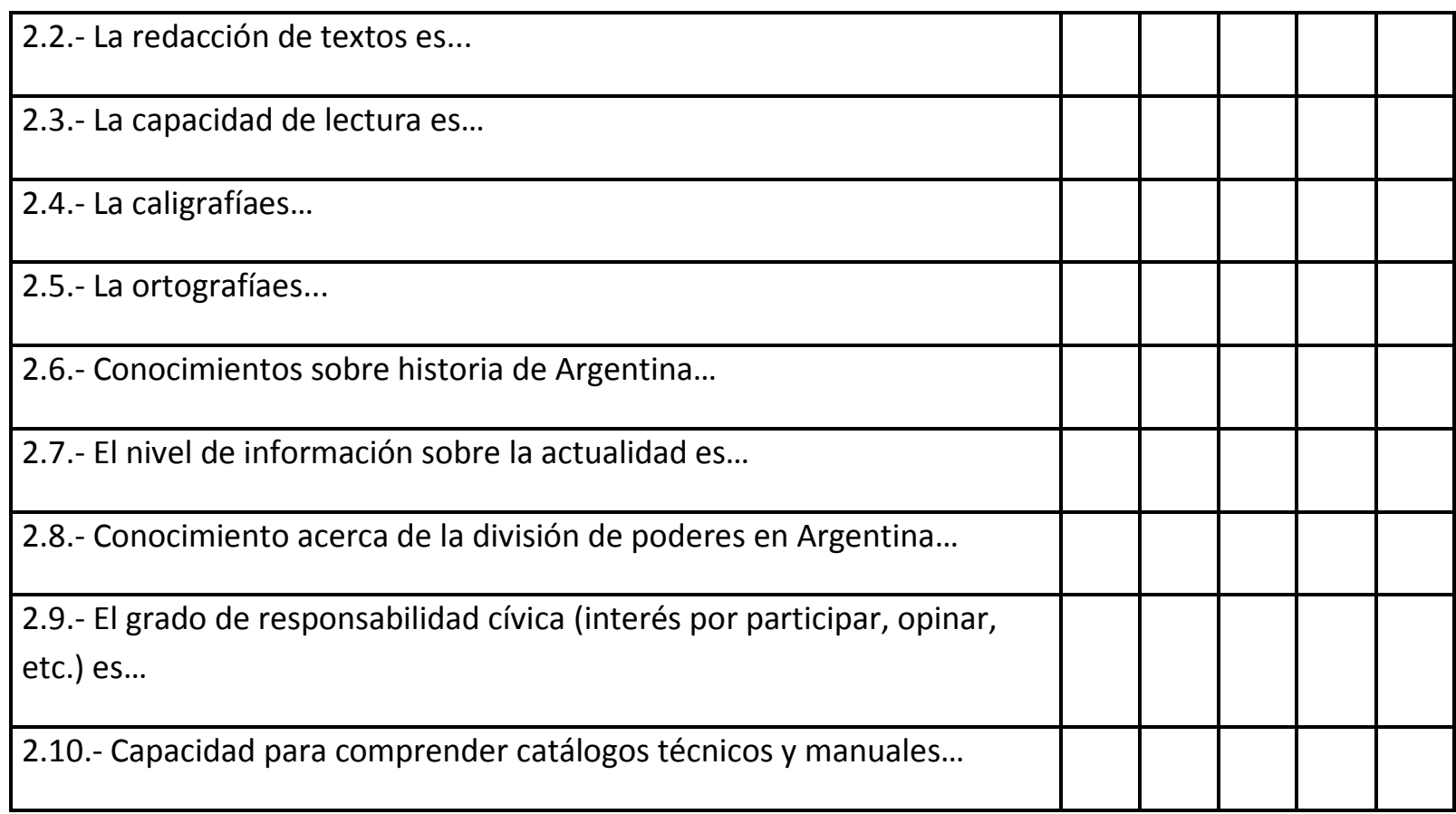

- Competencia científica: Hace referencia a los conocimientos científicos de un individuo y al uso de ese conocimiento para identificar problemas, adquirir nuevos conocimientos, explicar fenómenos científicos y extraer conclusiones basadas en pruebas sobre cuestiones relacionadas con la ciencia. Asimismo, comporta la comprensión de los rasgos característicos de la ciencia, entendida como un método del conocimiento y la investigación humanas, la percepción del modo en que la ciencia y la tecnología conforman el entorno material, intelectual y cultural, y la disposición a implicarse en asuntos relacionados con la ciencia y con las ideas de la ciencia como un ciudadano reflexivo.

Tabla 3: Capacidades a evaluar para competencia científica

\begin{tabular}{|c|c|c|c|c|c|}
\hline El individuo... & 1 & 2 & 3 & 4 & 5 \\
\hline 3.1.- Conocimiento acerca de los estados de la materia... & & & & & \\
\hline 3.2.-Conocimientosobreprimerosauxilios... & & & & & \\
\hline 3.3.- Conocimiento sobre seguridad e higiene... & & & & & \\
\hline 3.4.- Conocimiento sobre las principales enfermedades de Argentina... & & & & & \\
\hline
\end{tabular}


3.5.- Conocimiento sobre los elementos de medición...

3.6.- Conocimiento de los tipos de energía existentes...

3.7.- Conocimiento sobre el sistema solar...

3.8.- Conocimiento sobre el uso de Internet para búsquedas de información relevante es...

3.9.- El uso de los programas básicos de computación es...

3.10.- Conocimiento sobre las principales vías de contagio del SIDA...

3.11.- Conocimiento acerca de los principales elementos de la economía (inflación, tasas de interés, sistema cambiario, canasta básica)...

3.12.- Conocimiento de la tasa de mortalidad (edad promedio en argentina)...

- Aptitudes personales: capacidad que tiene el individuo para poder realizar satisfactoriamente una tarea. Hay que destacar que la aptitud está estrechamente relacionada con la inteligencia y con las habilidades tanto innatas como adquiridas fruto de un proceso de aprendizaje.

Tabla 4: Capacidades a evaluar para las aptitudes personales

\begin{tabular}{|l|l|l|l|l|l|}
\hline \multicolumn{1}{|c|}{ El individuo.... } & 1 & 2 & 3 & 4 & 5 \\
\hline 4.1.- Responsabilidad & & & & & \\
\hline 4.2.- Creatividad & & & & & \\
\hline 4.3.- Flexibilidad & & & & & \\
\hline 4.4.- Puntualidad & & & & & \\
\hline 4.5.- Respeto & & & & & \\
\hline 4.6.- Compañerismo & & & & & \\
\hline 4.7.- Valores & & & & & \\
\hline 4.8.- Interés y motivación & & & & & \\
\hline
\end{tabular}




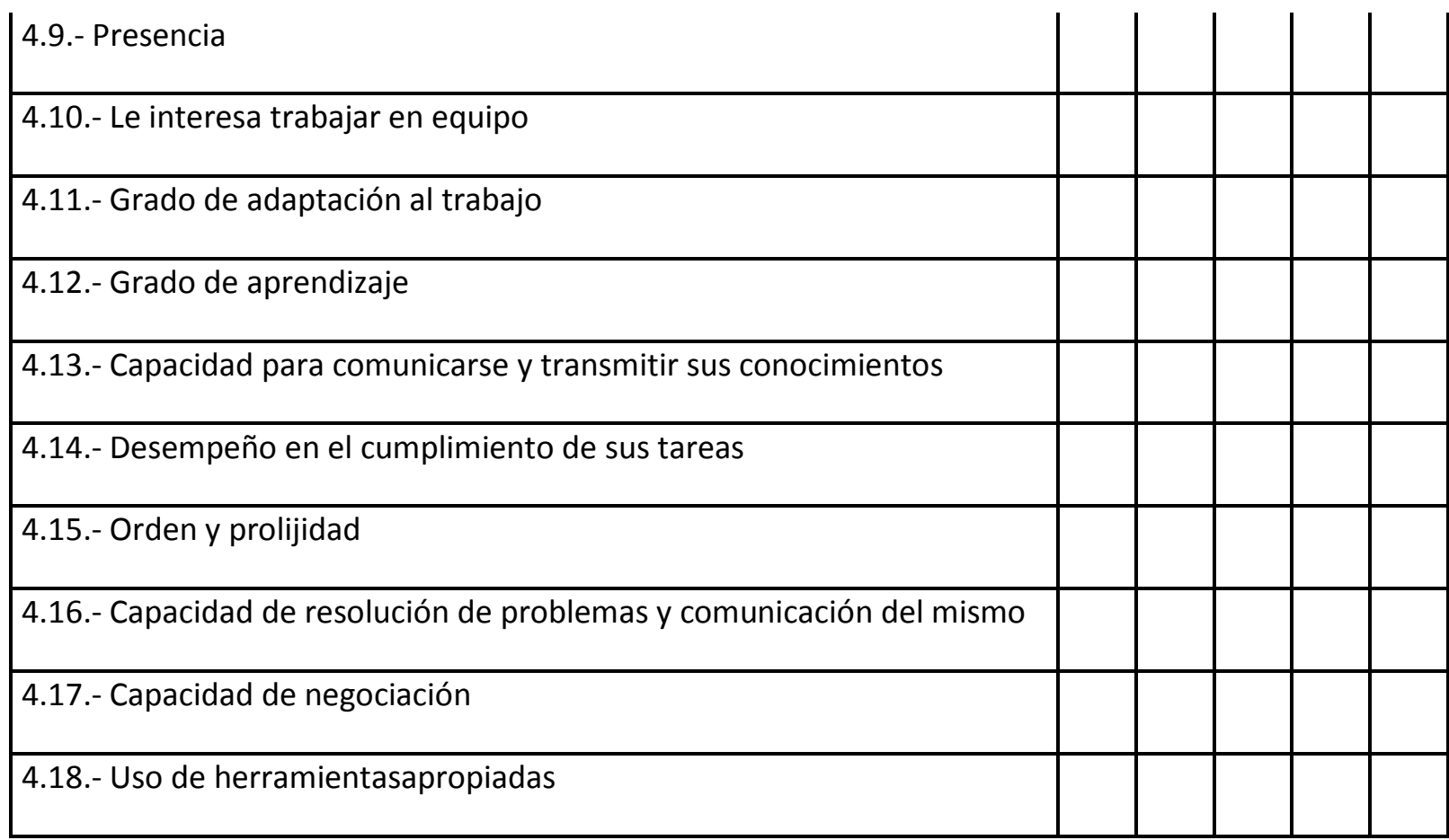

Las distintas opciones de respuestas presentes en la encuesta son las siguientes:

\begin{tabular}{|c|c|c|c|c|c|}
\hline Mal & Regular & Bien & Muy Bien & Excelente & NS/NC \\
\hline $\mathbf{1}$ & $\mathbf{2}$ & $\mathbf{3}$ & $\mathbf{4}$ & $\mathbf{5}$ & $\mathbf{6}$ \\
\hline $\begin{array}{c}\text { (calificación } \\
\text { O a 2) }\end{array}$ & $\begin{array}{c}\text { (calificación } \\
\text { más de 2 } \\
\text { hasta 4) }\end{array}$ & $\begin{array}{c}\text { (calificación } \\
\text { más de 4 } \\
\text { hasta 6) }\end{array}$ & $\begin{array}{c}\text { (calificación } \\
\text { más de 6 } \\
\text { hasta 8) }\end{array}$ & $\begin{array}{c}\text { (calificación } \\
\text { más de 8 } \\
\text { hasta 10) }\end{array}$ & $\begin{array}{c}\text { (No contesta) } \\
\text { No cone }\end{array}$ \\
\hline
\end{tabular}

\subsection{Técnicas de análisis}

Con los datos obtenidos del Ministerio de Educación de la provincia de Buenos Aires se generaron coeficientes indicativos del grado de desempeño de los alumnos del nivel secundario. Tales indicadores son la Matrícula bruta combinada, Sobre-edad escolar, Alfabetización y Analfabetismo. Estas variables fueron definidas anteriormente. 
Por otra parte, a las encuestas al panel de expertos se les aplicó un análisis estadístico univariado.Una vez obtenidos los indicadores pertinentes, los resultados fueron volcados en tablas y gráficos.

Los resultados de la encuesta fueron contabilizados y volcados en una tabla con el siguiente formato:

\begin{tabular}{|l|c|c|c|c|c|c|c|c|}
\hline \multicolumn{9}{|c|}{ Área } \\
\hline & Mal & Regular & Bien & Muy Bien & Excelente & NS/NC & & \\
\hline & 1 & 2 & 3 & 4 & 5 & 6 & Total & $\begin{array}{c}\text { Saldo de } \\
\text { Respuesta }\end{array}$ \\
\hline ¿El alumno...? & & & & & & & & \\
\hline & & & & & & & & \\
\hline Total & & & & & & & & \\
\hline Porcentaje & & & & & & & & \\
\hline
\end{tabular}

Luego se calculó el "Saldo de respuesta".El cálculo de ese promedio sigue idéntica metodología que la del Global CompetitivenessIndex del WorldEconomicForum para el procesamiento de la ExecutiveOpinionSurvey en que se pregunta sobre una serie de cuestiones y se solicita que se califique en un rango que va de 1 a 7 en que 1 es lo peor y 7 lo mejor y que luego se sintetiza a través de un promedio. Xavier Sala-i-Martin (Cabrera de Mar, Barcelona, España, 1963), es un economista de origen español y de nacionalidad estadounidense, articulista, catedrático de economía en la Universidad de Columbia y Asesor Jefe ("ChiefAdvisor") del WorldEconomicForum donde, además, es coautor del Global CompetitivenessReport y el padre intelectual del Global CompetitivenessIndex que ordena a más de 140 países del mundo según su competitividad)de cada pregunta realizada, en función de la fórmula siguiente:

$$
\text { Saldo de Respuesta }=\frac{\sum_{i=1}^{n} F_{i} \cdot i}{\sum^{n} F}
$$


Donde:

$\mathrm{F}_{\mathrm{i}}=$ Es la cantidad de respuestas (frecuencias) de cada ítem para cada valor de las opciones de respuesta

$\mathrm{i}=$ Es el valor de cada uno de las opciones de respuesta

A efectos de realizar la comparación con los datos de la última publicación disponible de PISA, fue necesario realizar un re-escalamiento de variables, toda vez que PISA utiliza una escala que va de 0 a 800 puntos y en la encuesta se usó un rango de 1 a 5.

Fue necesario establecer la ecuación de la recta de transformación en función de los ejes cartesianos de los extremos, con las equivalencias que constan la Tabla 5.

Tabla 5: Equivalencias para transformación

\begin{tabular}{|l|r|r|}
\hline & Encuesta & \multicolumn{2}{|c|}{ PISA } \\
\hline Mínimo & 1 & 0 \\
\hline Máximo & 5 & 800 \\
\hline
\end{tabular}

Los extremos conforman los pares siguientes:

$\left(\mathrm{x}_{0} ; \mathrm{y}_{0}\right)=(1 ; 0)$

$\left(\mathrm{x}_{1} ; \mathrm{y}_{1}\right)=(5 ; 800)$

De tal modo, la pendiente de la recta de transformación "m" es:

$$
m=\frac{\left(y_{1}-y_{0}\right)}{\left(x_{1}-x_{0}\right)}=\frac{(800-0)}{(5-1)}=200
$$

Y la ordenada al origen "b" es: 
$b=-m \cdot x_{0}+y_{0}=-200 \cdot 1+0=-200$

Y la ecuación de la recta de transformación es:

$y=m \cdot x+b=200 \cdot x-200=200 \cdot(x-1)$

7. Resultados de la Investigación

\subsection{Datos de Fuente Secundaria}

\section{Indices calculados para La Plata}

Teniendo en cuenta la descripción de Variables a Utilizar se calculan a continuación los Indices para la ciudad de La Plata.

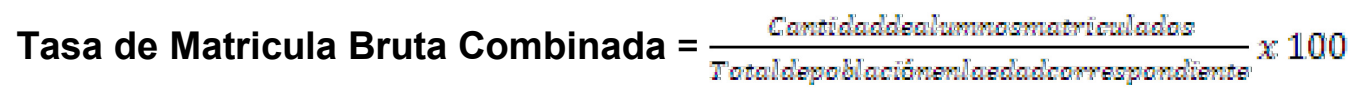

Tasa de Matricula Bruta Combinada $=(57898 / 66092) \times 100=87,6 \%$

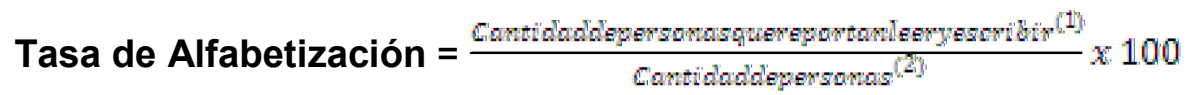

Tasa de Alfabetización= (65302 / 66092) $\times 100=98,8 \%$

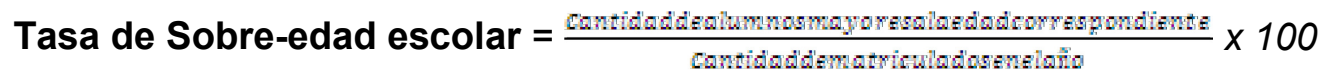

Tasa de Sobre-edad escolar $=(10791 / 42745) \times 100=25,2 \%$

Tasa de Alfabetización= $\frac{\text { Cantidad de alumnos que reportar no leer nil escribir" }}{\text { Toital de alumnos }}=100$

Tasa de Alfabetización $=(790 / 66092) \times 100=1,19 \%$ 


\section{Comparación de Indices La Plata-Región}

En la tabla siguiente se presentan los índices comparativos calculados para la ciudad de La Plata con los correspondientes a la Región.

Tabla 6: Comparación de Indices

\begin{tabular}{|l|r|r|r|r|}
\hline \multicolumn{4}{|c|}{ Tasa de Matriculación Bruta Combinada } \\
\hline & \multicolumn{2}{|c|}{$\mathbf{2 0 1 0}$} & \multicolumn{2}{c|}{$\mathbf{2 0 1 1}$} \\
\cline { 2 - 5 } & Región & La Plata & Región & \multicolumn{1}{|c|}{ La Pata } \\
\hline Cantidad de alumnos matriculados & 65.154 & 49.552 & 71.867 & 57.898 \\
\hline Total de población en la edad correspondiente & 84.886 & 67.930 & 82.922 & 66.092 \\
\hline Tasa de Matriculación Bruta Combinada & $\mathbf{7 6 , 7 5 \%}$ & $\mathbf{7 2 , 9 5 \%}$ & $\mathbf{8 6 , 6 7 \%}$ & $\mathbf{8 7 , 6 0 \%}$ \\
\hline
\end{tabular}

\section{Gráfico 1: Comparación de Indices}

\section{Tasa de Matriculación Bruta Combinada}

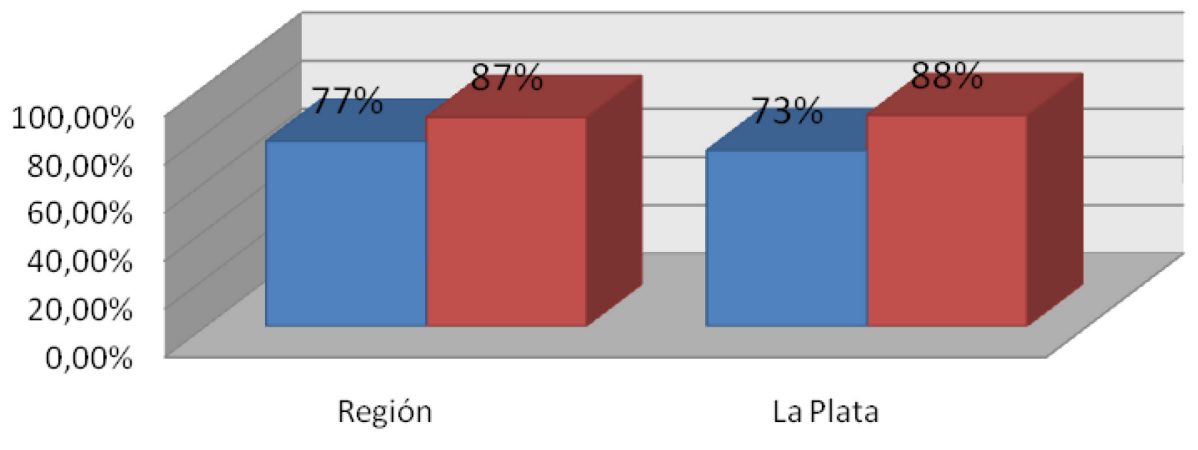

$2010 \square 2011$

Fuente: Elaboración propia

En el Gràfico 1 se observa un crecimiento en la tasa de matriculación entre el año 2010 y 2011, para La Plata y la región.

Gráfico 2:Comparación Alumnos Matriculados 


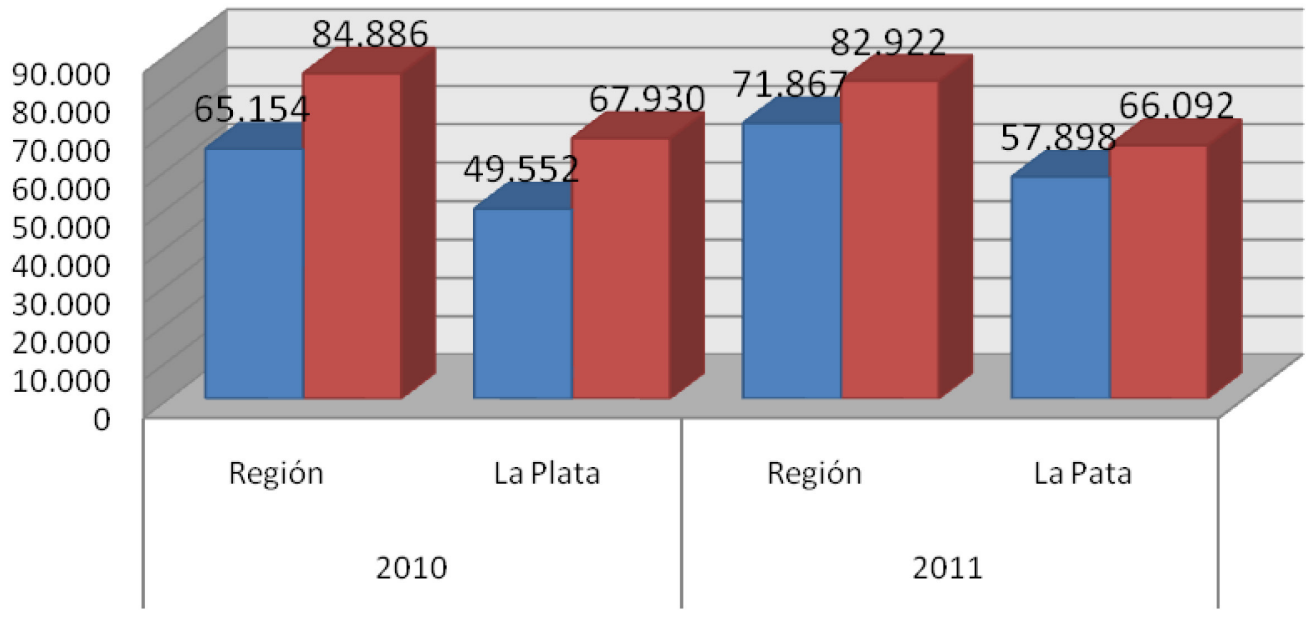

Tabla 7:Tasa de Sobre-edad escolar

\begin{tabular}{|l|r|r|r|r|}
\hline \multicolumn{4}{|c|}{ Tasa de Sobre-edad escolar } \\
\hline & \multicolumn{2}{|c|}{$\mathbf{2 0 1 0}$} & \multicolumn{2}{|c|}{$\mathbf{2 0 1 1}$} \\
\cline { 2 - 5 } & Región & La Plata & Región & La Plata \\
\hline Cantidad de alumnos mayores a la edad correspondiente & 18.314 & 14.260 & 13.870 & 10.791 \\
\hline Cantidad de matriculados en el curso & 45.876 & 34.957 & 52.934 & 42.745 \\
\hline
\end{tabular}

\section{Gràfico 3: Tasa de Sobre-edad Escolar}

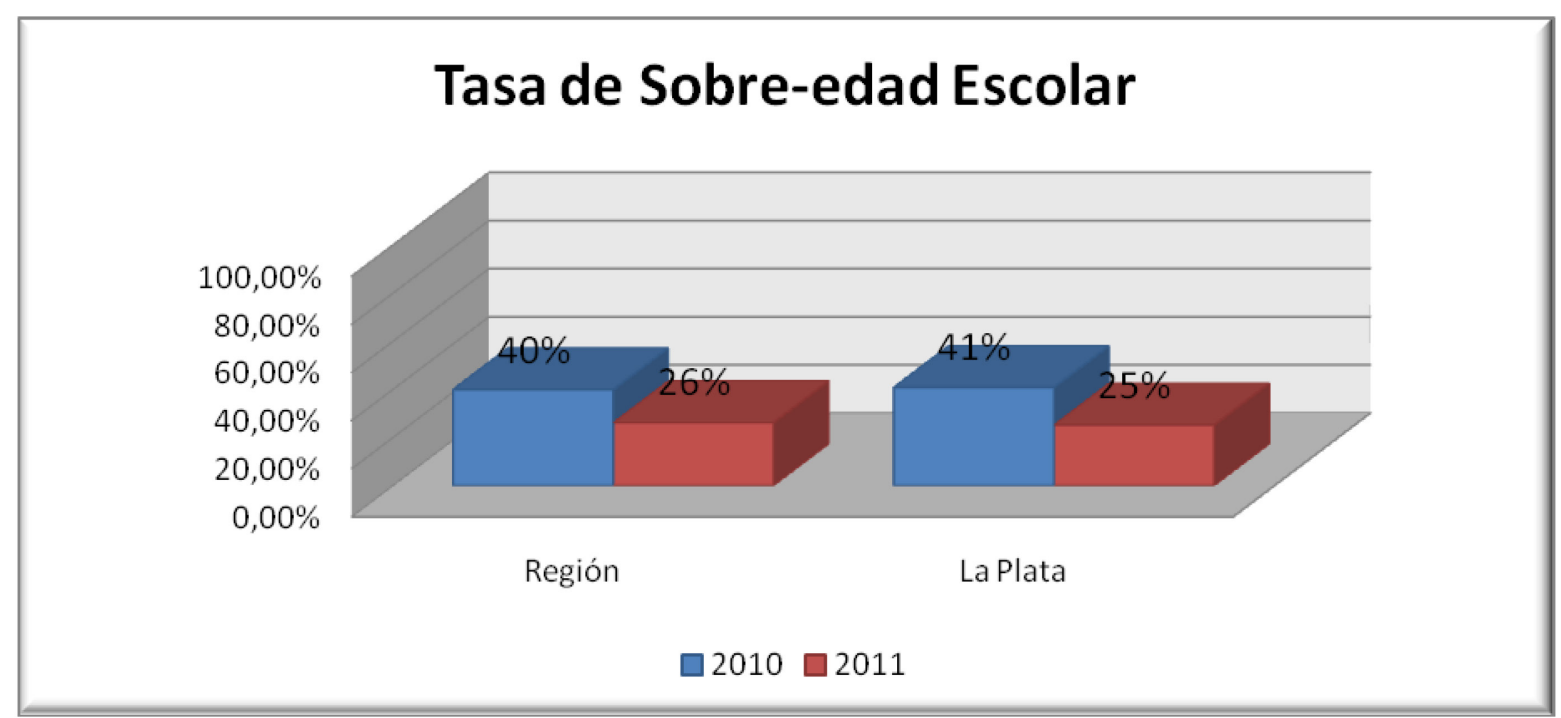

Fuente: Elaboración propia 
La tasa de sobre edad es cuando el alumno es mayor que la edad correspondiente para ese año y en el año 2011 disminuyo en la zona de La Plata y en la Regiòn.

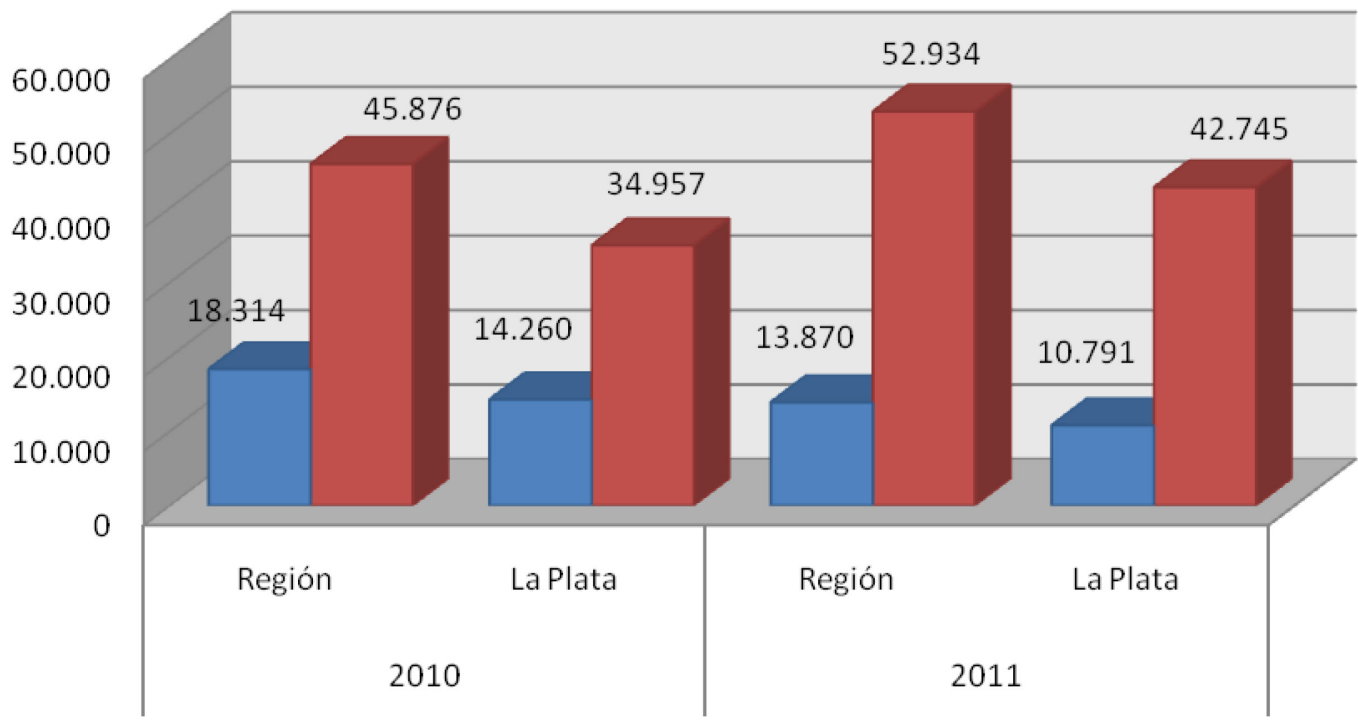

$\square$ Cant. de alumnos mayores a la edad correspondiente

$\square$ Cant. de matrículados en el curso

\begin{tabular}{|l|r|r|r|r|}
\hline \multicolumn{4}{|c|}{ Tasa de Alfabetización } \\
\hline & \multicolumn{2}{|c|}{$\mathbf{2 0 1 0}$} & \multicolumn{2}{|c|}{$\mathbf{2 0 1 1}$} \\
\cline { 2 - 5 } & Región & La Plata & Región & \multicolumn{1}{|c|}{ La Plata } \\
\hline Cantidad de personas que reportan leer y escribir & 83.856 & 67.115 & 81.923 & 65.302 \\
\hline Total de población en la edad correspondiente & 84.886 & 67.930 & 82.922 & 66.092 \\
\hline Tasa de Alfabetización & $\mathbf{9 8 , 7 9 \%}$ & $\mathbf{9 8 , 8 0 \%}$ & $\mathbf{9 8 , 8 0 \%}$ & $\mathbf{9 8 , 8 0 \%}$ \\
\hline
\end{tabular}




\section{Tasa de Alfabetización}

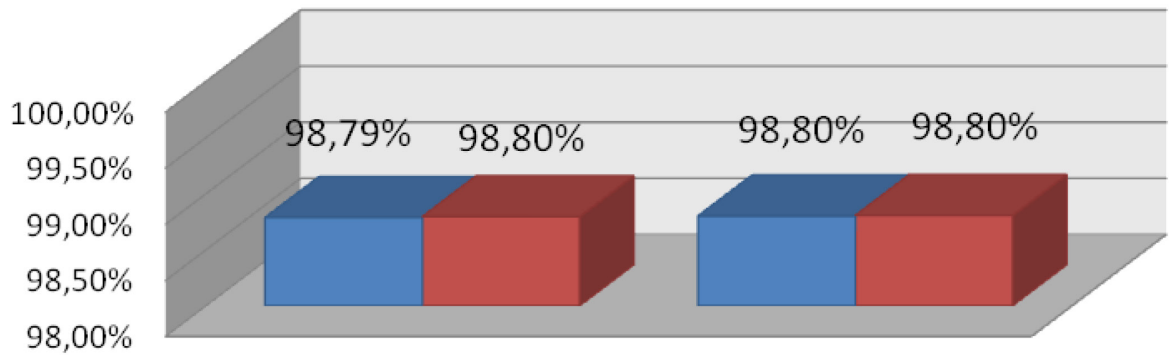

Región

La Plata

$\square 2010 \square 2011$

Fuente de elaboración propia grafico 3

La Tasa de alfabetización se mantuvo muy pareja comparando el año 2010 con el 2011, para La Plata y la Regiòn.

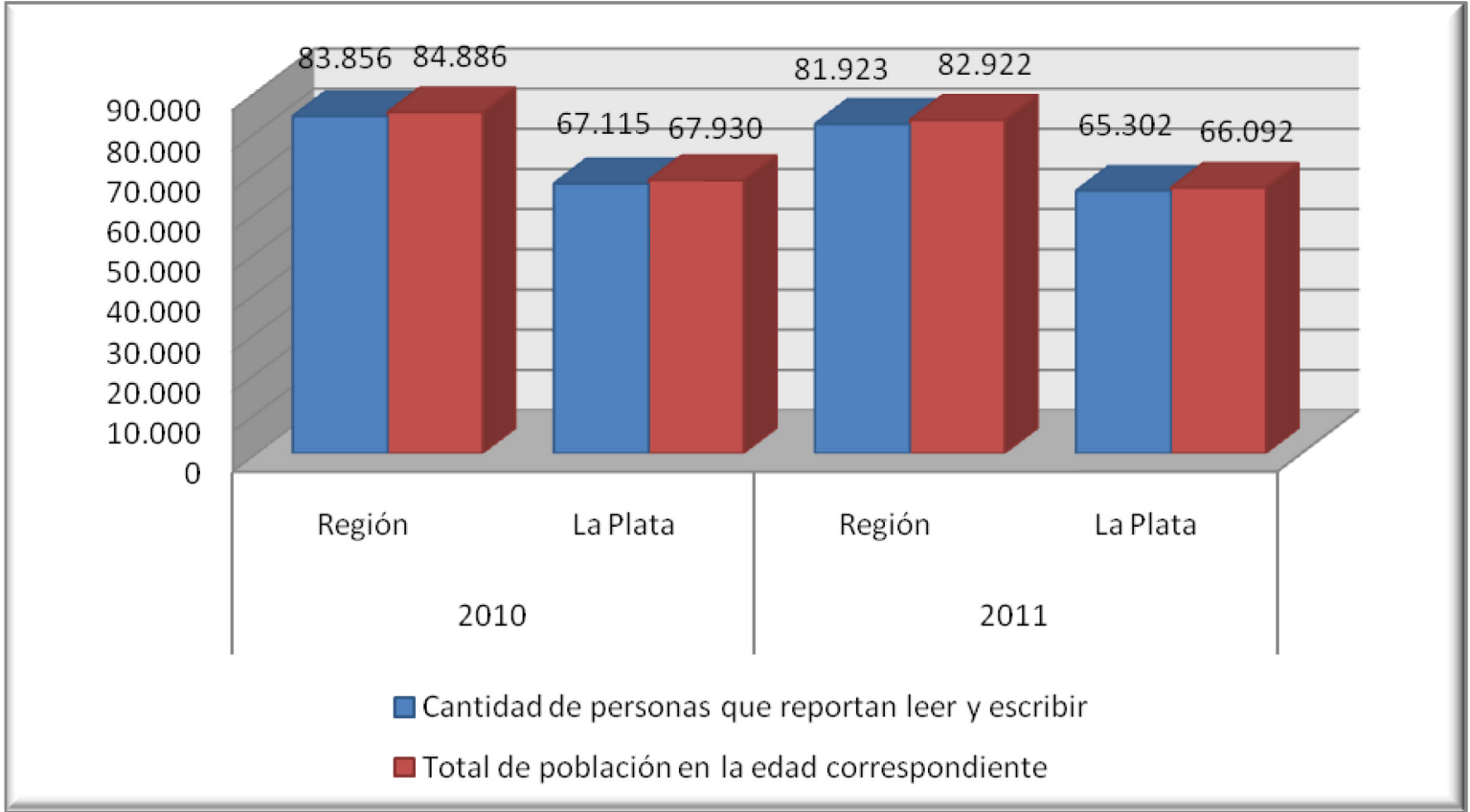

Fuente de elaboración propia

Tasa de Analfabetismo

Cantidad de personas que reportan no leer, ni escribir

Total de población en la edad correspondiente

\begin{tabular}{|r|r|r|r|}
\hline \multicolumn{2}{|c|}{2010} & \multicolumn{2}{c|}{2011} \\
\hline Región & La Plata & Región & La Plata \\
\hline 1.030 & 815 & 999 & 790 \\
\hline 84.886 & 67.930 & 82.922 & 66.092 \\
\hline
\end{tabular}




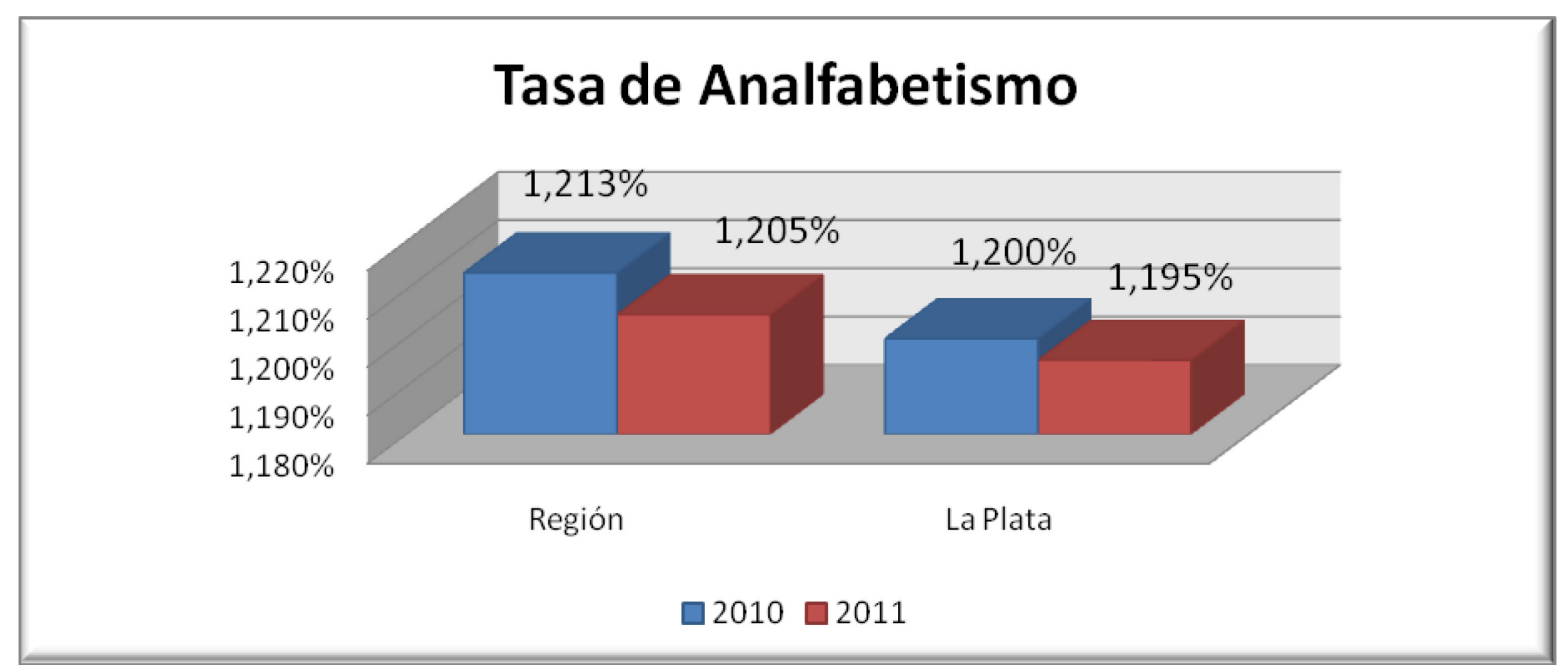

Fuente:Elaboración propia

\subsection{Datos de Fuente primaria}

En los párrafos siguientes se describe la información recabada de la opinión de los expertos. En primer lugar la opinión vertida por los expertos docentes y posteriormente la correspondiente a los empresarios.

7.2.1 Docentes

ÁreaMatemáticas 


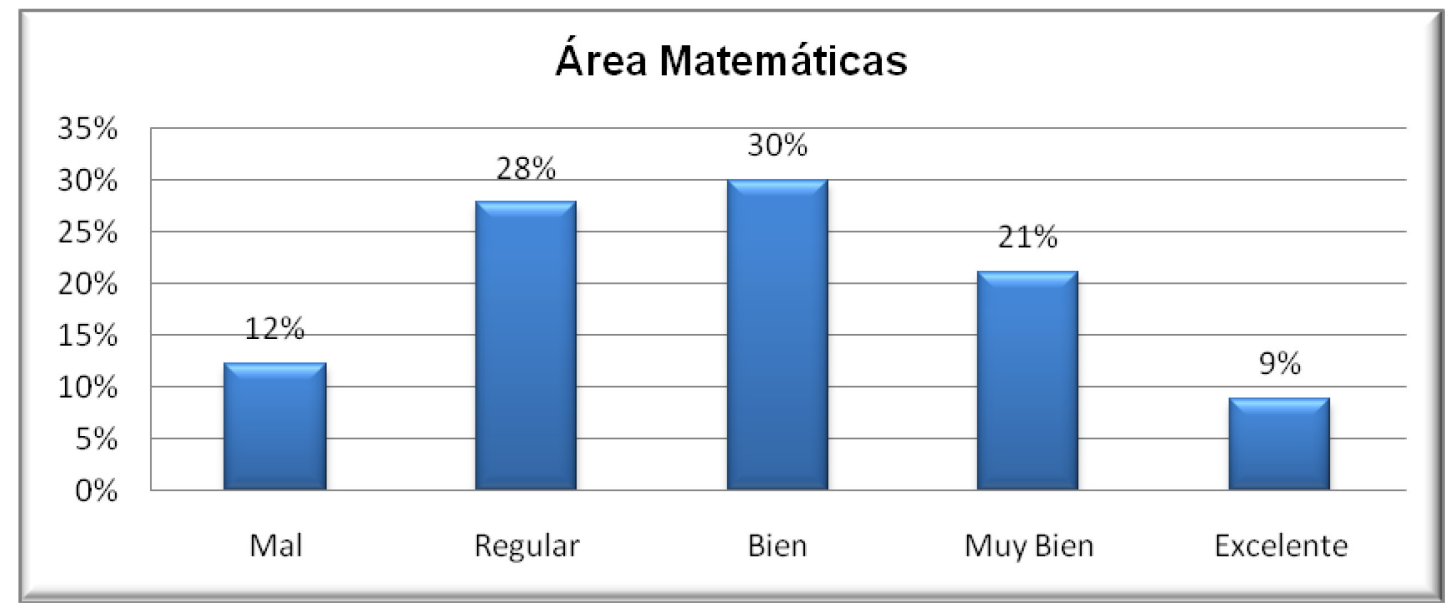

Fuente: Elaboración propia

En el gráfico se observa que la mayor concentración se presenta para las categorías comprendidas entre regular $28 \%$, Bien $30 \%$ y muy Bien $21 \%$, entre los tres repreentan el $79 \%$ de la evaluación dada por el panel de expertos docentes.

Los temas donde obtuvieron mayor puntuación son en: conocimiento acerca de los sistemas monetarios de Argentina y realizar cálculos sencillos sin uso de la tecnología. Los más bajos se dan en si es capaz de calcular el volumen de un cuerpo, es capaz de calcular la superficie de un objeto y si realiza conversiones con unidades de medidas.

\section{Saldo Respuesta Docentes Área Matemáticas}

1.1.- Cuentas básicas sin uso de tecnología... 1.2.- Cálculos de porcentajes simples..

1.3.- Conversiones con unidades de medidas...

1.4.- Conoce los tipos de triángulos existentes... 1.5.- Distingue los distintos tipos de figuras geométricas... 1.6.- Realiza las operaciones básicas con fracciones...

1.7.- Calcula la superficie de un objeto ... 1.8.- Calcula el volumen de un cuerpo... 1.9.- Conoce los sistemas monetarios utilizados en Argentina ... 1.10.- Noción sobre patrones de medida... 1.11.- Conoce y comprende los distintos tipos de gráficos... 1.12.- Comprende datos estadísticos... 1.13.- Realiza un cálculo financiero elemental..

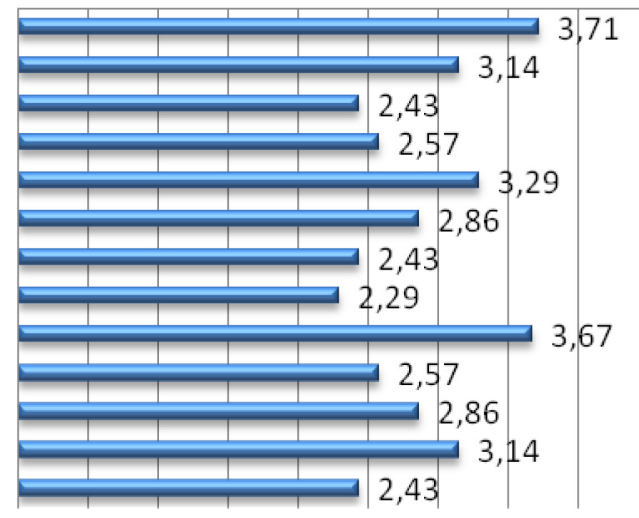

Fuente: Elaboración propia 


\section{Área Lengua}

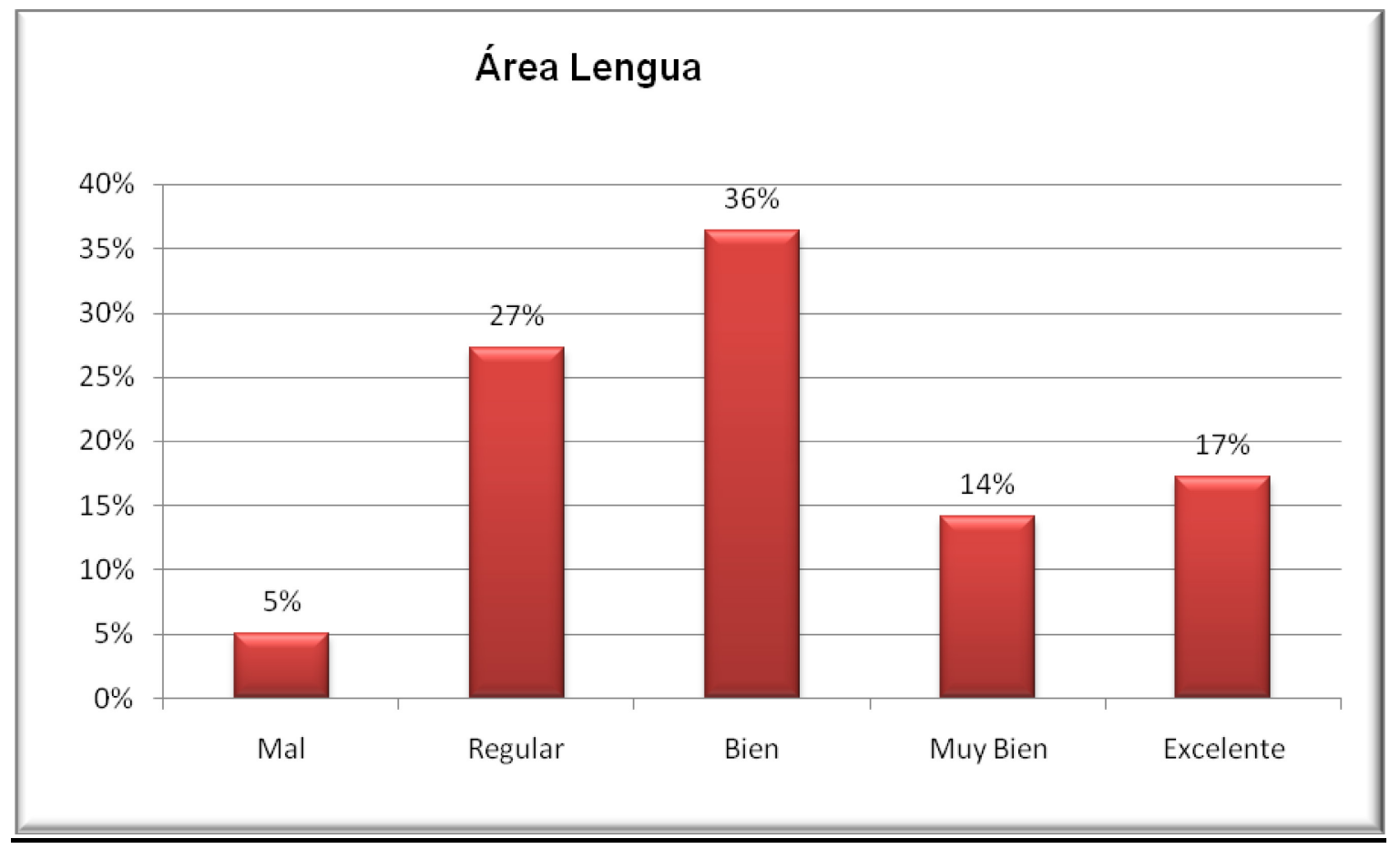

Fuente: Elaboración propia

Lo más destacado por los docentes se encuentra en las columnas Bien $36 \%$ y Regular $27 \%$. Las preguntas con mejor puntuación son si sabe entender un texto, extraer la idea principal y posee habilidad de lectura.Los menos destacados son la ortografía, la caligrafía y desempeño oral. 


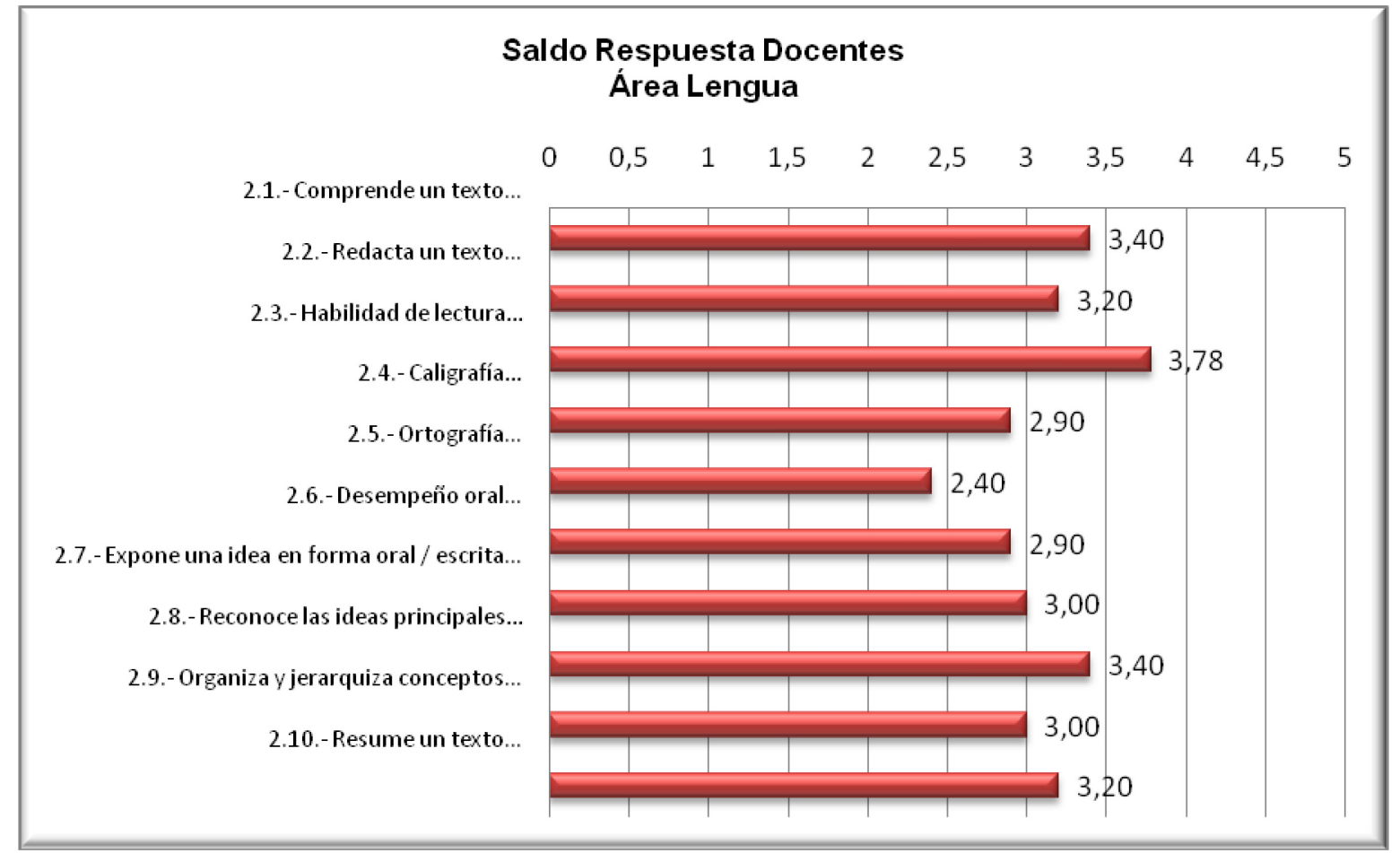

Fuente: Elaboración propia

\section{Área Ciencias}

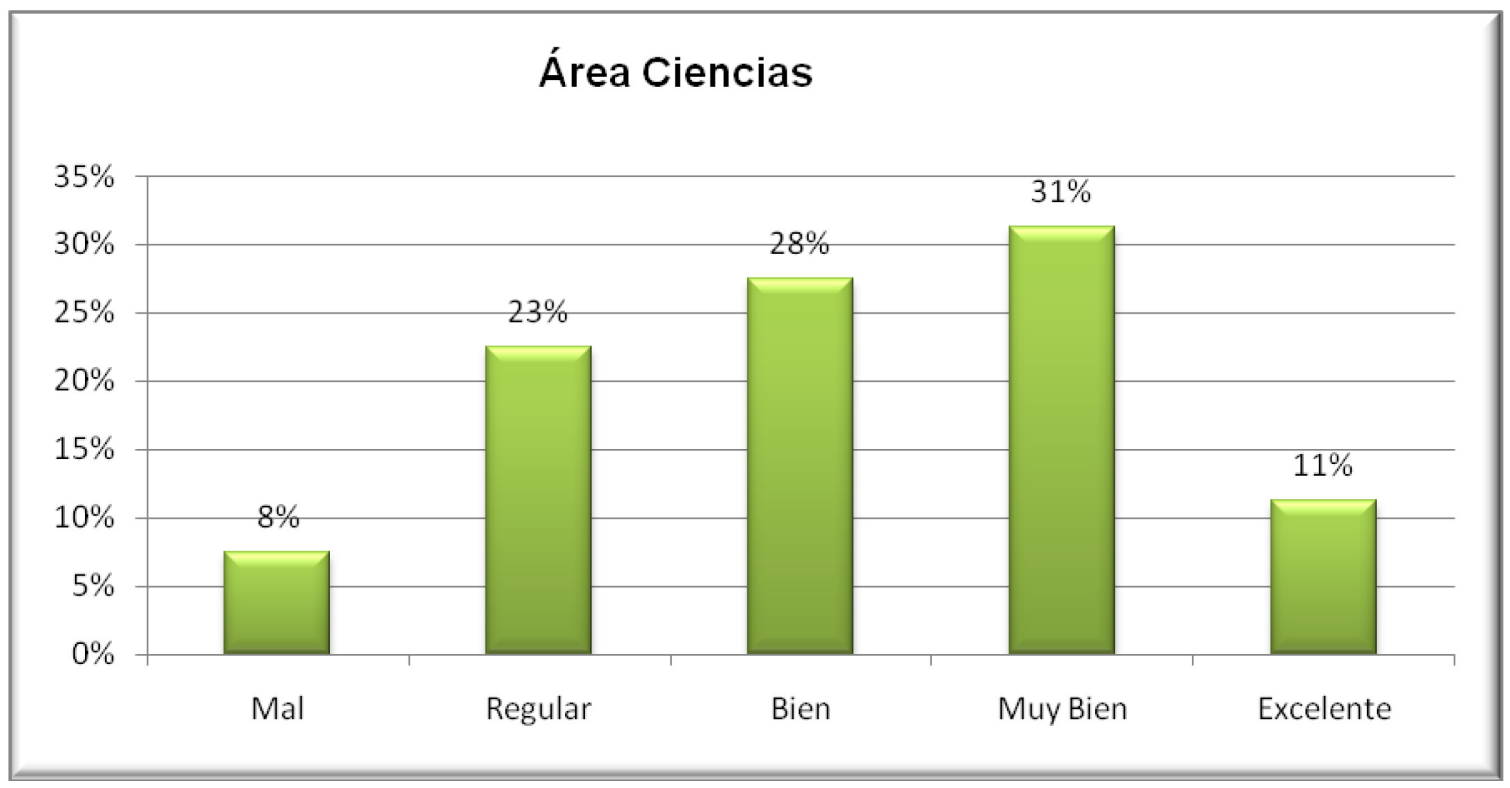

Fuente: Elaboración propia

Las categorías más frecuentes en la opinión de los docentes expertos se encuentraen la correspondiente a la modalidad Muy Bien con el $31 \%$ y Bien con el $28 \%$, 
los temas más destacados son los conocimientos sobre las vías de contagio del sida, usa los programas de computadorasy uso de internet, los menos destacados son el conocimiento de las principales enfermedades e la Argentina y conocimiento sobre primeros auxilios.

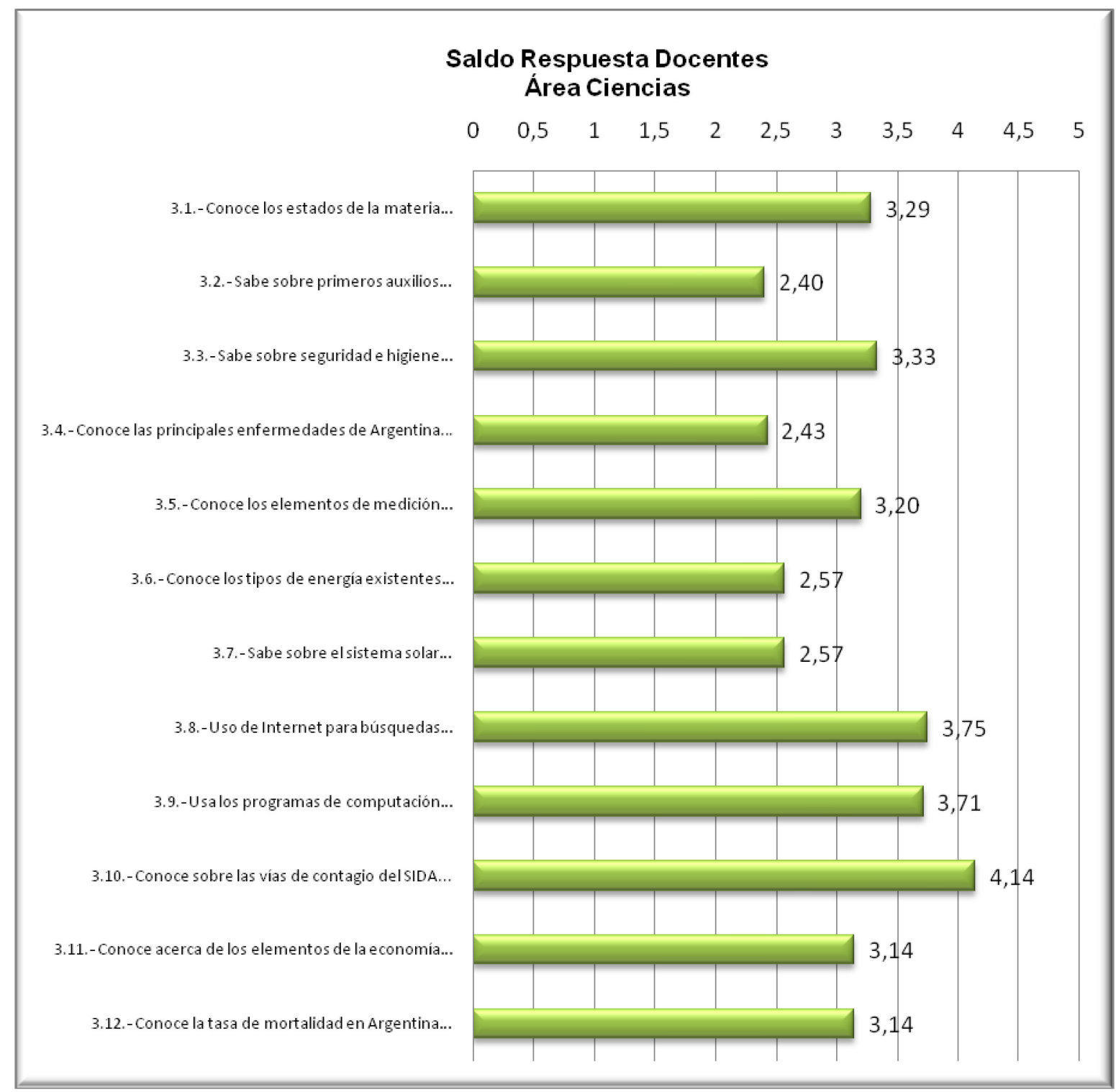

Fuente: Elaboración propia

\section{Área Aptitudes Personales}




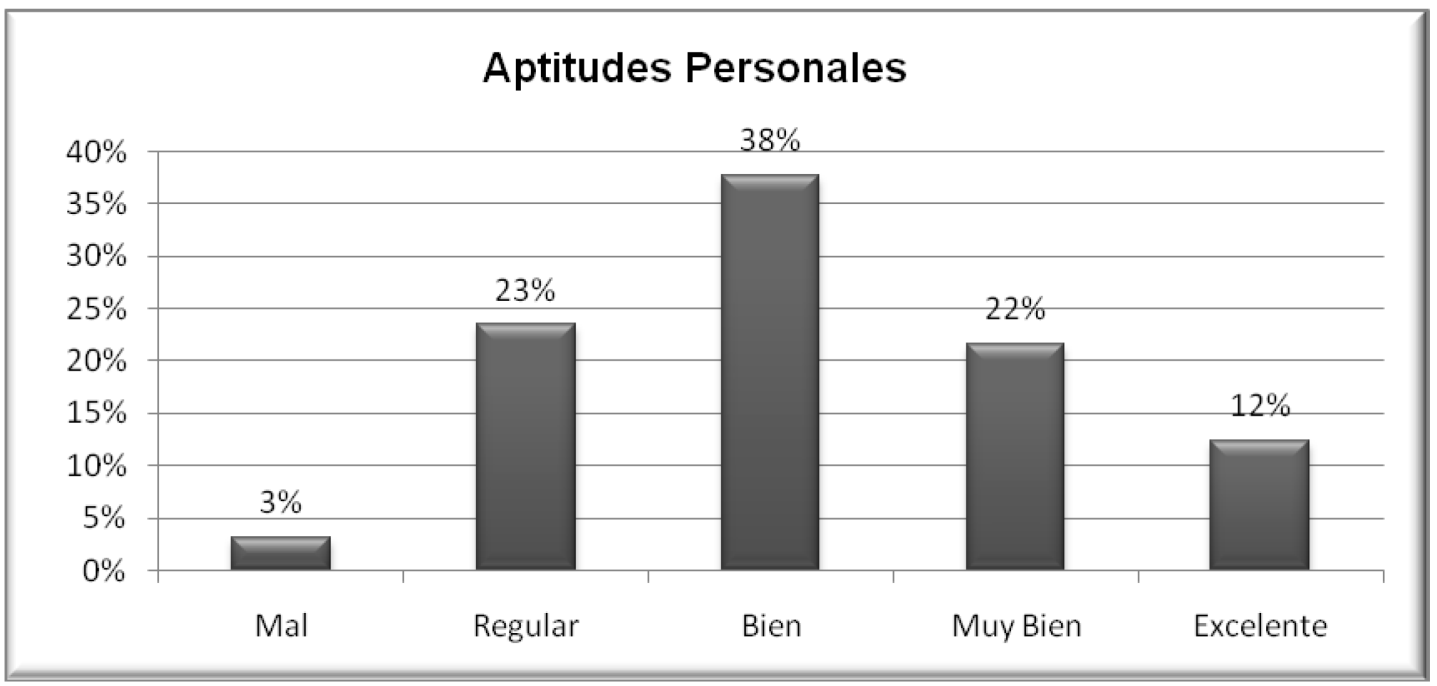

Fuente: Elaboración propia

La opinión de los docentes se encuentra concentrada en el centro conBien $38 \%$, a ambos lados Muy Bien 21\% y Regular 23\%. Los temas donde más se destacan soncompañerismo, respeto y uso de herramientas adecuadas. Las menos destacadas son orden, prolijidad y puntualidad.

\section{Saldo Respuesta Docentes Aptitudes Personales}

$\begin{array}{lllllllllll}0 & 0,5 & 1 & 1,5 & 2 & 2,5 & 3 & 3,5 & 4 & 4,5 & 5\end{array}$

4.1.- Responsabilidad

4.2.- Creatividad

4.3.-Flexibilidad

4.4.-Puntualidad

4.5.- Respeto

4.6.- Compañerismo

4.7.- Valores

4.8.- Interés y motivación

4.9.- Presencia

4.10.- Interés para trabajar en equipo

4.11.- Grado de adaptación al trabajo

4.12.- Grado de aprendizaje

4.13.- Capacidad para comunicarse y transmitir sus.

4.14.- Desempeño en el cumplimiento de sus tareas

4.15.-Orden y prolijidad

4.16.- Capacidad de resolución de problemas y su..

4.17.- Capacidad de negociación

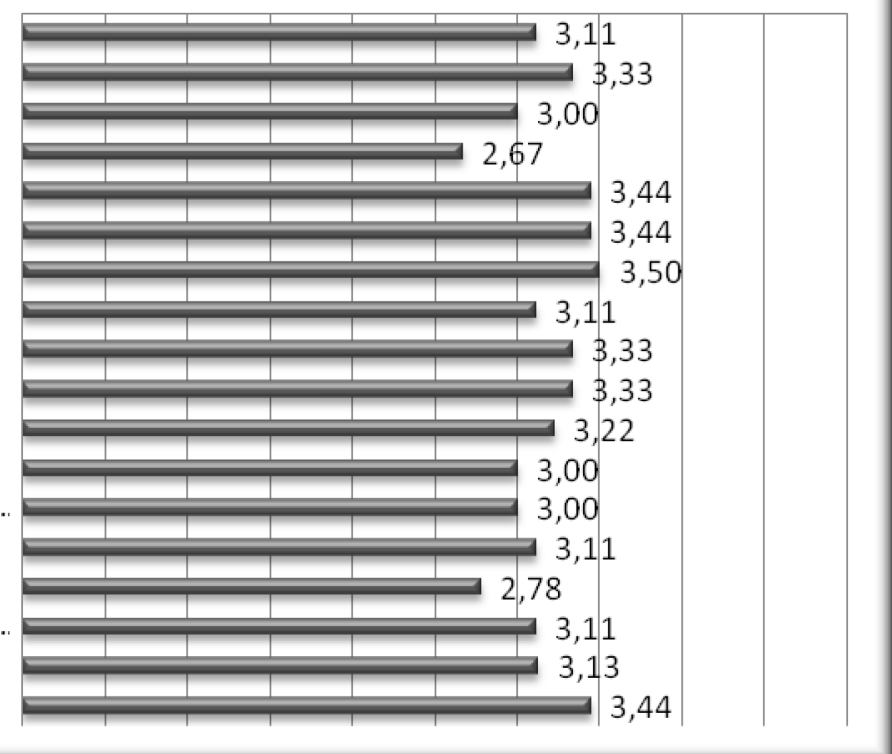

4.18.-Uso de herramientas apropiadas

Fuente: Elaboración propia 


\section{Calificación global Docentes}

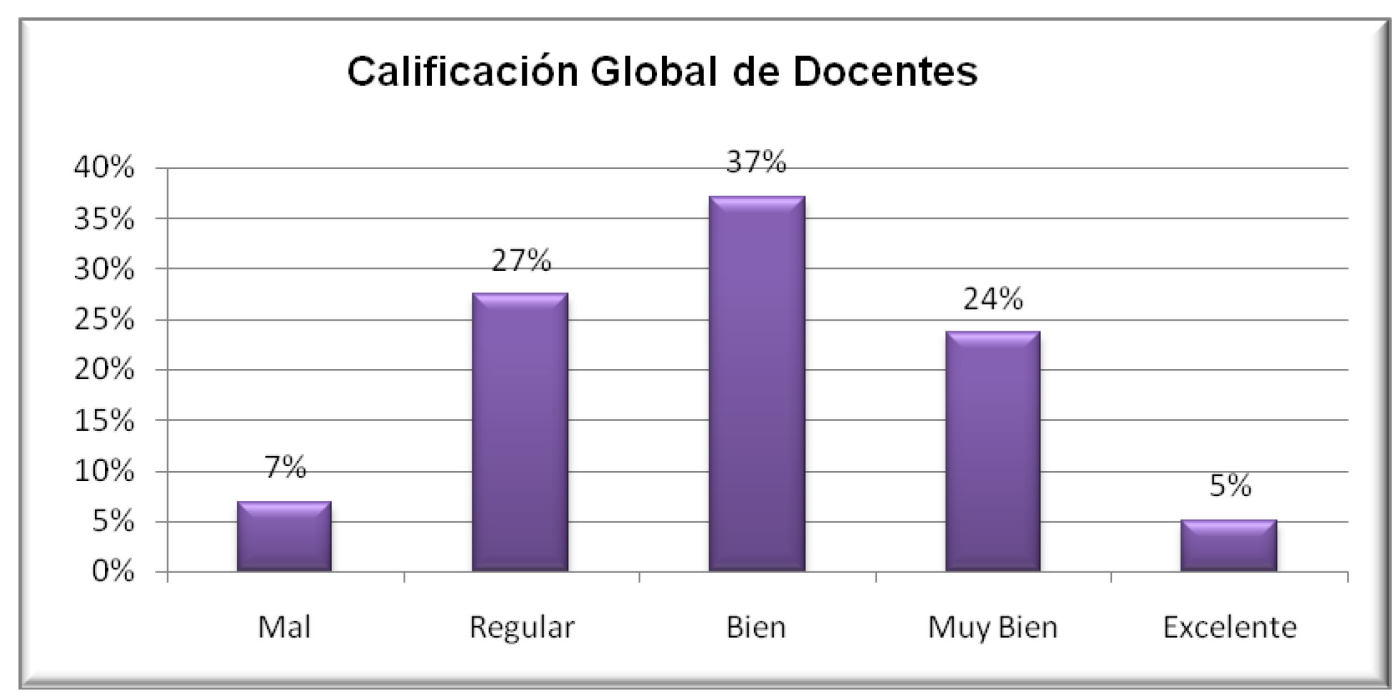

Fuente: Elaboración propia

En la calificación global del panel de expertos compuesto por docentes, es la sumatoria de todas las áreas evaluadas. Matemàticas, lengua, ciencia, aptitudes personales. En los gráficos se aprecia que la respuesta con mayor porcentaje es Bien $37 \%$, seguido por Regular $27 \%$, Muy bien $24 \%$, Excelente $5 \%$ y Mal $7 \%$.Los mejores resultados se dan en el Área de aptitudes personales y ciencias, la más baja se da en matemáticas. 


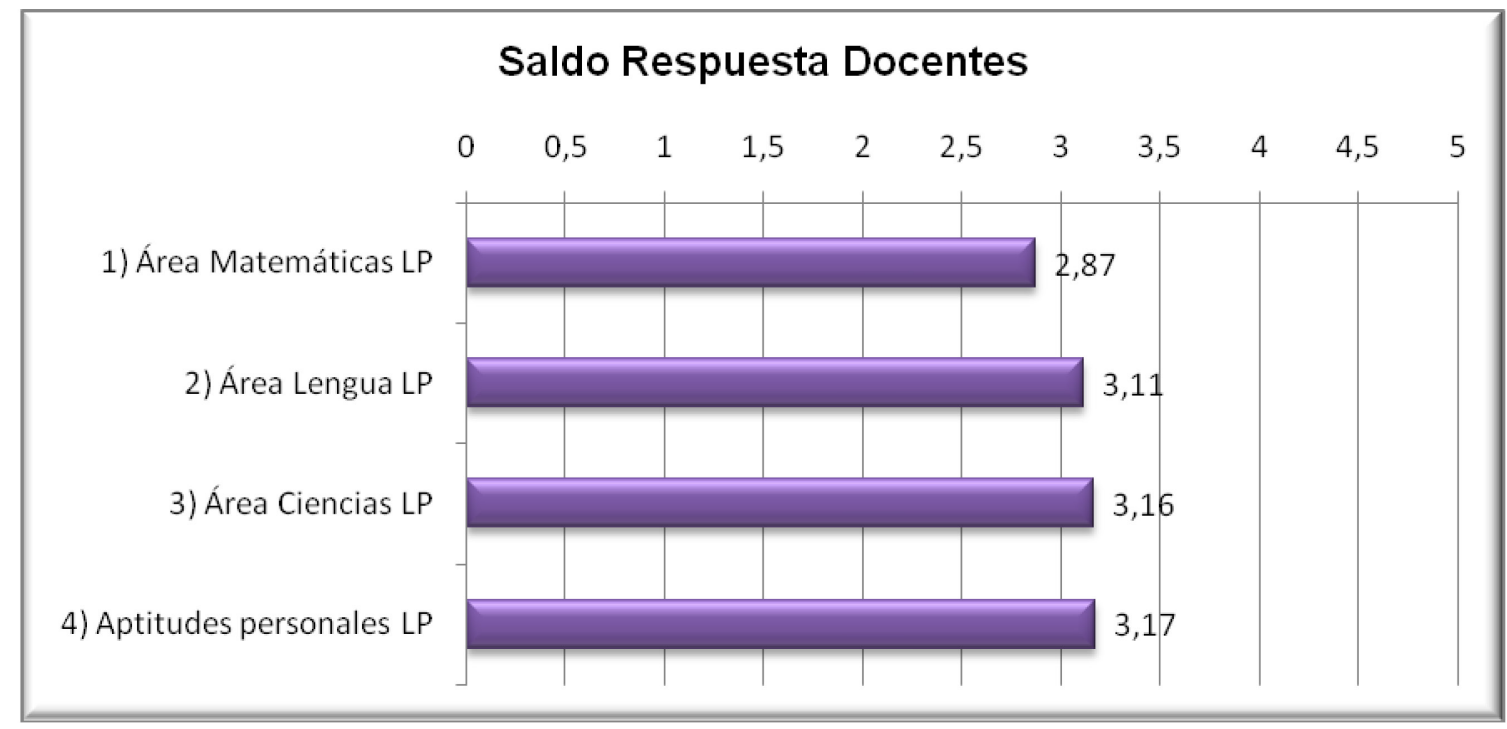

Fuente: Elaboración propia

\section{$\underline{\text { Área Matemáticas }}$}

\section{Área Matemáticas}

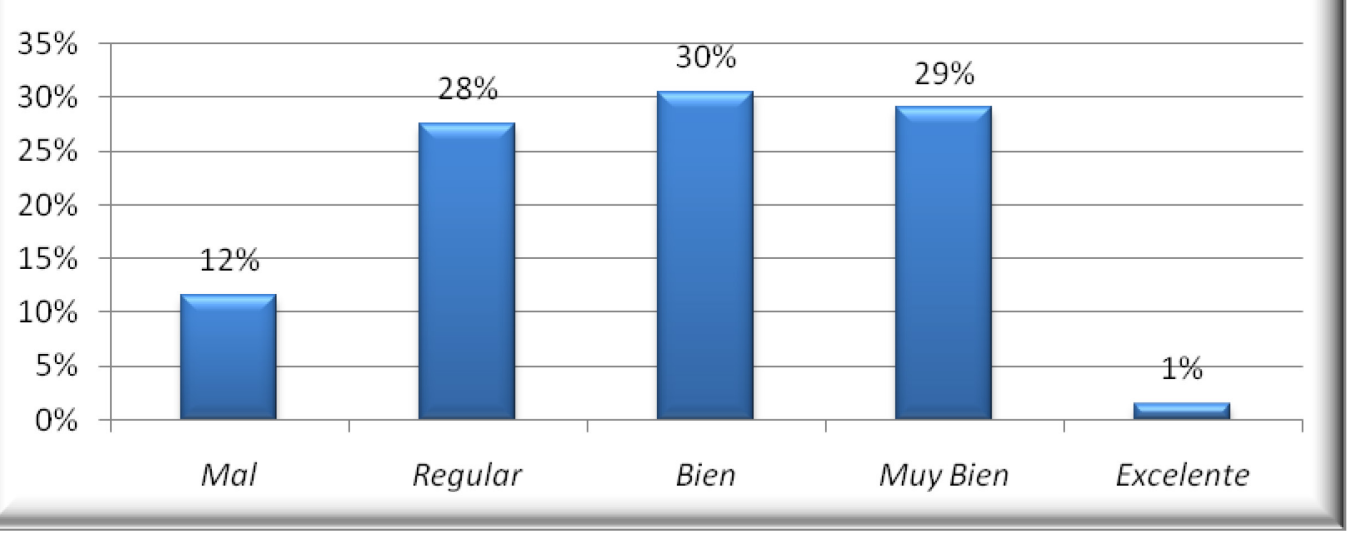

Fuente: Elaboración propia

En el gráfico se ve claramente que la mayor concentración se da entre Regular 28 $\%$, Bien $30 \%$ y Muy Bien $29 \%$, entre los tres tienen el $87 \%$ de la evaluación dada por el panel de expertos Empresarios. Los temas donde obtuvieron mayor puntuación son en: conocimiento acerca de si realiza cuentas básicas sin uso de la tecnología, conocimiento sobre los distintos gráficos y los sistemas monetarios en la Argentina, los de menor puntuación están relacionados con la conversión de las distintas unidades de medidas. 


\section{Saldo Respuesta Empresarios Área Matemáticas}

1.1.- Cuentas básicas sin uso de tecnología..

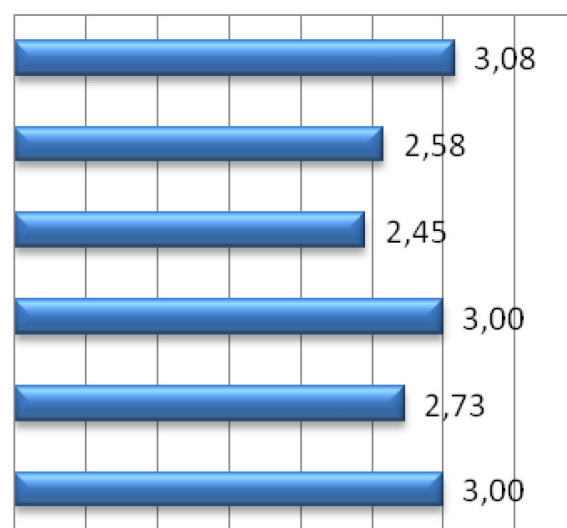

1.6.- Conoce y comprende los distintos tipos de gráficos..

1.5.- Noción sobre patrones de medida...

1.2.- Cálculo de porcentajes simples..

1.3.- Conversiones con unidades de medidas.

1.4.- Conoce los sistemas monetarios utilizados en Argentina..

Fuente: Elaboración propia

\section{Área Lengua}

\section{Área Lengua}

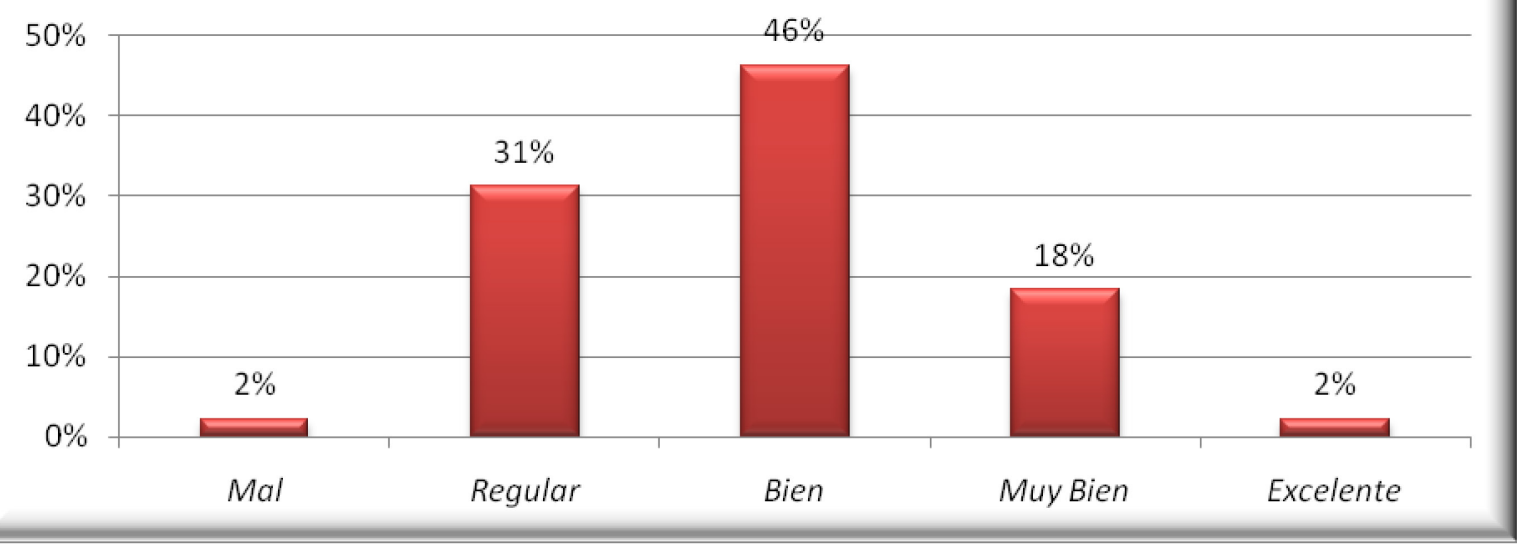

Fuente: Elaboración propia

En el gráfico se ve claramente que la opinión del panel de expertos empresarios se concentró en el centro donde la respuesta Bien tiene el $46 \%$.

Las mejores fueron comprensión de textos y el desempeño oral, las más bajas son ortografía y caligrafía. 


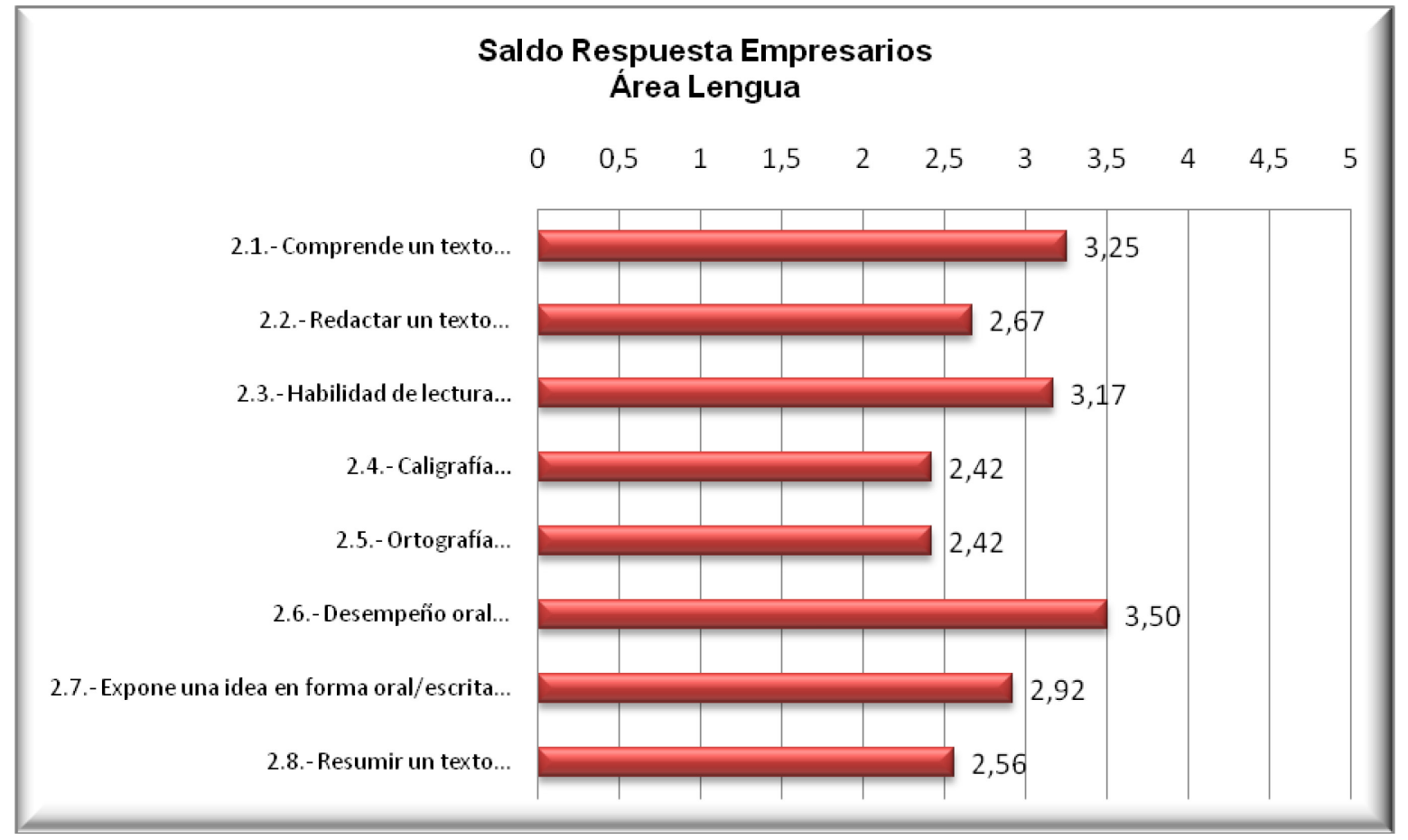

Fuente: Elaboración propia

\section{Área Ciencias}

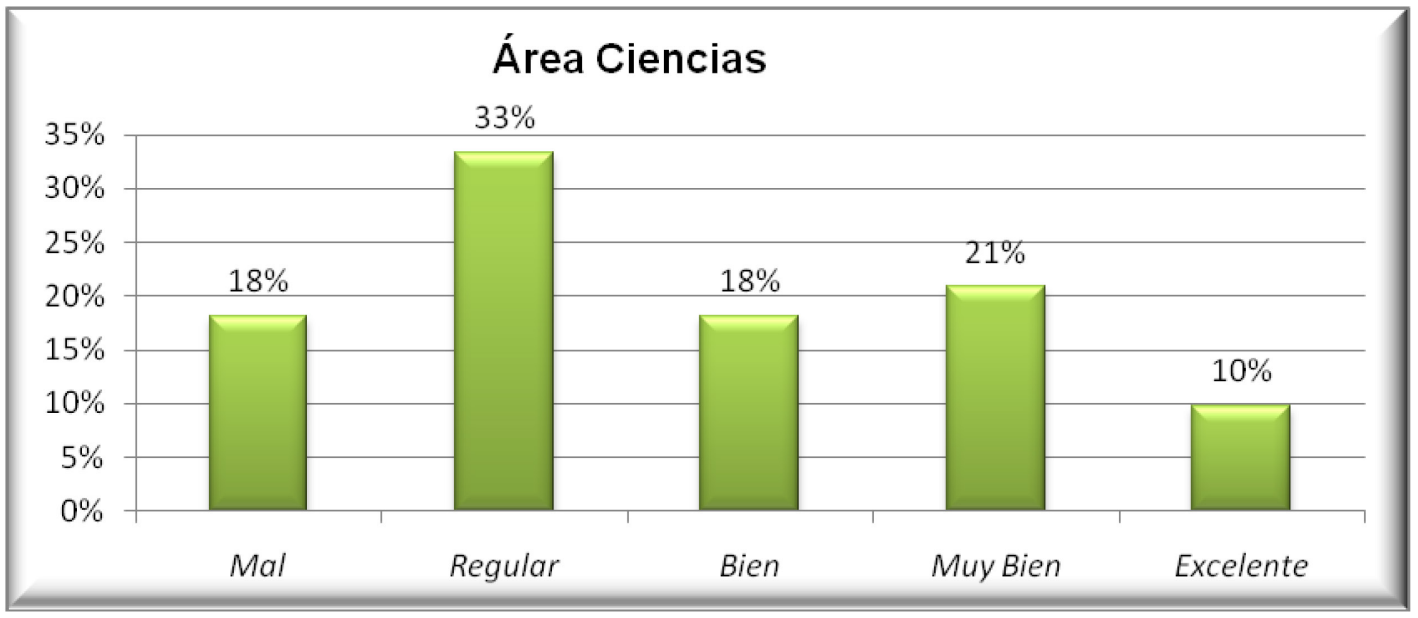

Fuente: Elaboración propia

En ciencias la opinión del panel de expertos Empresarios estuvo concentrada en la columna Regular con el 33\%, luego las demás opciones se repartieron parejos en malo 18\%, Bien 18\%, Muy Bien 21\%y Excelente 10\%. Las mejores calificaciones se dieron en uso de internet para búsqueda de información, uso de los programas básicos de 
computacióny los más bajos sobre conocimiento de elementos de medición y conocimiento sobre primeros auxilios.

\section{Saldo Respuesta Empresarios Área Ciencias}

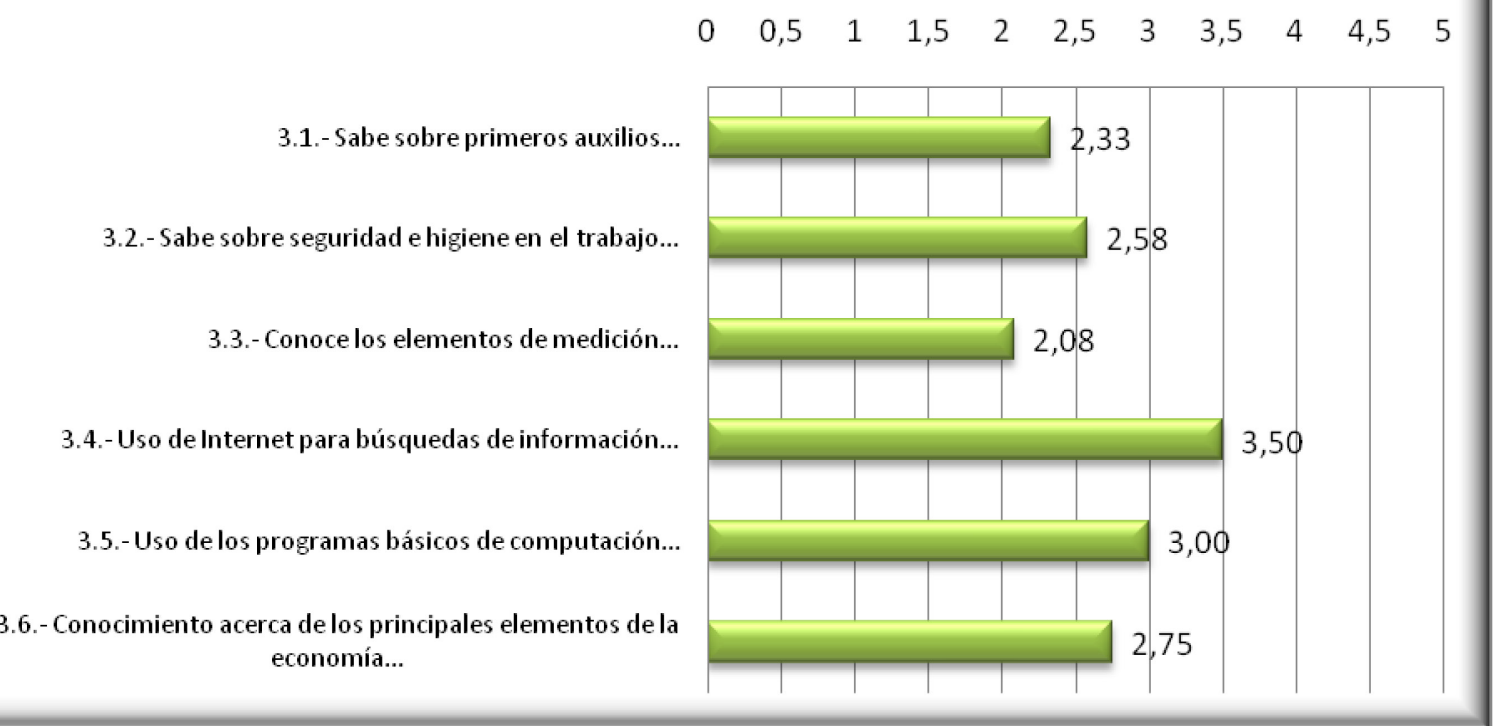

Fuente: Elaboración propia

\section{Área Aptitudes Personales}

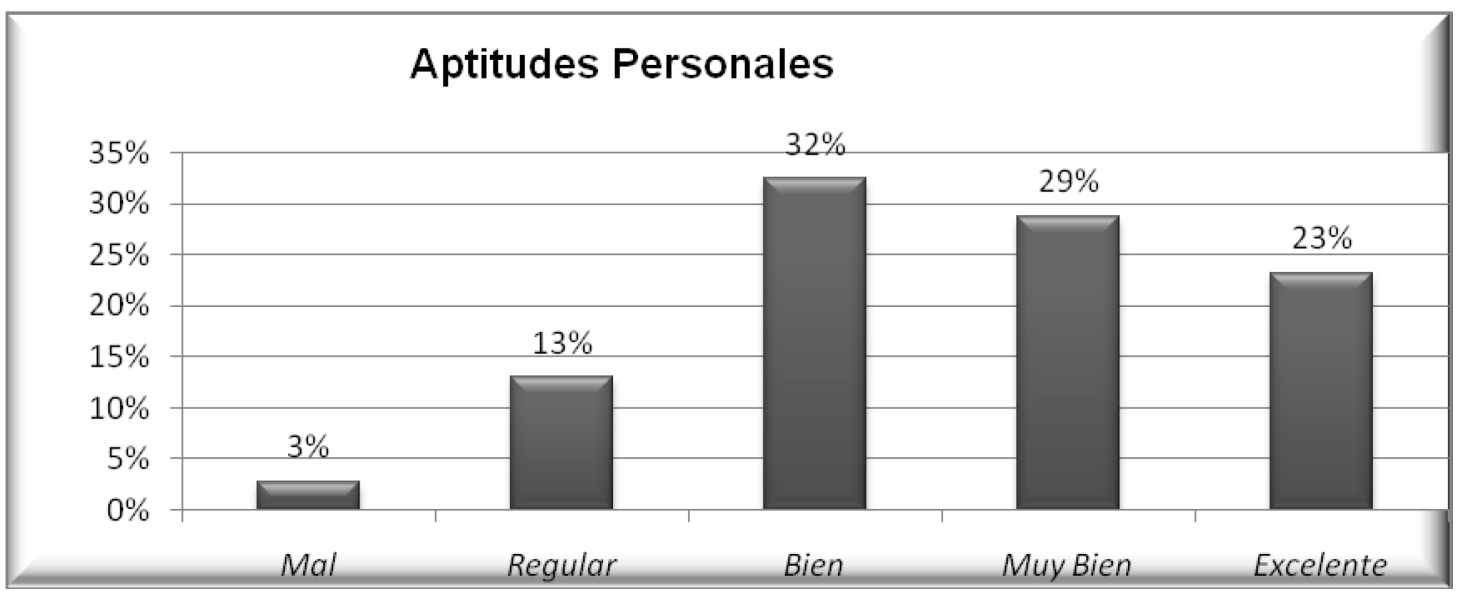

Fuente: Elaboración propia

En actitudes personales el panel de expertos Empresarios tuvo una buena calificación con Bien 32\%, Muy Bien 29\% y excelente 23\%, los mejores puntajes son 
respeto, compañerismo y las de menor calificación esta la puntualidad y la capacidad de negociación.

\section{Saldo Respuesta Empresarios Aptitudes personales}

$\begin{array}{lllllllllll}0 & 0,5 & 1 & 1,5 & 2 & 2,5 & 3 & 3,5 & 4 & 4,5 & 5\end{array}$

4.13. - Capacidad para comunicarse y transmitir sus. 4.14.- Desempeño en el cumplimiento de sus tareas 4.15.- Orden y prolijidad 4.16.- Capacidad de resolución de problemas y su. 4.17. - Capacidad de negociación 4.18.-Uso de herramientas apropiadas

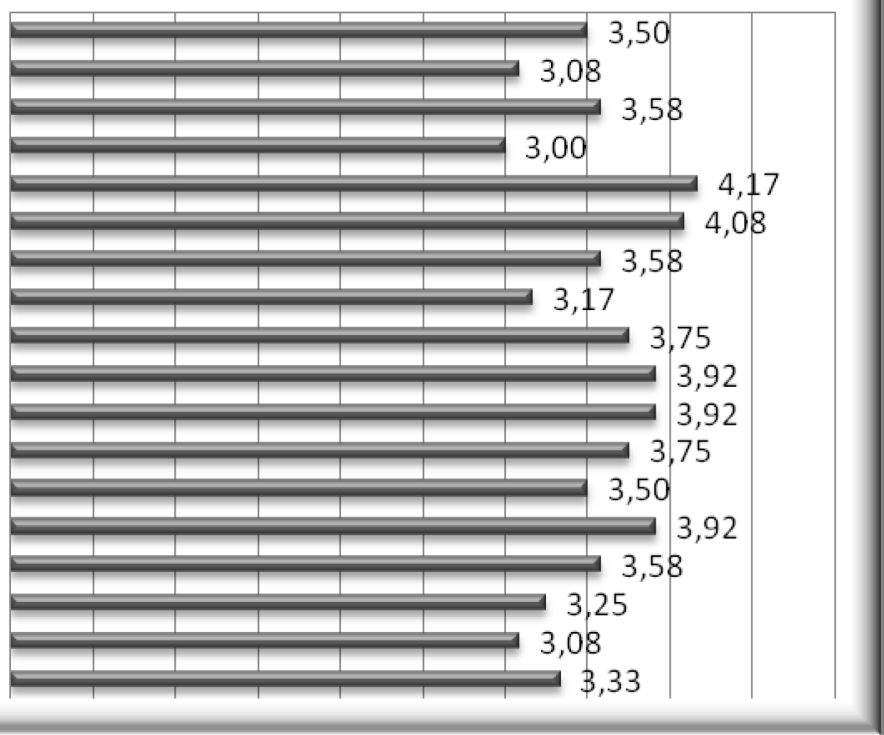

Fuente: Elaboración propia

\section{Calificación global Empresarios}

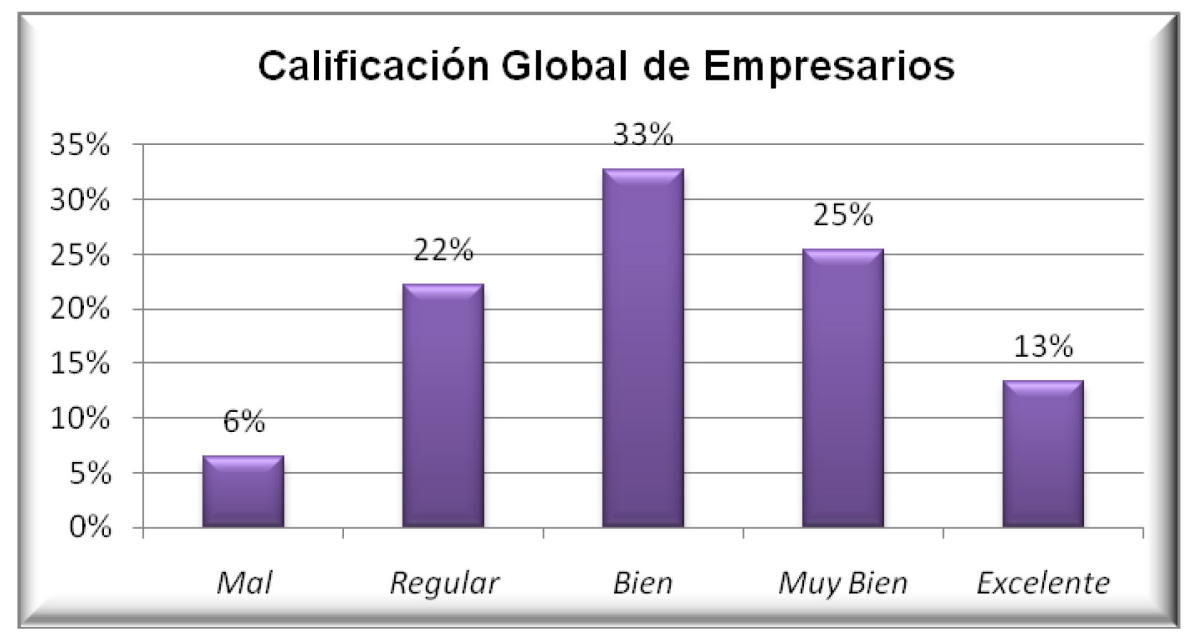

Fuente: Elaboración propia 
La calificación global de empresarios se encuentra concentrada en la columna de Bien $33 \%$ y a ambos lados equilibrada con Muy Bien a la derecha con $25 \%$ y Regular a la izquierda con $22 \%$.

El saldo de respuesta más destacado se da en el Área de lengua con 4,11 y el menos destacado en el Área de ciencias con 2,86.

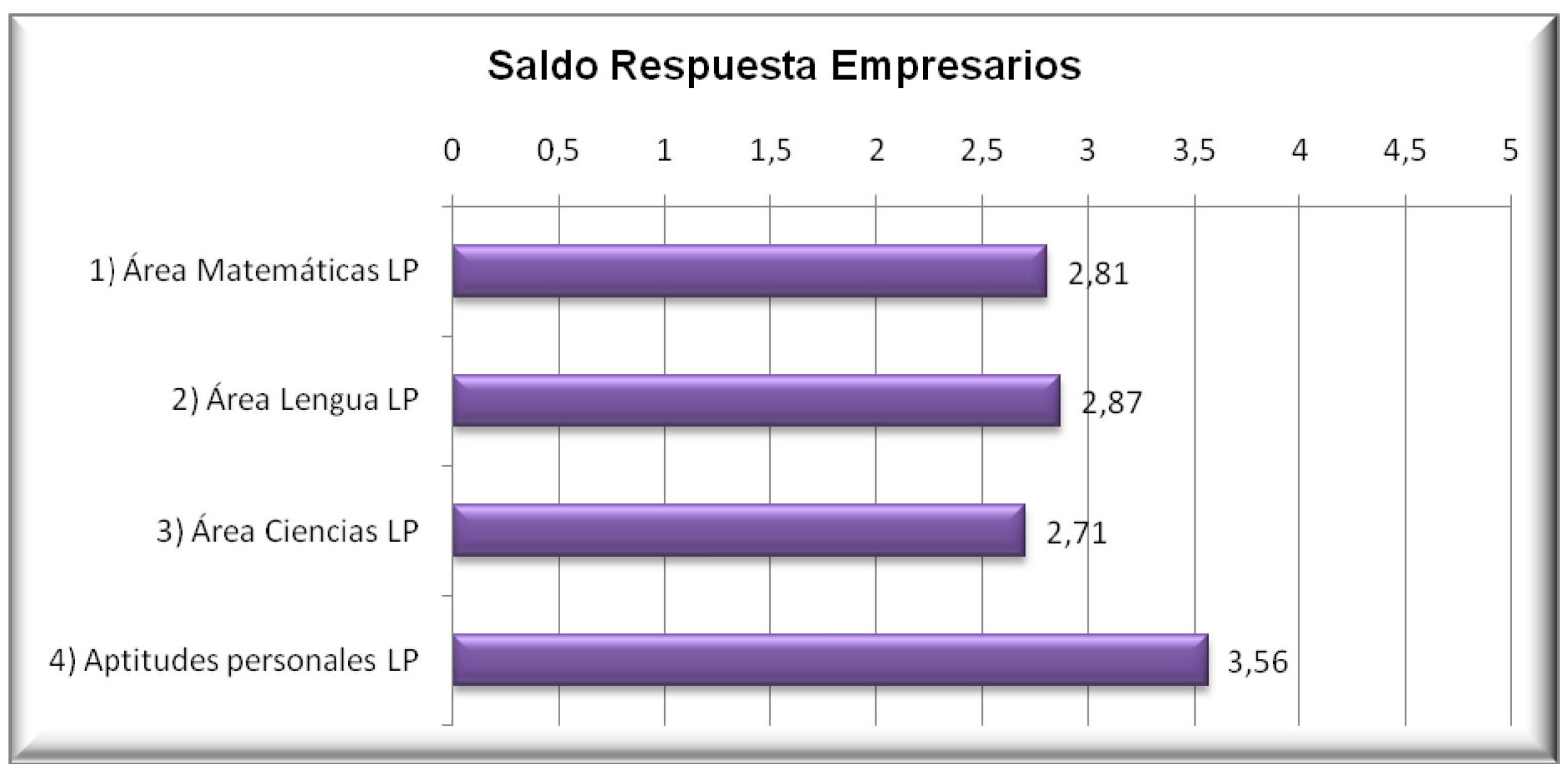

Fuente: Elaboración propia

\section{$\underline{\text { 7.2.3 Total Global }}$}

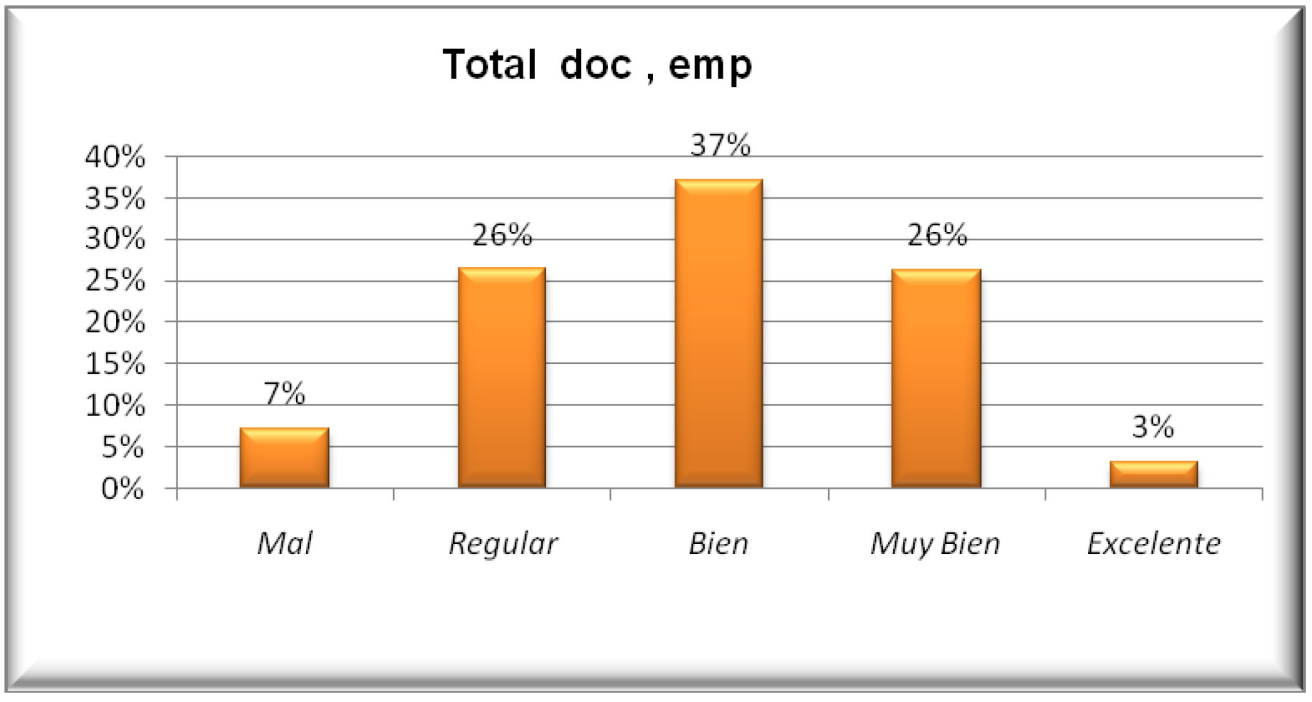


Fuente: Elaboración propia

El Total Global hace referencia a la sumatoria de los resultados de ambos paneles de expertos, docentes y empresarios. En este punto, se aprecia que en líneas generales el nivel de educación de los egresados del secundario es Bueno (37\%), y centrado porque Regular tiene un (26\%) al igual que muy bien. Con menor porcentaje se encuentran las otras opciones, como sonMal (7\%), y Excelente (3\%).Ambos paneles de expertos presentan resultados similares acerca de la educación, ya que tanto los docentes como los empresarios opinan que el nivel de educación es Buena, con inclinación a Regular. El saldo de respuesta de los empresarios de 2,91 es menor al de los docentes de 2,93.

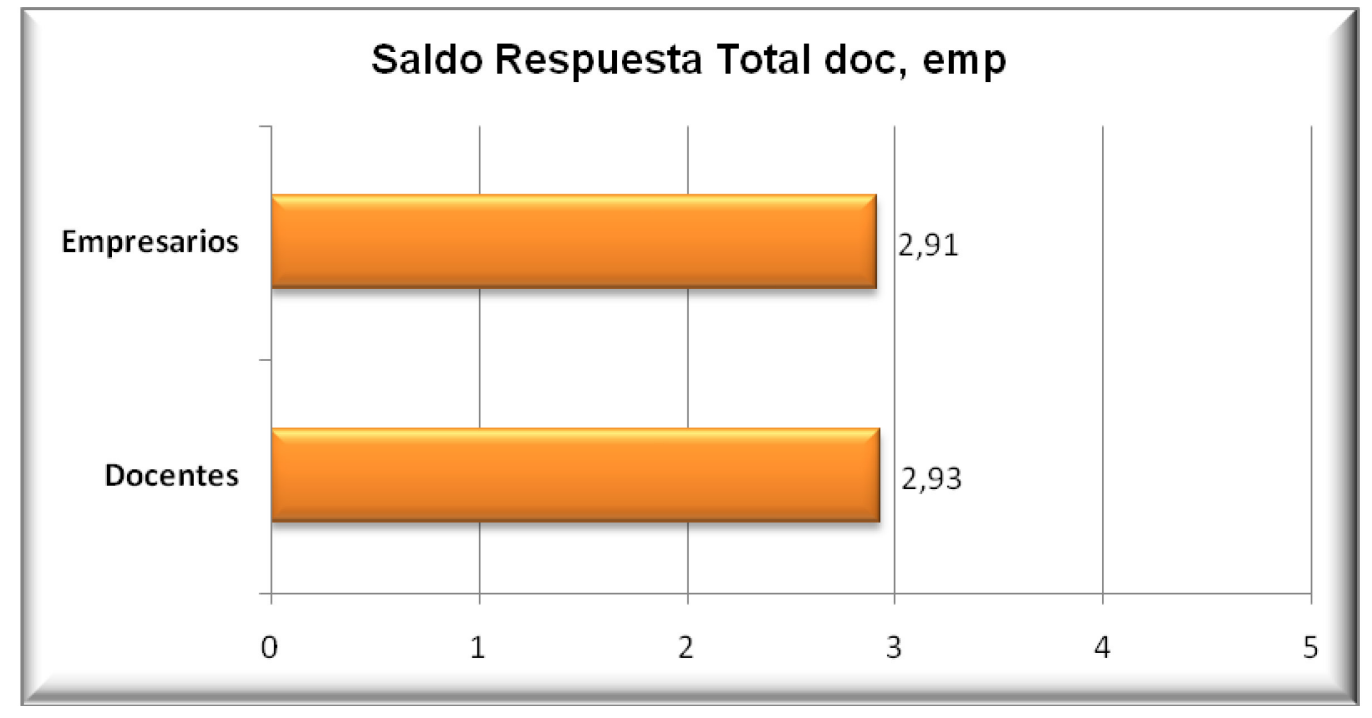

Fuente: Elaboración propia

$\underline{\text { 7.2.4. Comparación de respuestas Docentes y Empresarios }}$

\section{Área Matemáticas}




\section{Área Matemáticas}

$\begin{array}{lllllllllll}0 & 0,5 & 1 & 1,5 & 2 & 2,5 & 3 & 3,5 & 4 & 4,5 & 5\end{array}$

1.1.- Realiza cuentas básicas sin uso de...

1.2.- Realiza cálculos de porcentajes simples...

1.3.- Realiza conversiones con unidades de...

1.4.- Conoce los sistemas monetarios utilizados.

1.5.- Tiene noción sobre patrones de medida...

1.6.- Conoce y comprende los distintos tipos de.

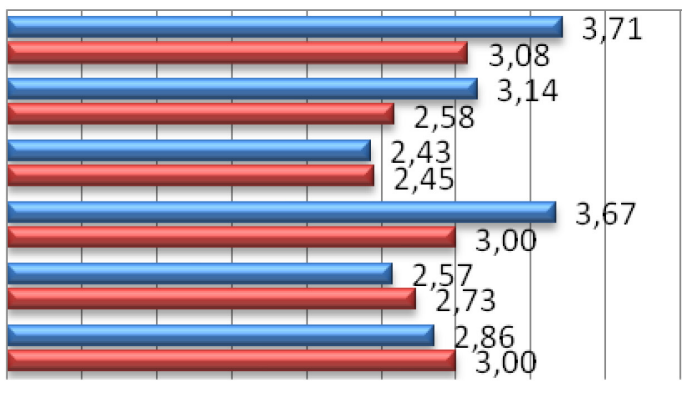

$\nabla$ Docentes $\boldsymbol{\Delta}$ Empresarios

Fuente: Elaboración propia

En el grafico se puede observar que el panel de expertos docentes tiene una mejor calificación que el panel de expertos Empresarios en los puntos donde debe realizar cuentas básicas sin uso de la tecnología, realiza cálculos de porcentajes simples y en los conocimientos acerca de los sistemas monetarios utilizados en la Argentina. En cambio el panel de expertos Empresarios tiene mejor calificación en que el alumno tiene noción sobre patrones de medidas, conoce y comprende los distintos tipos de gráficos y realiza conversiones con unidades de medidas.

\section{Área Lengua}

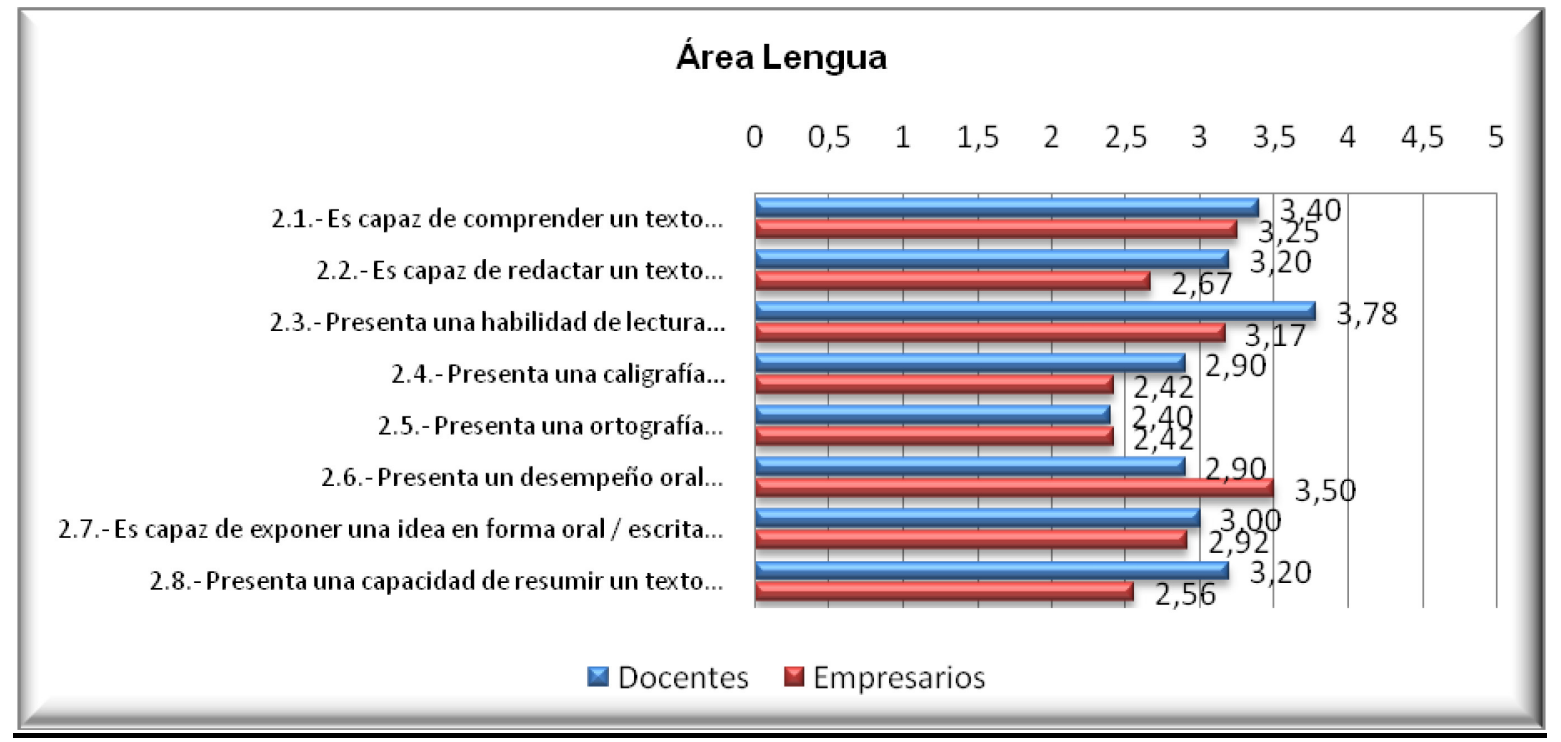

Fuente: Elaboración propia 
En lengua el panel de expertos docentes tiene una mejor calificación que los empresarios en es capaz de comprender un texto, presenta habilidad de lectura, es capaz de redactar un texto, presenta una buena caligrafía, es capaz de exponer una idea en forma oral y en presenta una buena capacidad para resumir un texto.

Mientras que los empresarios tienen una mejor calificación solamente en que presenta una buen desempeño oral.

En lengua se aprecia la gran diferencia de evaluación entre empresarios y docentes, mientras que los empresarios son bien críticos, en los docentes se nota el grado de compromiso que poseen en el aprendizaje de los alumnos y de aquí una mejor calificación.

Los empresarios solo dieron buena calificación en expresión oral y esto tiene que ver con el trabajo, el alumno aprende muy bien lo que debe expresar en el desenvolvimiento de su tarea y lo repite a diario y para el empresario eso está bien.

\section{Área Ciencias}

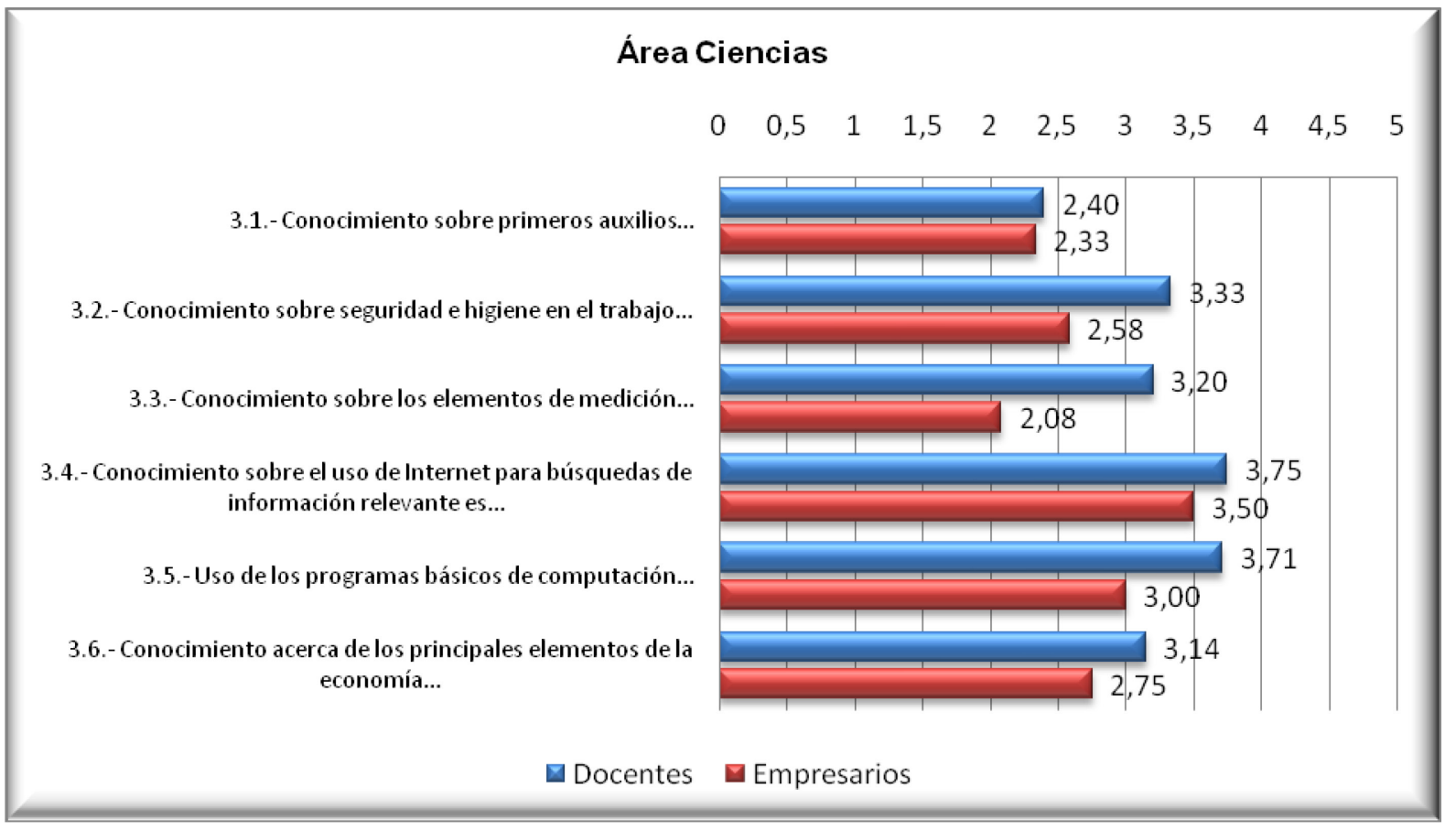

Fuente: Elaboración propia 
En ciencias el panel de expertos empresarios no tuvo mejor calificación que los docentes en ninguna de las preguntas. Las de mayor diferencia entre lospaneles deexpertos se encuentra en conocimiento sobre seguridad e higiene en el trabajo, conocimiento sobre elementos de medición y uso de los programas básicos de computación, en las preguntas que más se acercan son conocimientos sobre primeros auxilios y conocimiento sobre el uso de internet para búsquedas de información relevante.

\section{Área Aptitudes Personales}

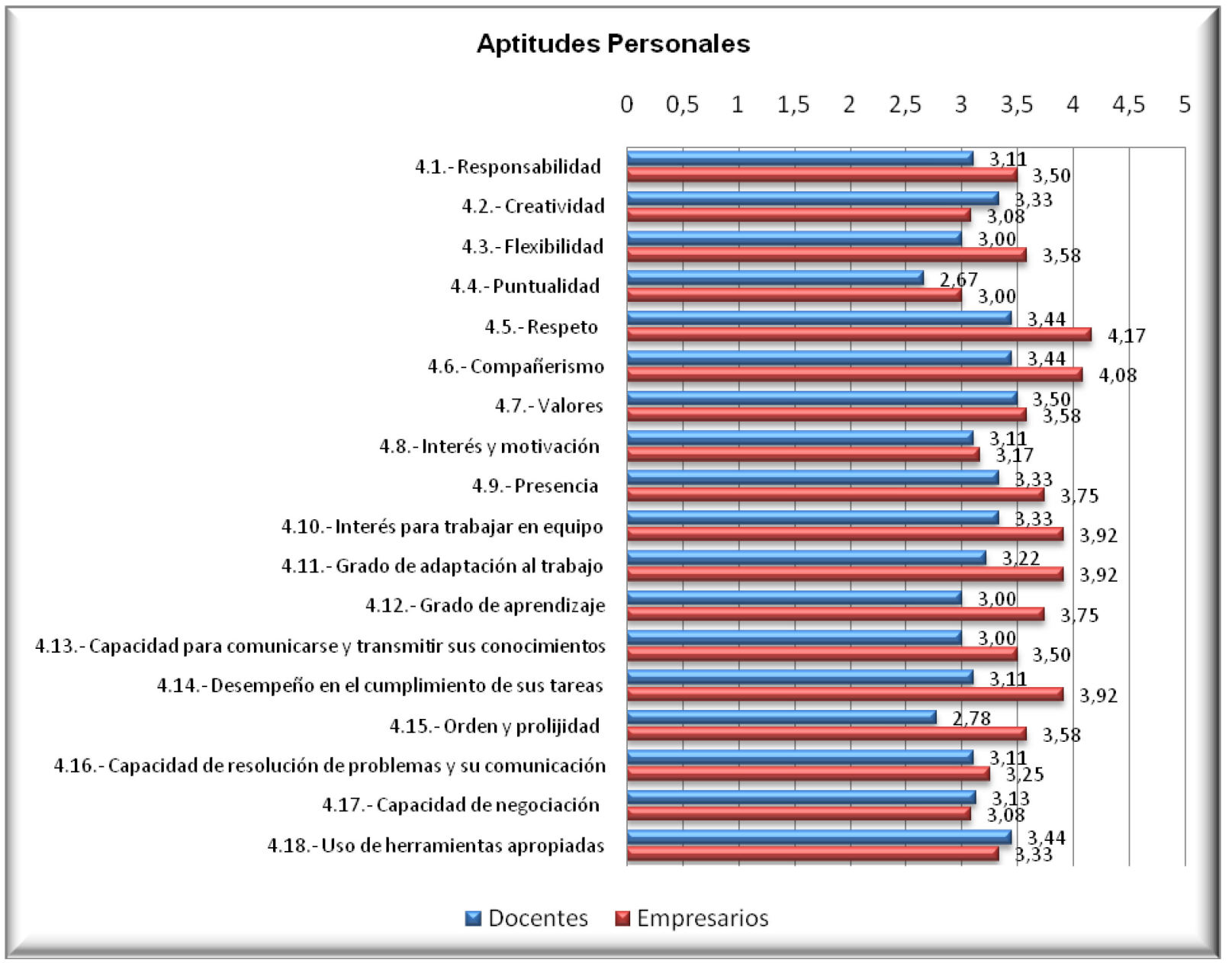

Fuente: Elaboración propia

En aptitudes personales el panel de expertos de empresarios tienen una mejor calificación que el panel de expertos docentes, los puntos donde dieron una mejor calificación fueron: 
responsabilidad, flexibilidad, respeto, compañerismo, presencia, interés por el trabajo en equipo, grado de adaptación al trabajo, grado de aprendizaje, capacidad para comunicarse y transmitir sus ideas, desempeño en el cumplimiento de sus tareas, orden y prolijidad. Mientras que el panel de expertos docentes tiene una mejor calificación en uso de herramientas apropiadas y creatividad.

\subsubsection{Comparación Total respuesta docentes y empresarios}

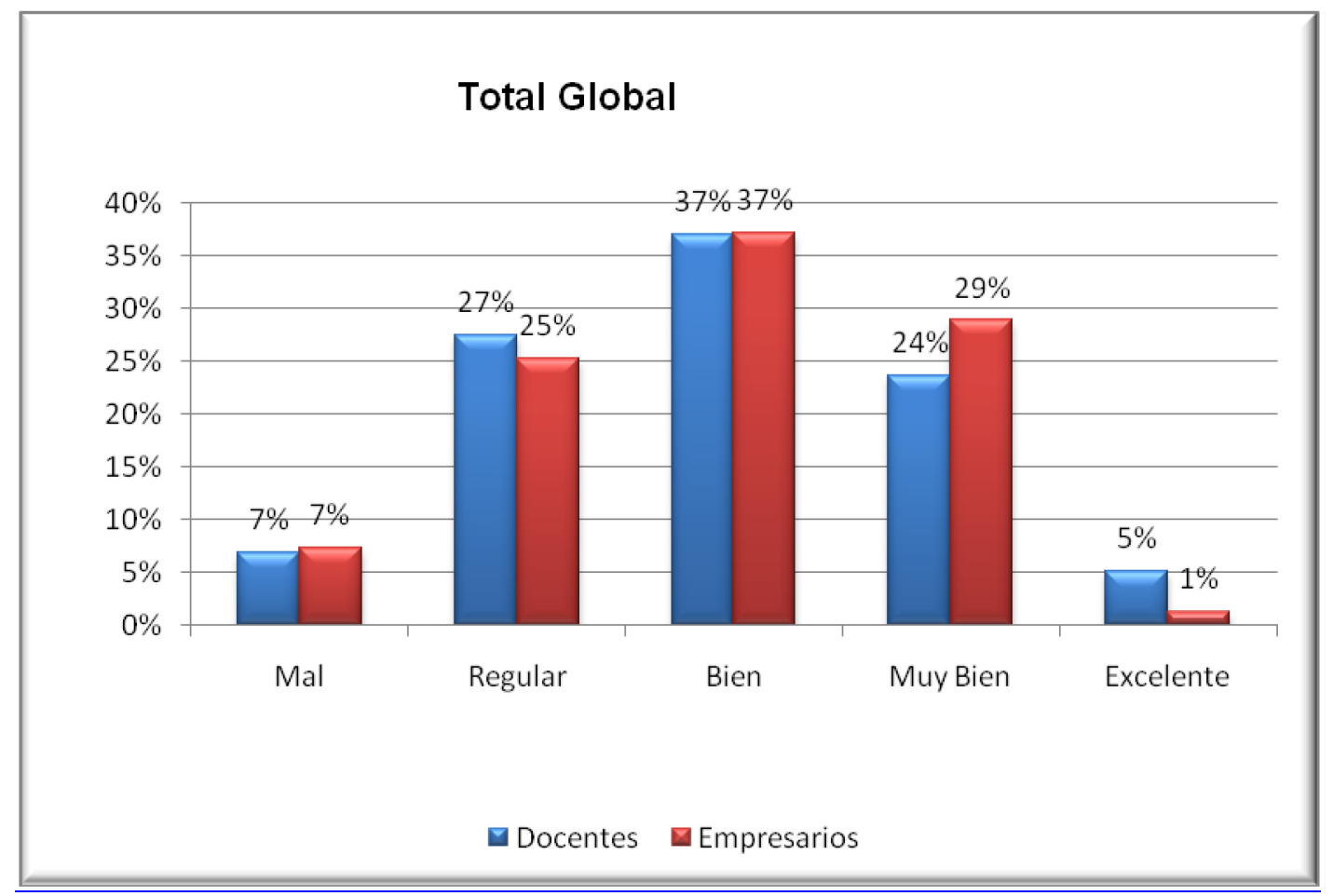

Fuente: Elaboración propia

El Total Global hace referencia a la sumatoria de los resultados de ambos paneles de expertos, docentes y empresarios. Se aprecia que en líneas generales que la respuesta bien es similar tanto en docentes como empresarios con el $37 \%$, en muy bien los empresarios tienen un $29 \%$ y los docentes están abajo con un $24 \%$, en regular el panel de expertos docentes con un $27 \%$ mientras que los empresarios con un $24 \%$, la respuesta mal es pareja con un $7 \%$ y en la respuesta excelentes losdocentes calificaron mejor en $5 \%$ contra $1 \%$ de los empresarios 
En el saldo de respuestas de respuesta Global en matemáticas la opinión fue muy similar 2,8 para empresarios contra 2,87 de los docentes, en las asignaturas Lengua y ciencia los docentes calificaron mejor a alumno, mientras que en aptitudes personales los docentes le dieron el 3,56 contra el 3,17 de los docentes

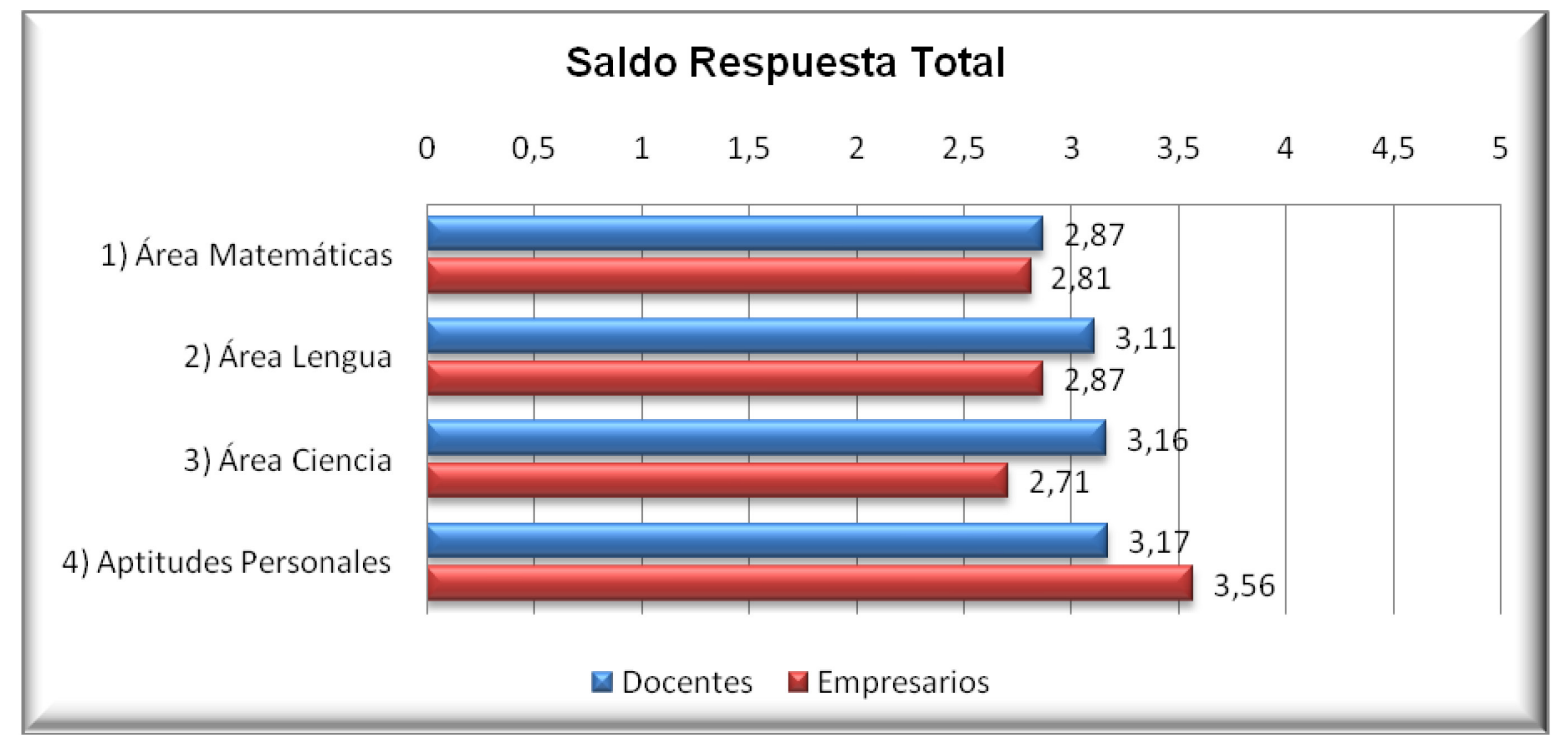

Fuente: Elaboración propia

\section{$\underline{\text { 7.2.6 Comparación regional respuestas de docentes }}$}

En esta comparación, se tiene en cuenta el nivel de la calidad educativa del secundario, según el panel de expertos de docentes, de la región compuesta por los partidos de La Plata, Berisso y Ensenada. A su vez, en los gráficos, se puede apreciar las diferencias que presentan estos resultados, en relación a La Plata.

$\underline{\text { Respuestas de docentes: áreaMatemáticas }}$ 


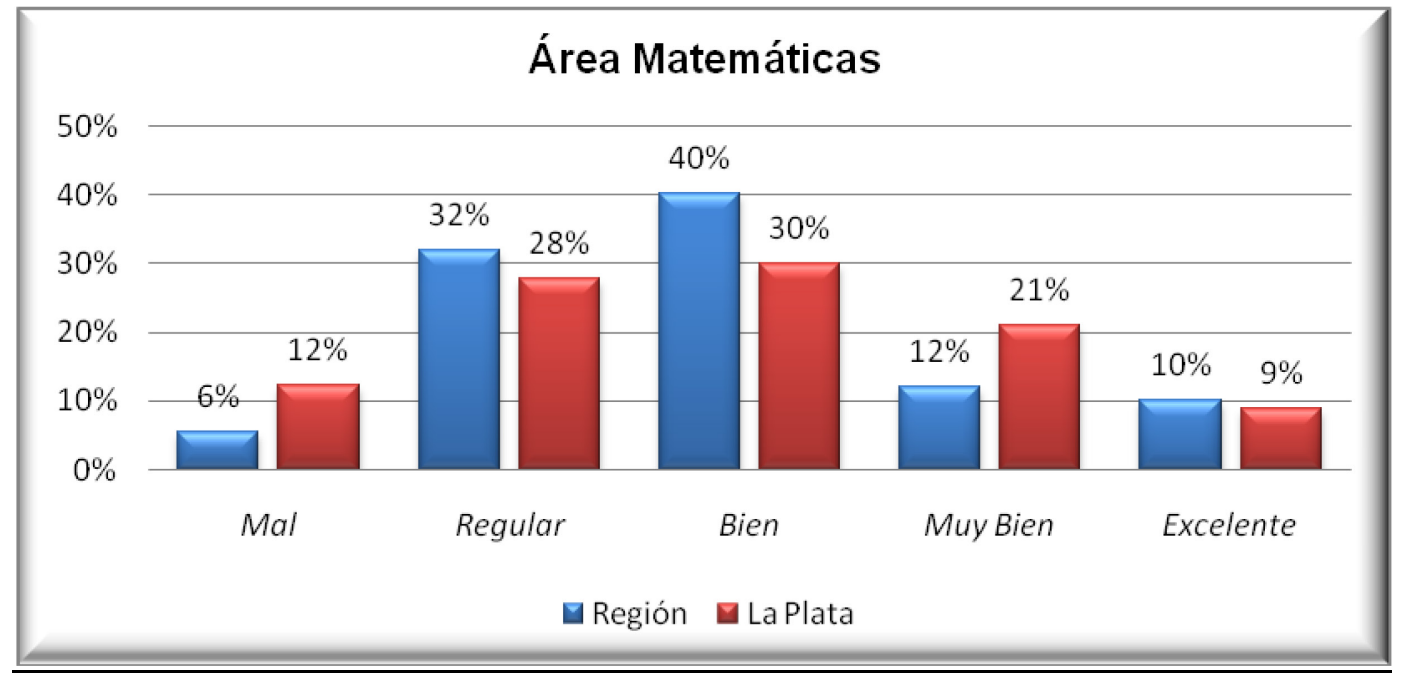

Fuente: Elaboración propia

En matemáticas en el punto bien y regular la región tiene una mejor calificación que la Plata, pero en muy bien y mal La Plata tiene mejor calificación que la región.

Los puntos donde mejor califica la Plata son cuentas básicas sin uso de la computadora, conoce los sistemas monetarios en la Argentina, comprende datos estadísticos, mientras que la región tiene mejor índice de respuestas en que el alumno distingue las distintas figuras geométricas, conoce los distintos tipos de triángulos y conoce y comprende los distintos tipos de gráficos 


\section{Área Matemáticas}

1.1.- Cuentas básicas sin uso de tecnología...

1.2.- Cálculo de porcentajes simples, responde...

1.3.- Conversiones con unidades de medidas...

1.4. - Conoce los tipos de triángulos existentes...

1.5.- Distingue los distintos tipos de figuras geométricas...

1.6.-Realiza las operaciones básicas con fracciones...

1.7.- Calcula la superficie de un objeto ...

1.8.- Calcular el volumen de un cuerpo...

1.9.- Conoce los sistemas monetarios utilizados en Argentina...

1.10.-Tiene noción sobre patrones de medida...

1.11.- Conoce y comprende los distintos tipos de gráficos..

1.12.- Comprende datos estadísticos...

1.13.- Realiza un cálculo financiero elemental...
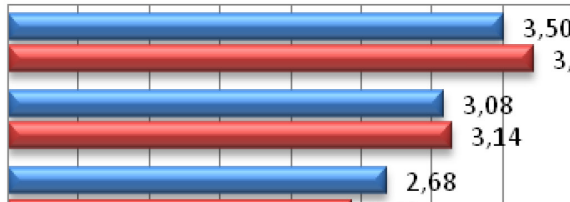

2,43
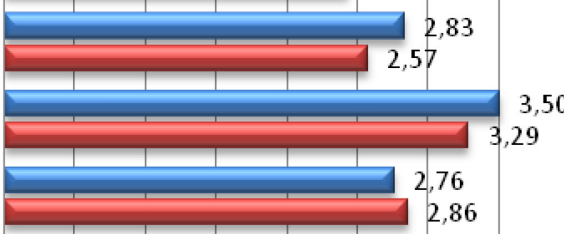

2,86
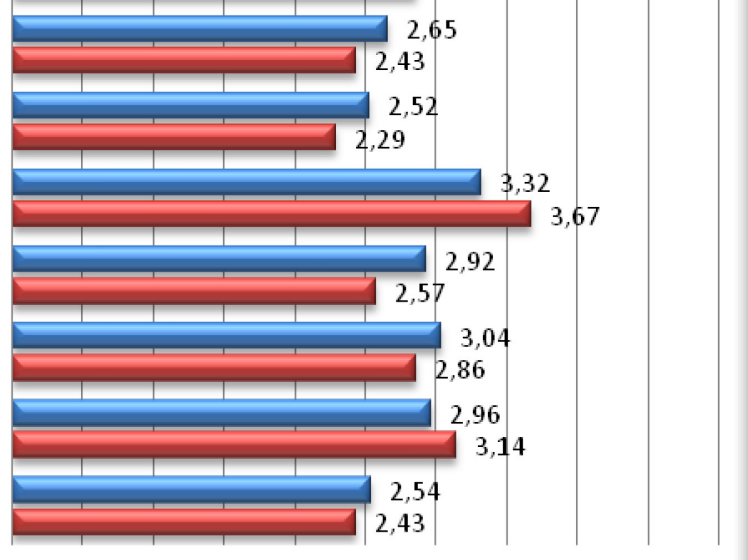

Región

La Plata

Fuente: Elaboración propia

$\underline{\text { Respuestas de docentes: áreaLengua }}$ 


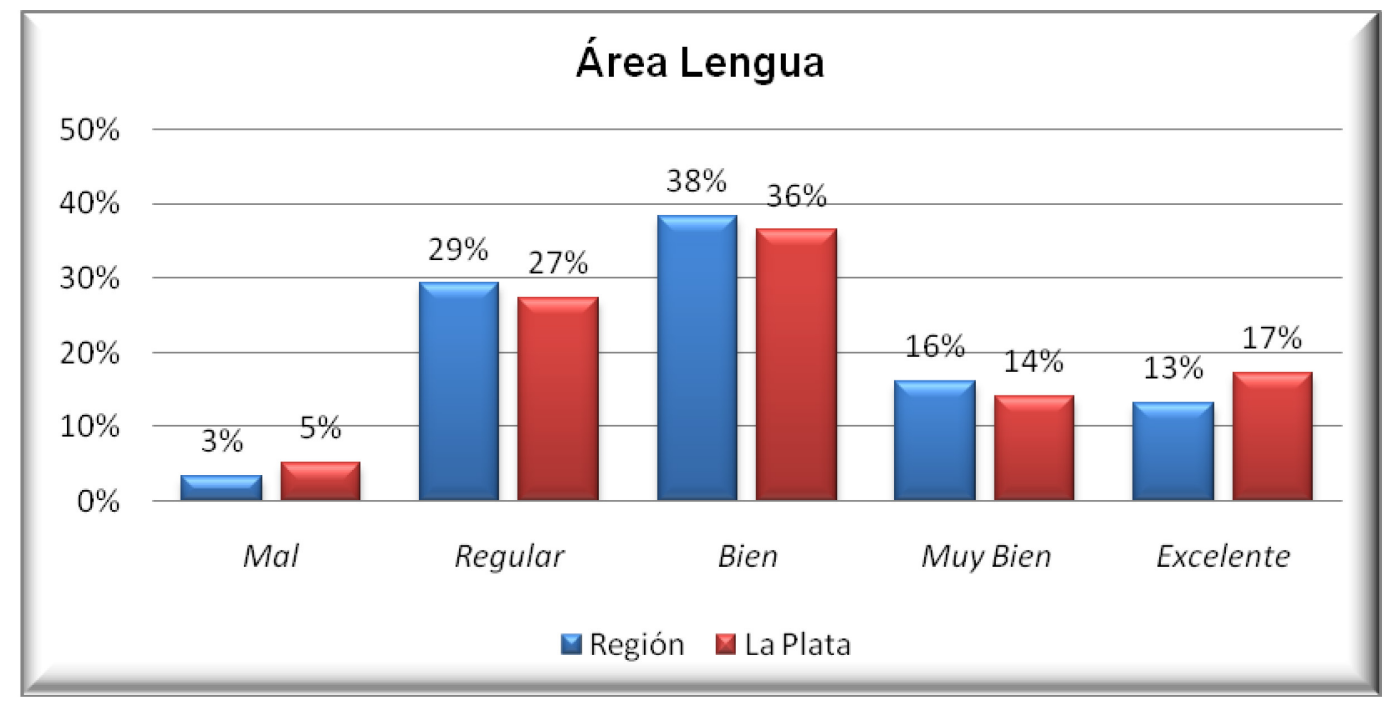

Fuente: Elaboración propia

En Lengua tanto los paneles de expertos de la Plata y la región coinciden en los puntos Bien y Regular, mientras que en la categoría Excelente la Plata tiene un porcentaje de $17 \%$, es superior al de la región (13\%).Los temas en que califica mejor el panel de expertos de La Plata es en caligrafía y en reconocer las ideas principales de un texto.

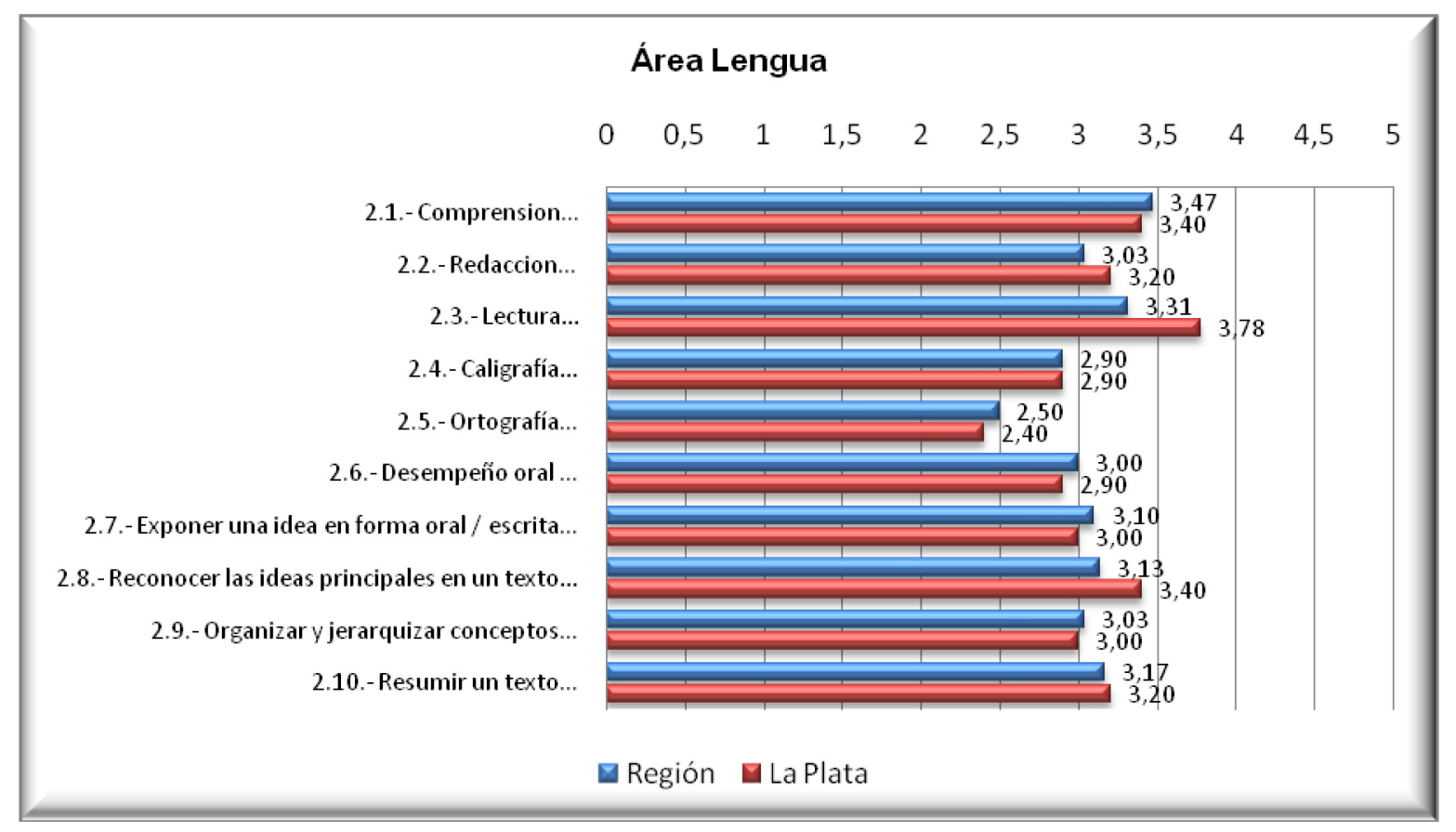

Fuente: Elaboración propia

$\underline{\text { Respuestas de docentes: áreaCiencias }}$ 


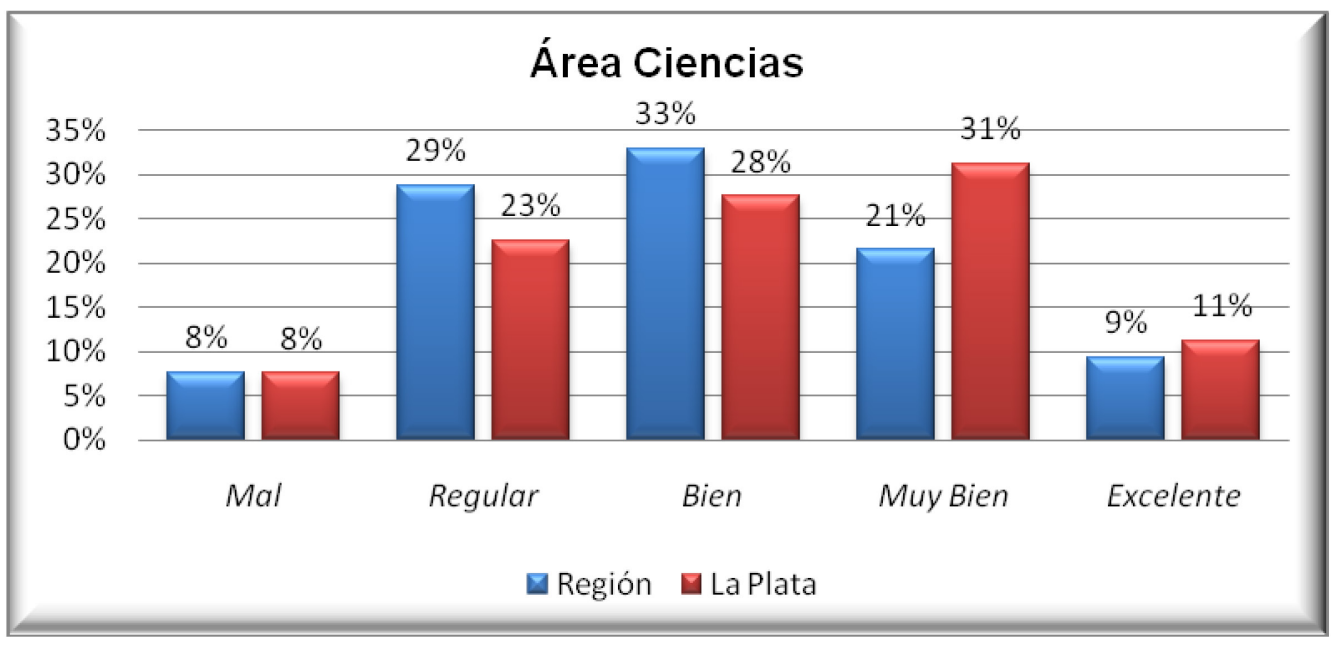

Fuente: Elaboración propia

En el área ciencias las calificaciones en Excelente y en Mal coinciden el panel de expertos de la región con el panel de expertos de La Plata, mientras que en Regular y Bien la región tiene una mejor calificación y para Muy Bien La Plata le dio 31\% y la región $21 \%$.Los temas donde mejor calificó el panel de expertos de La Plata si el alumno conoce los estados de la materia, sabe sobre seguridad e higuiene, conoce los elementos de medición, uso de los programas básicos de computación, conoce sobre las vías de contagio del sida, conoce a cerca de la tasa de mortalidad en la Argentina

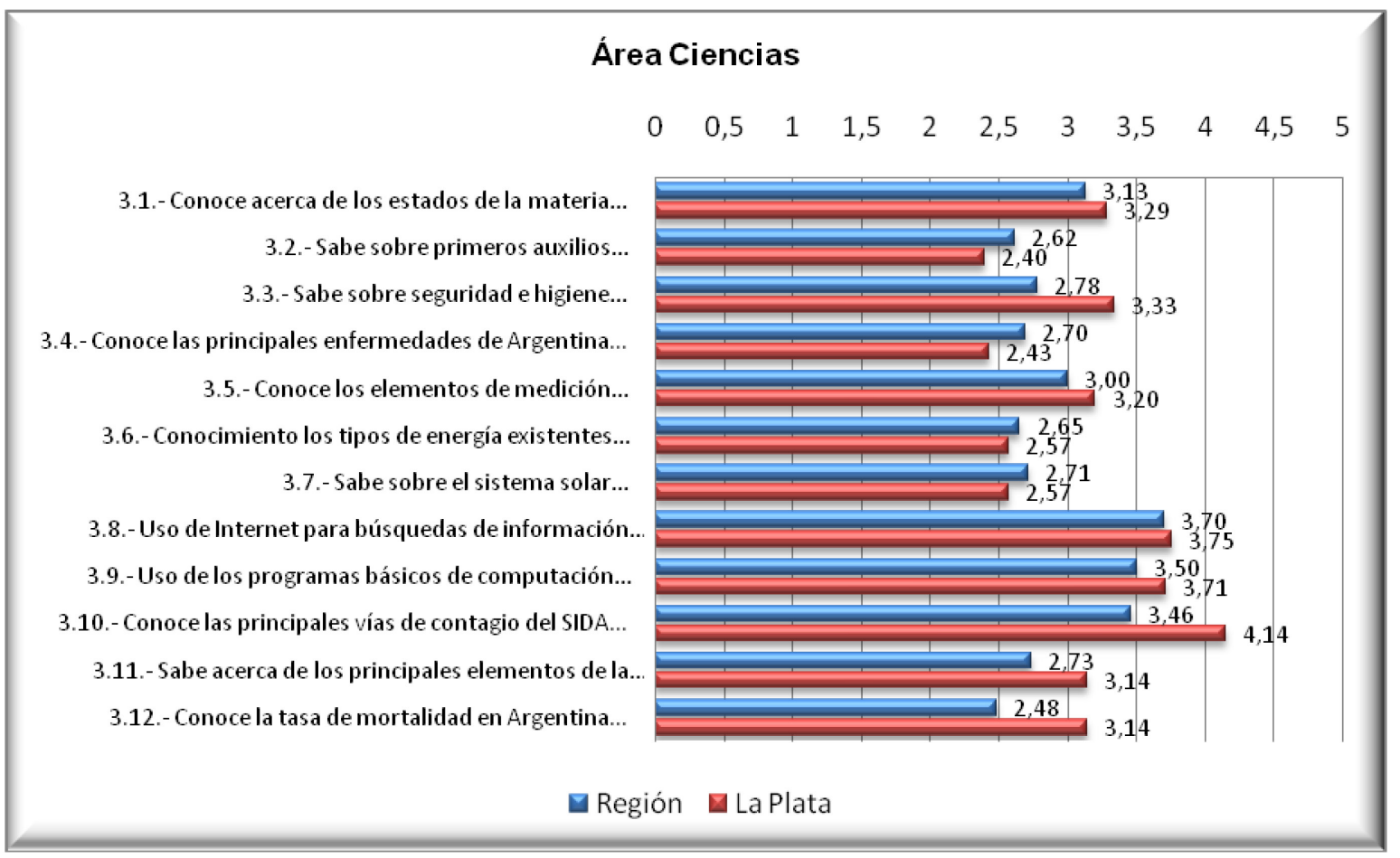

Fuente: Elaboración propia 


\section{$\underline{\text { Respuestas de docentes: áreaAptitudes Personales }}$}

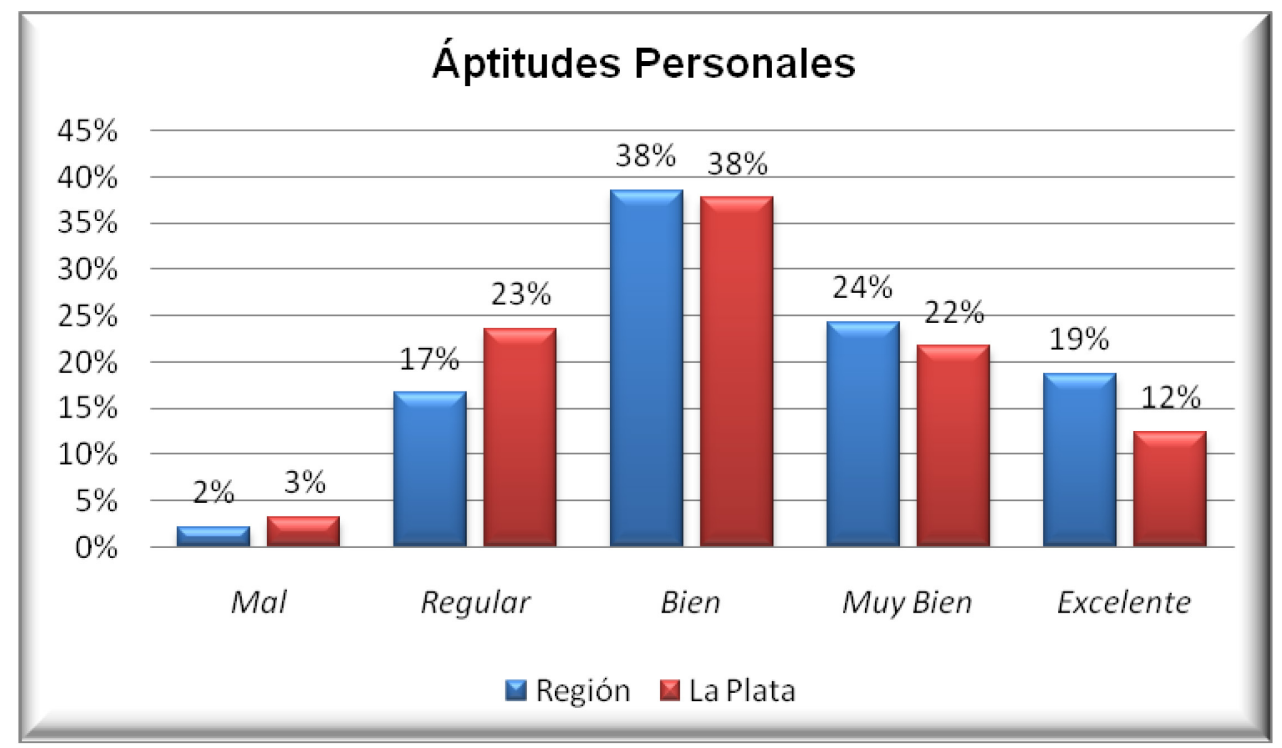

Fuente: Elaboración propia

En Aptitudes personal es muy parejo en todos los niveles,Mal, Regular, Bien, Muy Bien, solo en excelente hay una diferencia a favor del panel de expertos de los docentes de la región $19 \%$ respecto a los docentes de La Plata $12 \%$.

En los saldos de respuestael panel de expertos docentesde la región tiene mejor puntaje que el panel de expertos docentes de La plata. En las 18 consultas el panel de docente experto de la región tiene mejor saldo de respuesta que el panel de docentes expertos de La Plata.

La mayor diferencia a favor de la región se da en el respeto de 3,69 la región a 3,44 La Plata, flexibilidad con 3,38 la región y 3 La Plata,interés por trabajar en equipo con 3,75 la región y 3,33 La Plata. 


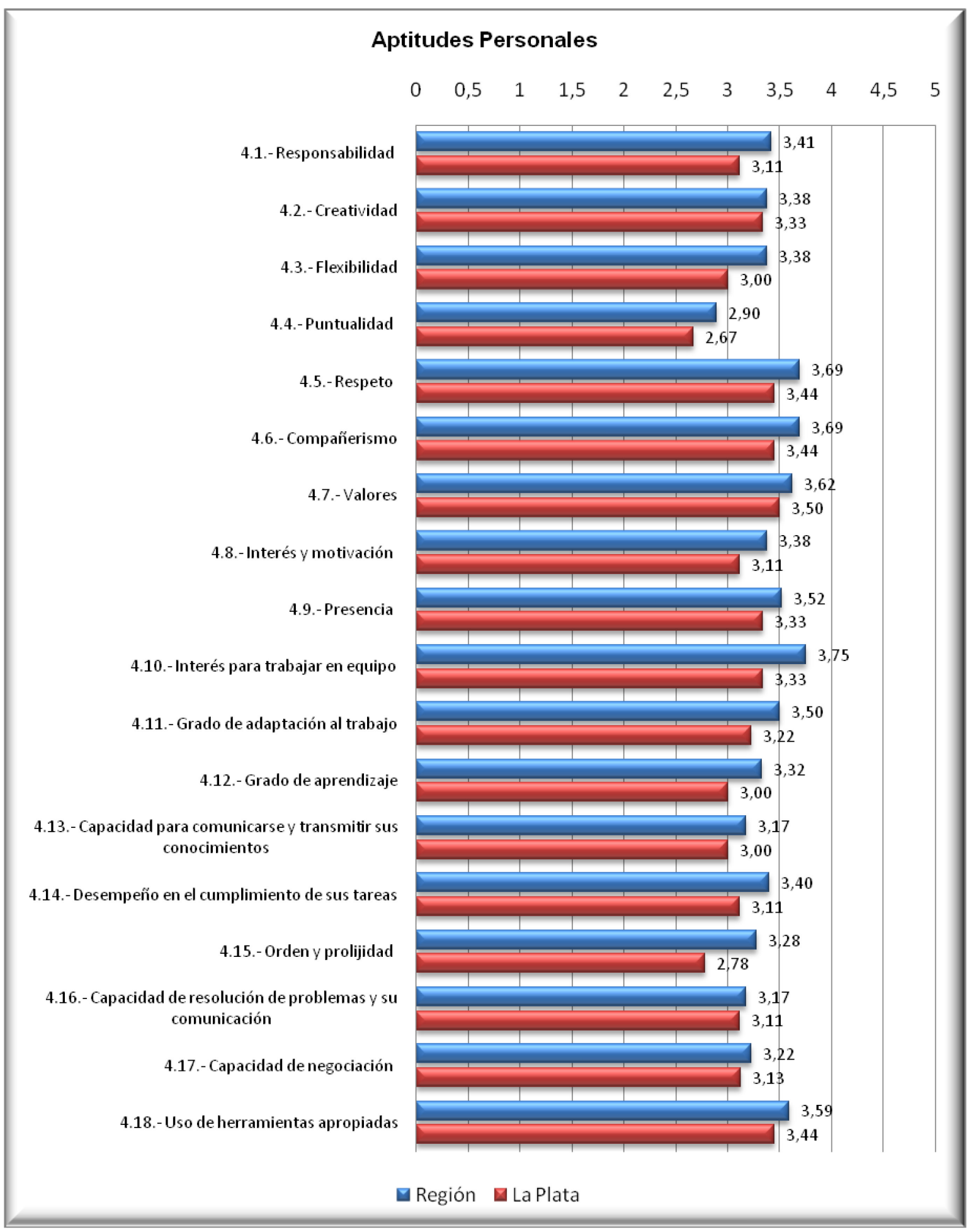

Fuente: Elaboración propia

\section{Global Regional Docente}




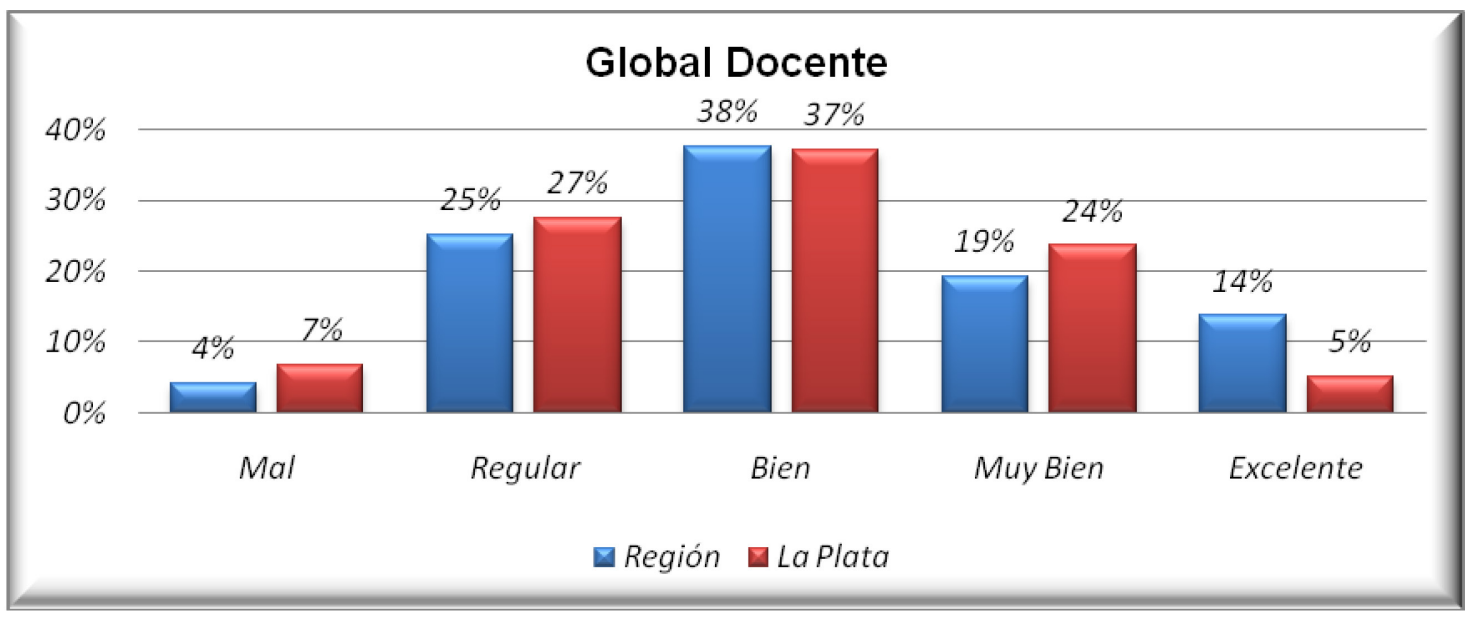

Fuente: Elaboración propia

En este punto se puede observar los resultados globales docentes, y la diferencia que presenta la sumatoria de los resultados de La Plata con el de la región. Aquí la diferencia más importante a favor del panel de expertos docentes de La Plata se da en el punto muy bien, con $19 \%$ para la región y 24 para La Plata y en excelente 14 para la región y $5 \%$ para La Plata.

\section{Saldo de Respuesta total regional Docente}

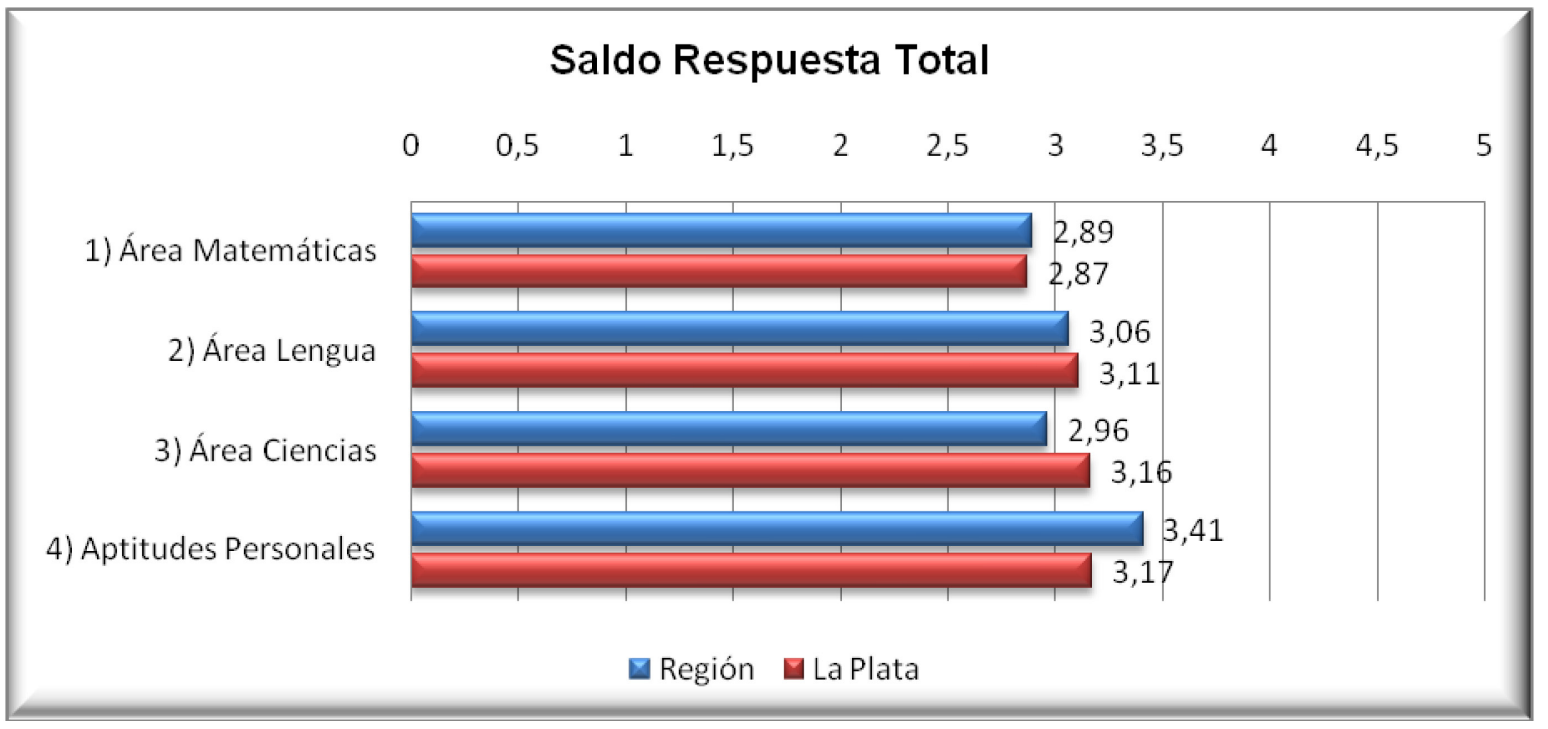

Fuente: Elaboración propia 
El saldo de respuesta es muy parejo, se destacan aptitudes personales con 3,17 para La Plata y 3,41 para la región, mientras que área ciencias le da 3,16 La Plata y 2,96 La región.

\section{$\underline{\text { 7.2.7 Comparación regional respuestas de empresarios }}$}

En este punto, se presenta la comparación entre los resultados de La Plata y los de la región, compuesta por los partidos de La Plata, Berisso y Ensenada. Estos son los resultados del nivel de calidad del secundario, según el panel de expertos compuesto por empresarios.

\section{Respuestas de Empresarios: área Matemáticas}

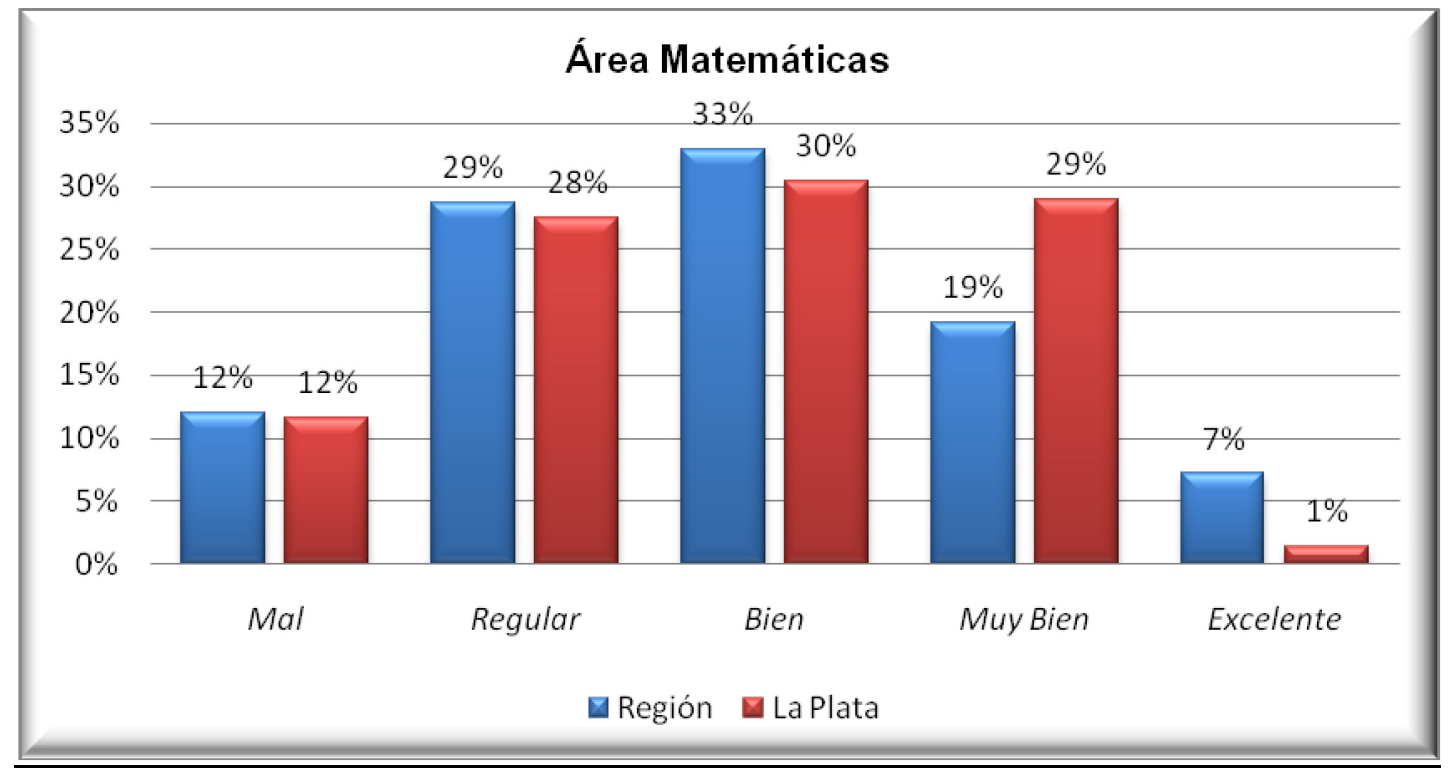

Fuente: Elaboración propia

En matemàticas la comparaciòn de paneles de expertos empresarios de la regiòn y de La Plata es igual en la calificaciòn Mal y muy similar en la calificaciòn Regular y Bien, para muy bien el panel de expertos empresarios de La Plata le da el $29 \%$, mientras que el $19 \%$ de la regiòn, en Excelente posee un $7 \%$ de la regiòn contra un $1 \%$ de la Plata.

En el saldo de respuesta es muy similar la opiniòn de expertos empresarios de la regiòn y La Plata, la diferencia màs grande se da en cuentas bàsicas sin uso de la tecnologia con 3,08 para La Plata y 2,79 para la regiòn. 


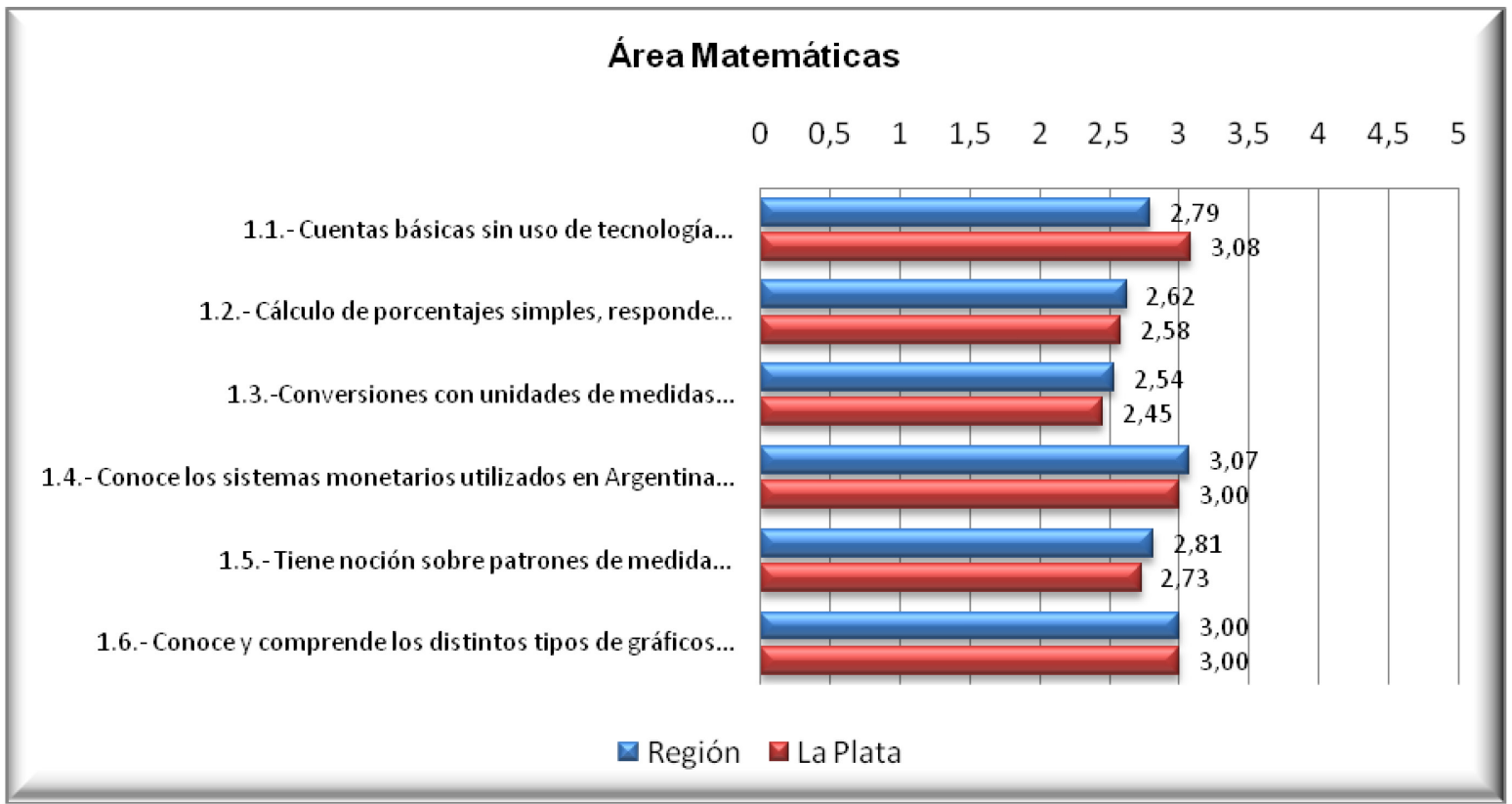

Fuente: Elaboración propia

\section{Respuestas de Empresarios: áreaLengua}

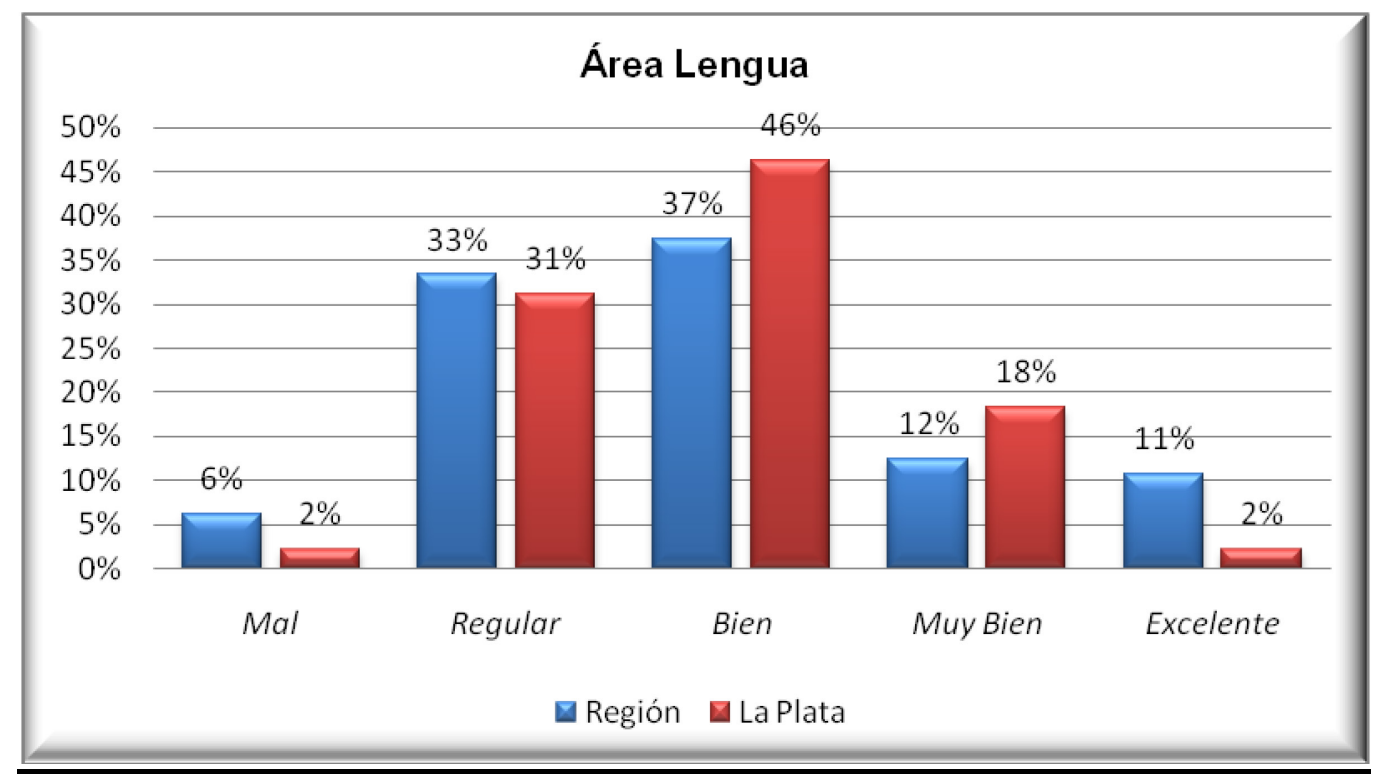

Fuente: Elaboración propia

En Lengua el panel de expertos empresarios de la Plata tiene mejor porcentaje en las preguntas Bien con el $46 \%$ contra $37 \%$ de la región y en Muy Bien con el $18 \%$ de La Plata contra el $12 \%$ de la región, mientras que la calificación Mal, Regular y Excelente le da mejor porcentaje a la región. 
En el saldo de respuesta la mayor diferencia a favor de La Plata ocurre en el desempeño oral del alumno con 3,5 contra 3,34, mientras que en la región la mayor diferencia a resumir textos con 2,84 para la región y 2,56 para La Plata.

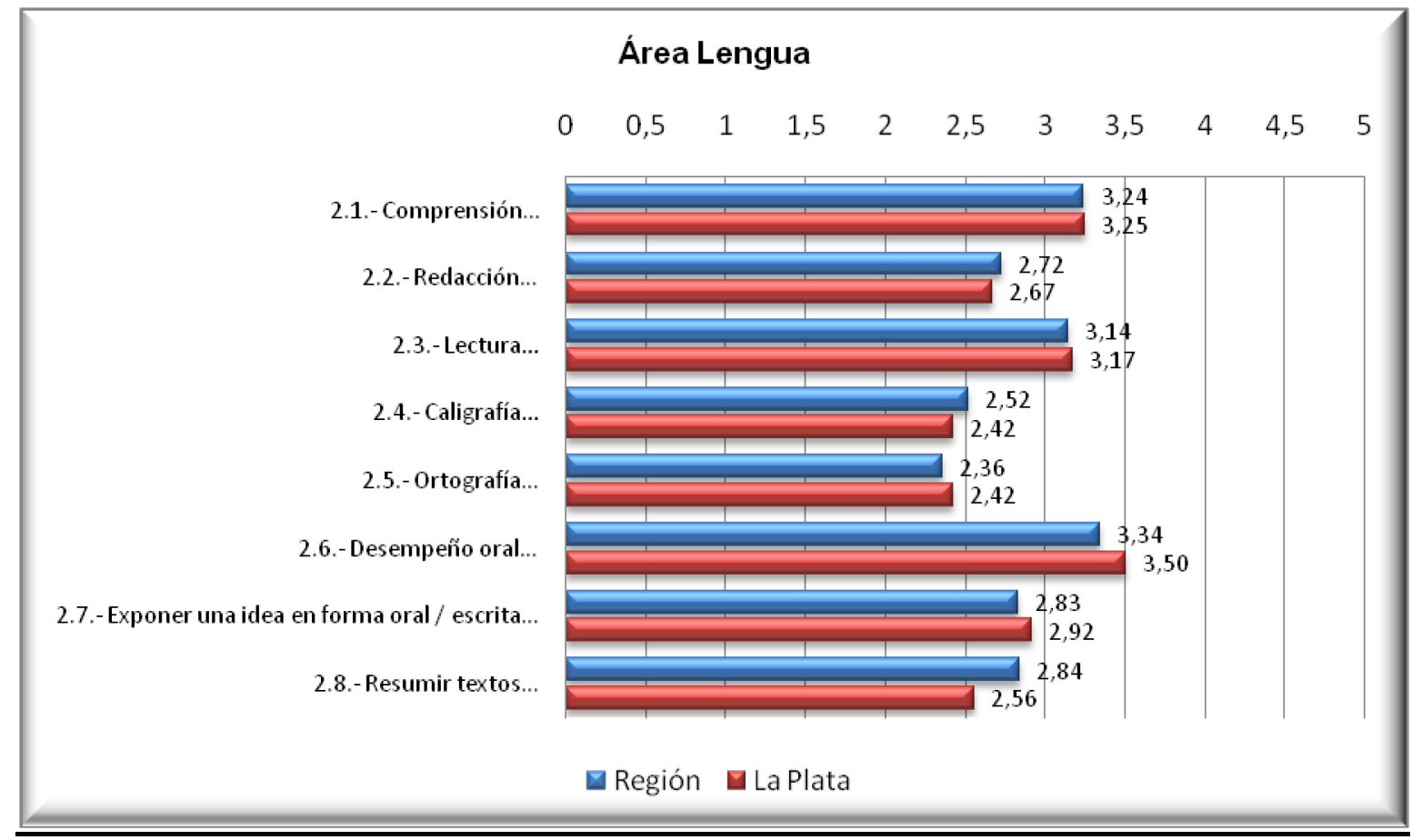

Fuente: Elaboración propia

\section{$\underline{\text { Respuestas de Empresarios: áreaCiencias }}$}

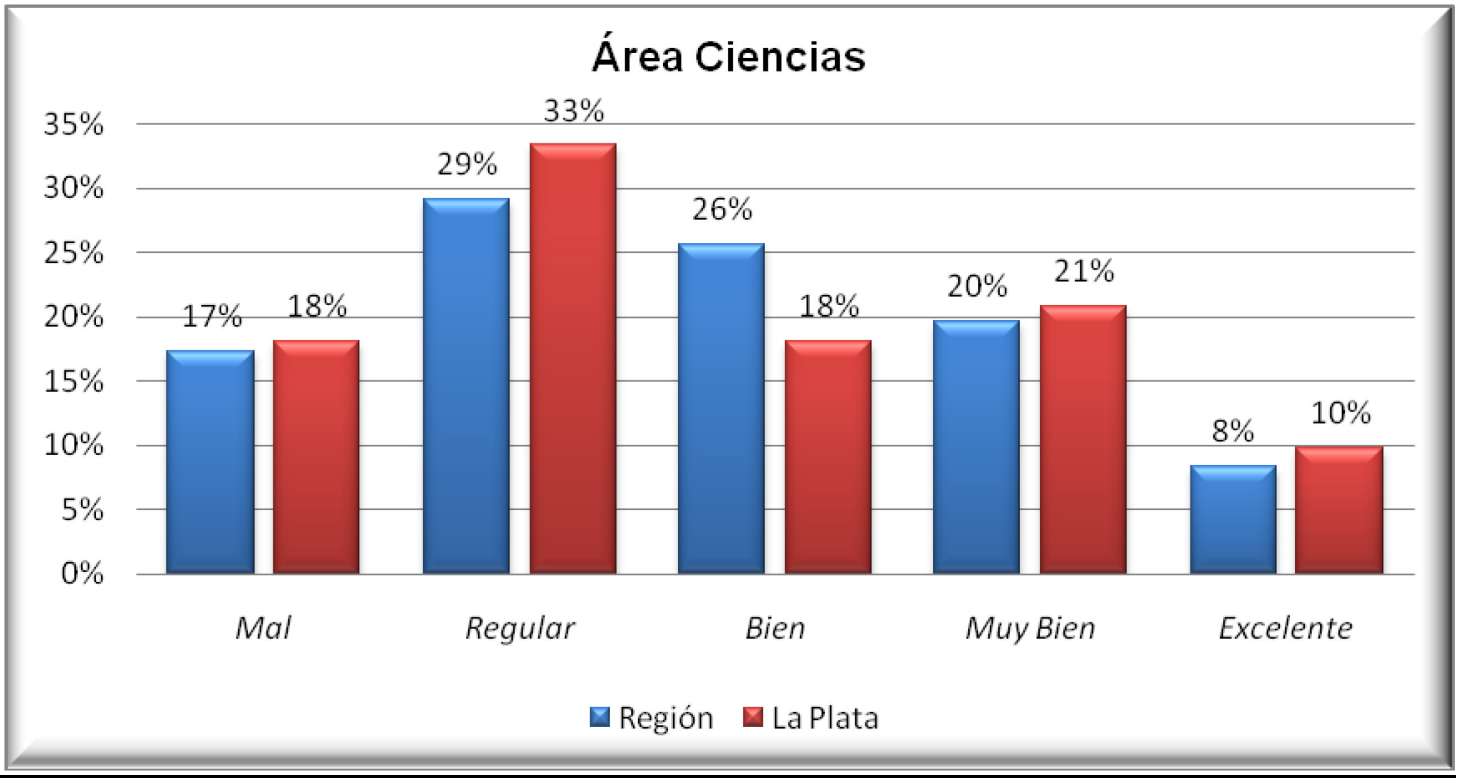


Fuente: Elaboración propia

Los porcentajes son muy similares, en Bien la región tiene un $26 \%$ mientras que en La Plata es del 18\%, en Regular la región le da el $29 \%$ en tanto que La Plata le da el $33 \%$.La máxima diferencia en saldo de respuesta se da en conoce los elementos de medición con 2,44 para la región y 2,08 para La Plata y en conoce los principales elementos de la economía con 2,75 para La Plata y 2,46 para la región.

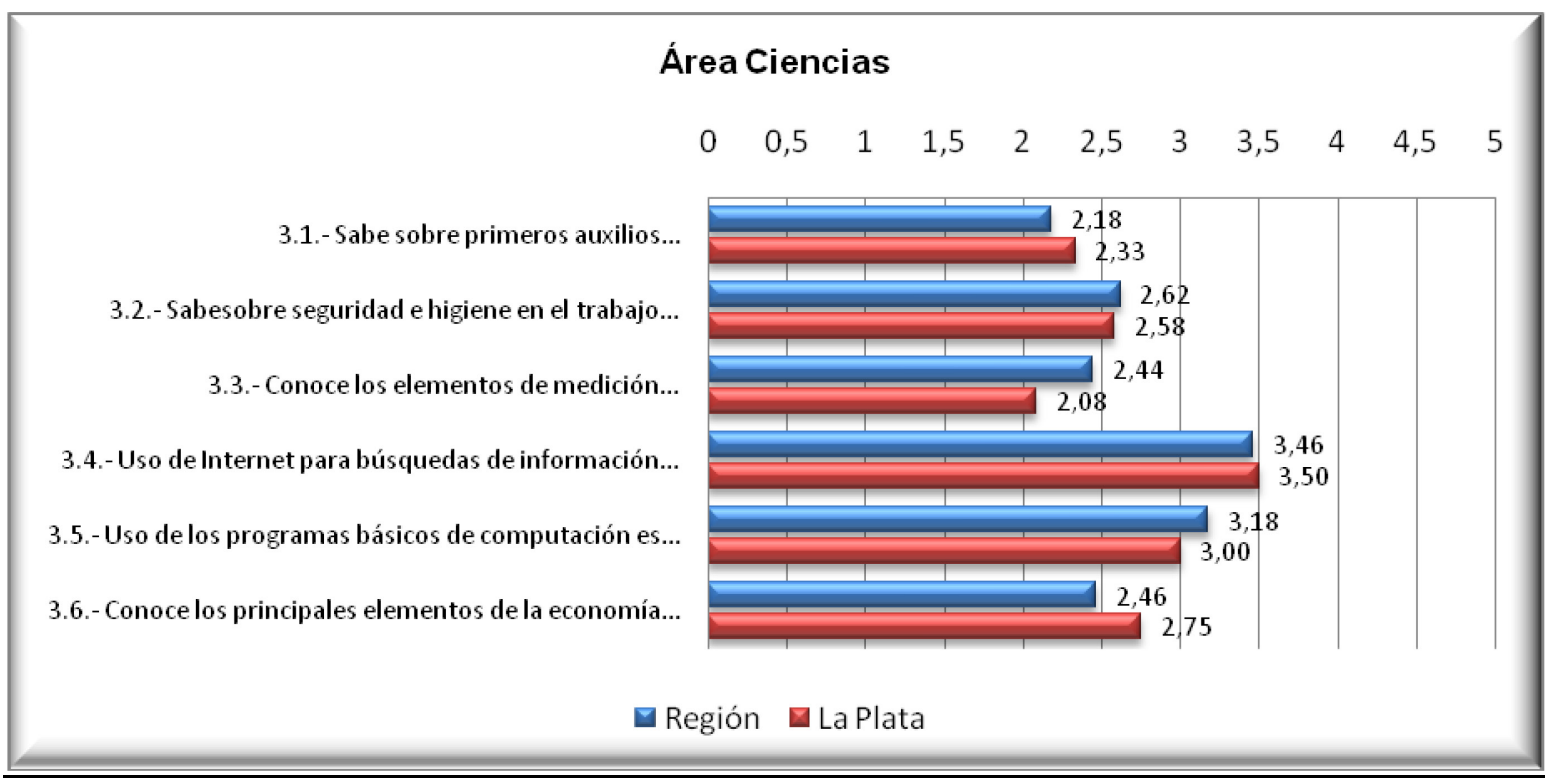

Fuente: Elaboración propia

Respuestas de Empresarios: áreaAptitudes personales

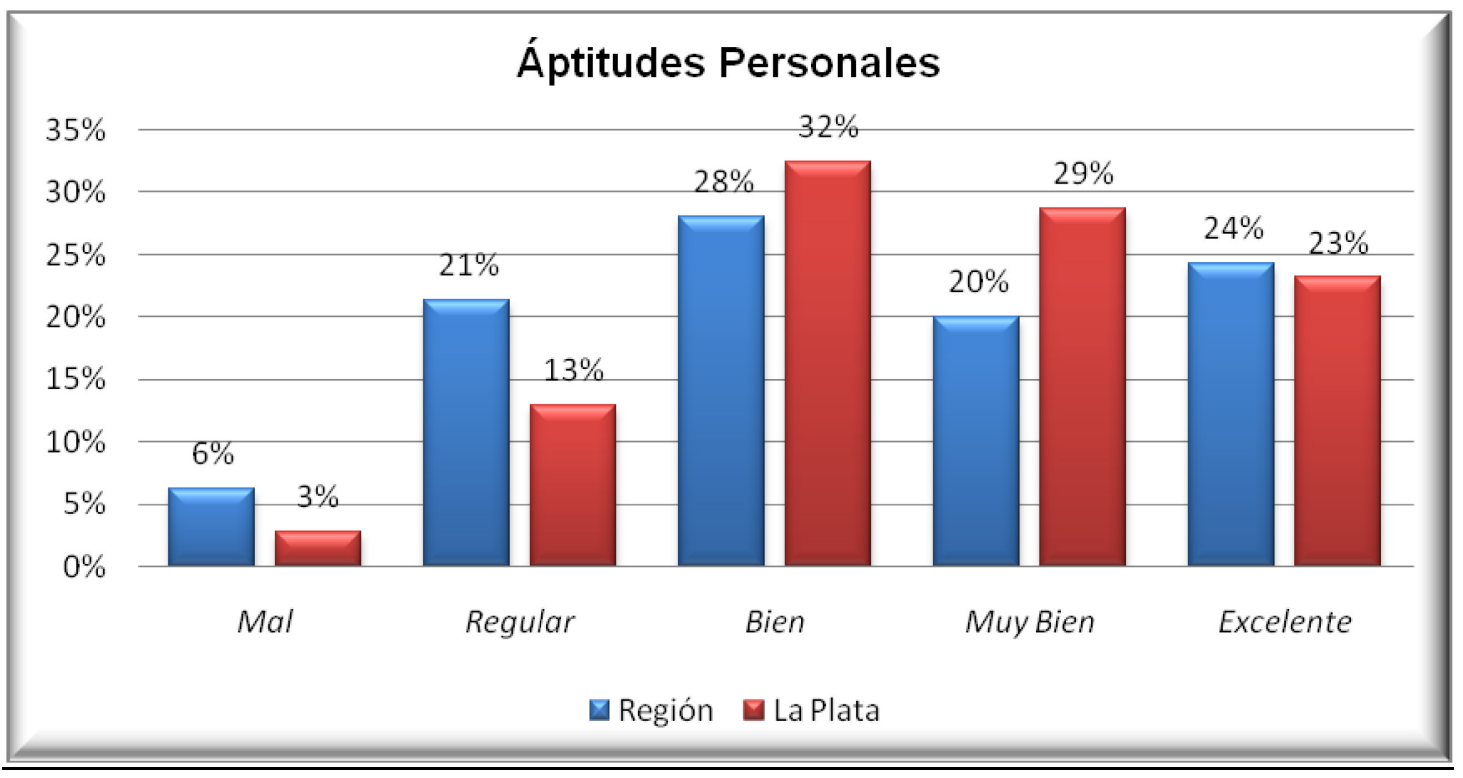


Fuente: Elaboración propia

En aptitudes personales solo es similar la calificación Excelente, en la calificación Mal y Regular tiene mejor opinión la región y en Muy Bien tiene mayor calificación La Plata.

En saldo de respuesta en prácticamente todas las preguntas tiene mejor calificación el panel de expertos empresarios de La Plata donde las mayores diferencias respecto al panel de expertos empresarios de la región se da en respeto, compañerismo, interés para trabajar en equipo, desempeño en el cumplimiento de su tareas y grado de adaptación al trabajo. 


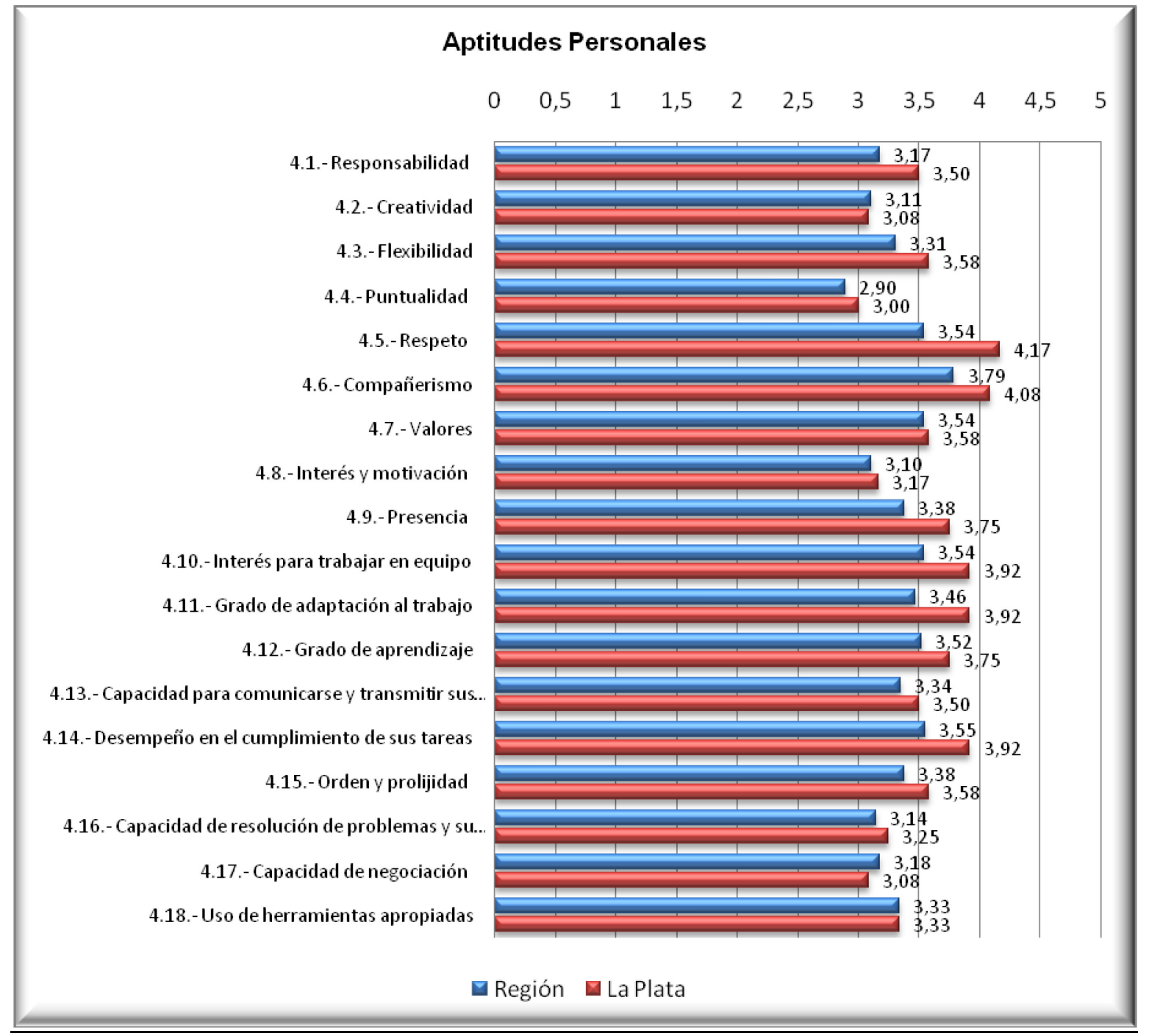

Fuente: Elaboración propia

\section{Global Regional empresarios}




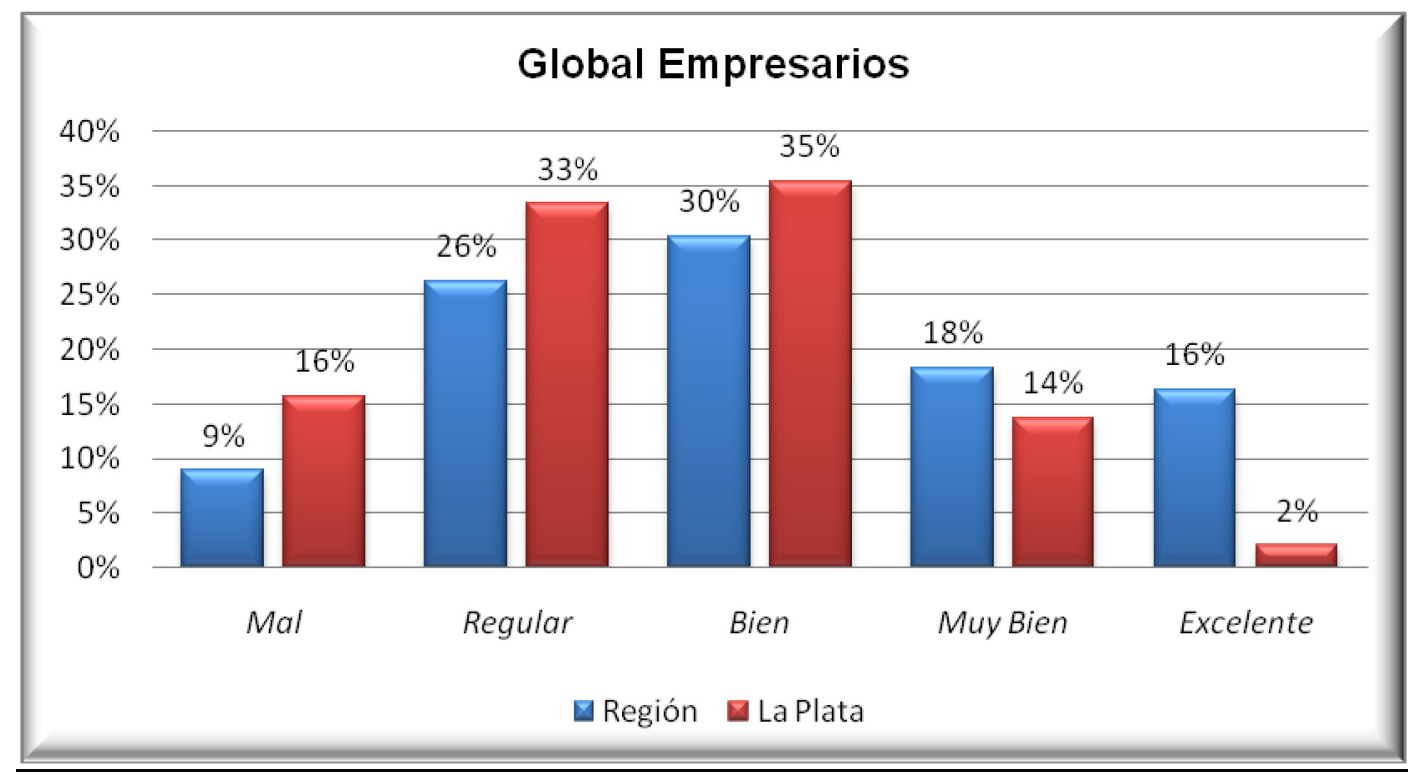

Fuente: Elaboración propia

En este punto, se puede apreciar los resultados globales de los empresarios, y su respectiva comparación con la región. Se puede observar que el panel de expertos empresarios de La Plata tiene una mayor evaluación en Mal, Rgular y Bien, mientras que la región tiene mejor calificación en Muy Bien y Excelente.

\section{Saldo de Respuesta total regional empresarios}

En el gráfico de saldo de respuesta se puede observar que el panel de expertos empresarios de la región tiene una mejor calificación en todas las materias respecto a La Plata.

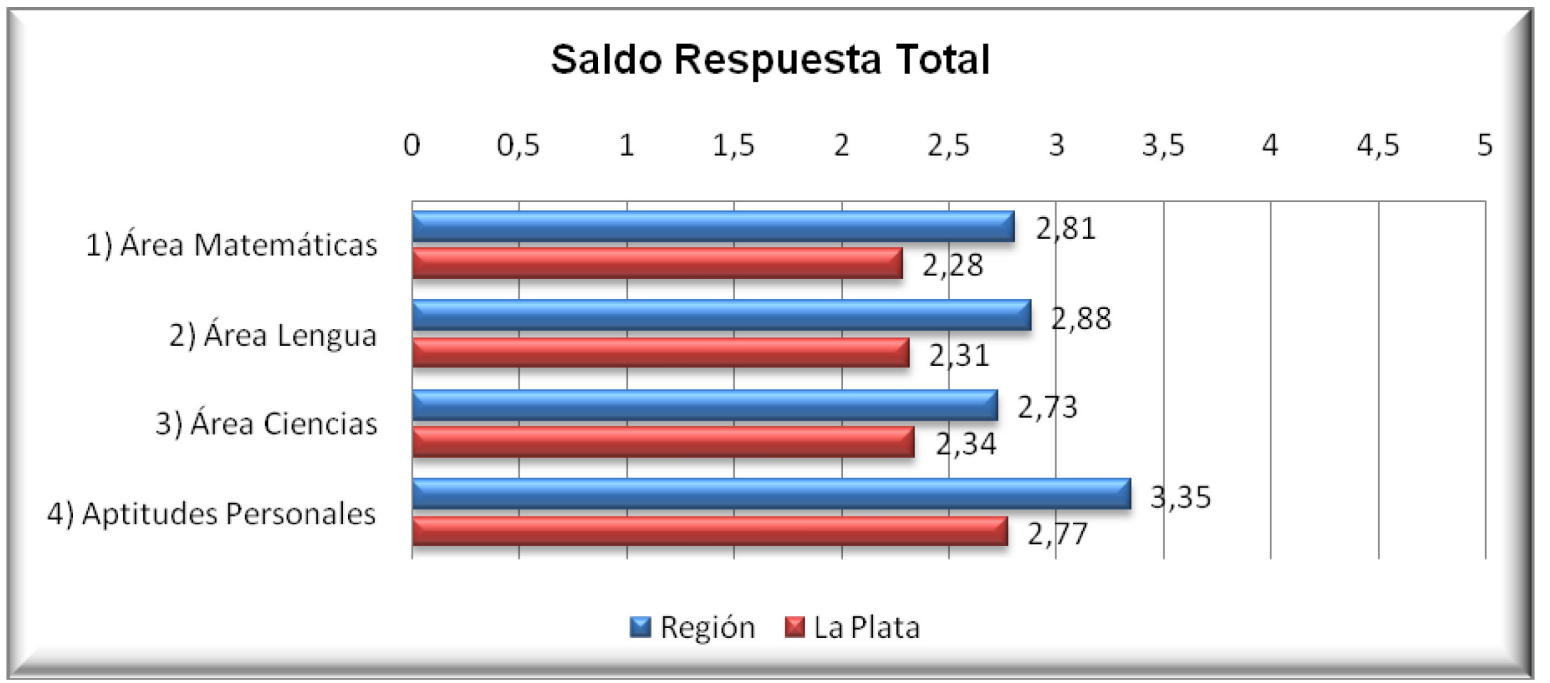

Fuente: Elaboración propia 


\subsubsection{Total regional}

El total regional hace referencia a la sumatoria de todos los resultados obtenidos en la encuesta, es decir los del panel de expertos de docentes, y el de los empresarios. A su vez, se puede observar en los siguientes gráficos la diferencia que hay entre estos resultados y los de la región, la cual está compuesta por los partidos de La Plata, Berisso y Ensenada.

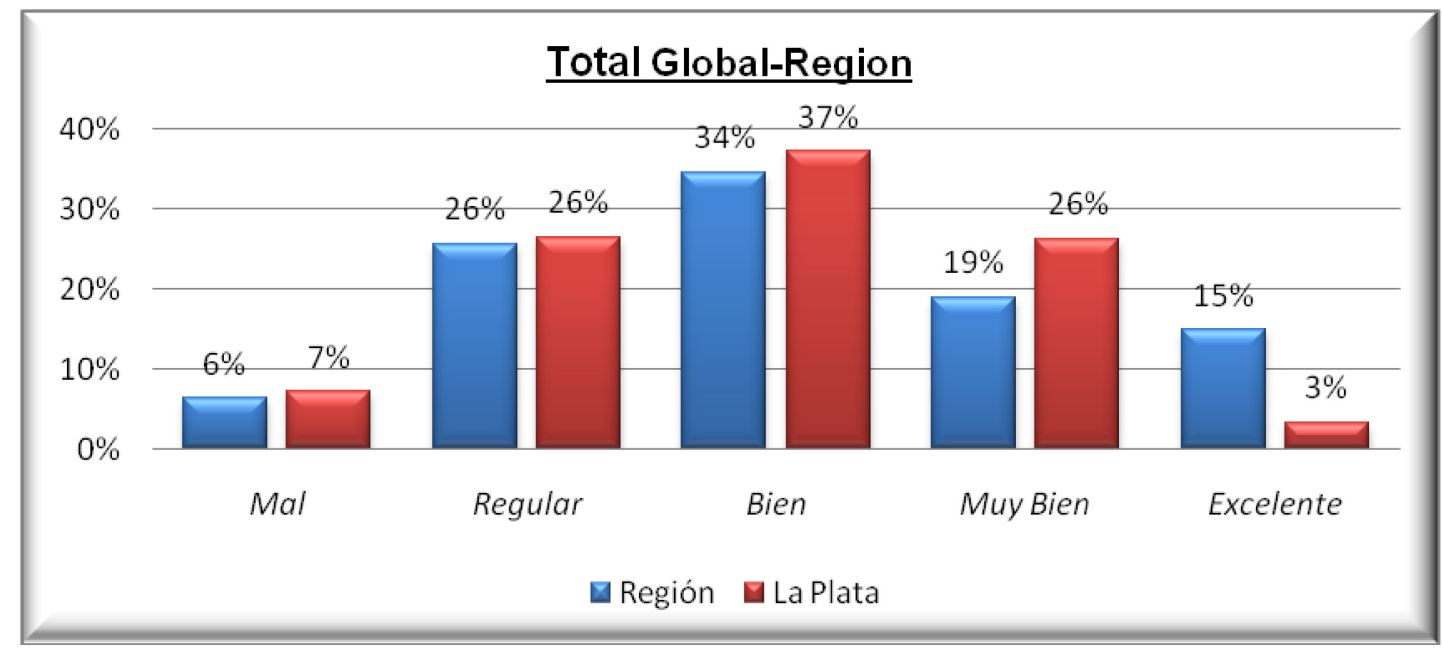

Fuente: Elaboración propia

En el caso del gráfico global, el cual representa los saldos respuestas totales de los docentes y los empresarios, comparados con la región, se puede ver que en ambos casos, los resultados obtenidos en La Plata están por debajo de la región.

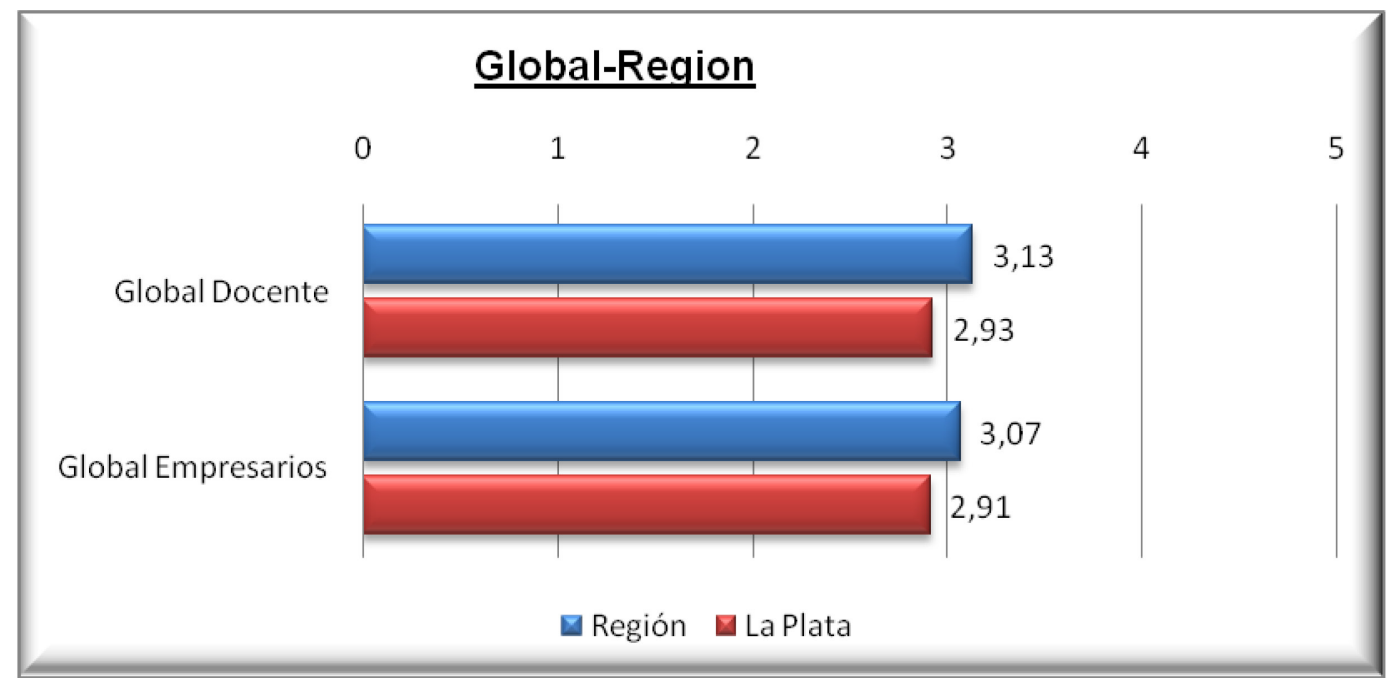

Fuente: Elaboración propia 
Por último, el saldo de respuesta total, que hace referencia a todas las respuestas de las áreas evaluadas, tanto de empresarios como docentes. En este caso se observa que, como resumen de los gráficos anteriores, La Plata tiene un menor nivel educativo, en comparación con la región, con una diferencia, la región 3,10 y La Plata 2,92.

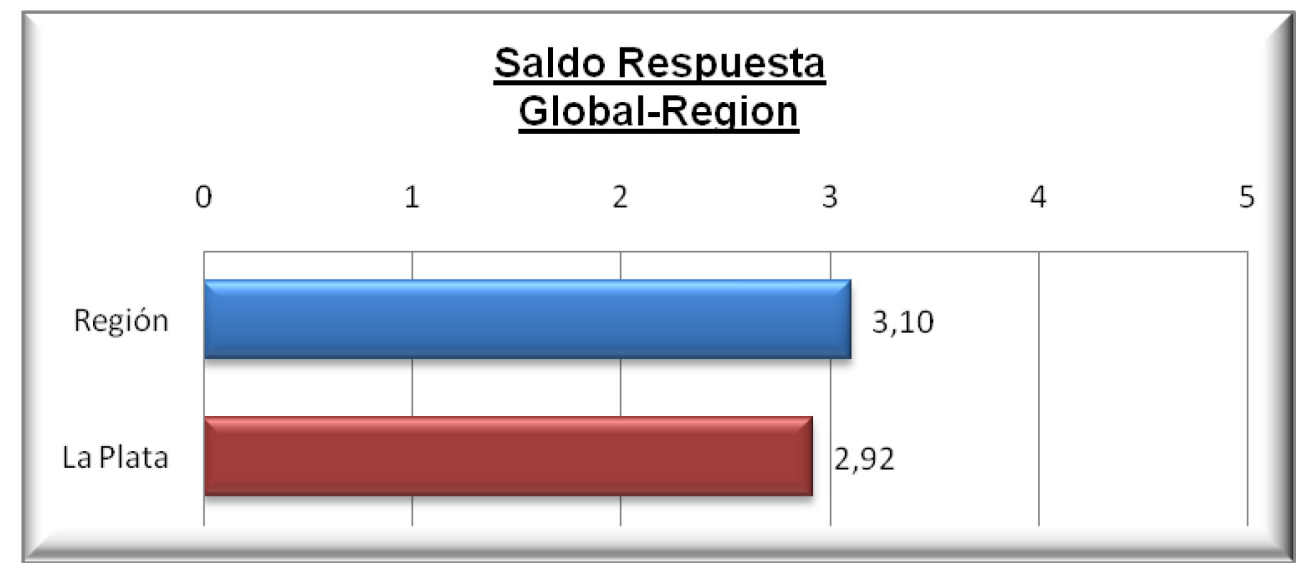

Fuente: Elaboración propia

\section{$\underline{7.2 .9 \text { Comparación internacional }}$}

El resumen de las calificaciones para La Plata por áreas es:

\begin{tabular}{|c|c|c|c|}
\hline & Matemáticas & Lengua & Ciencias \\
\hline La Plata (Docentes) & 2,87 & 3,11 & 3,16 \\
\hline La Plata (Empresarios) & 2,81 & 2,87 & 2,71 \\
\hline Total La Plata & 2,85 & 3,01 & 2,97 \\
\hline
\end{tabular}

Valores transformados equivalentes a los de Pisa

\begin{tabular}{|l|r|r|r|}
\hline & Matemáticas & \multicolumn{1}{c|}{ Lengua } & \multicolumn{1}{c|}{ Ciencias } \\
\hline La Plata (Docentes) & 373,00 & 422,00 & 433,00 \\
\hline La Plata (Empresarios) & 362,00 & 374,00 & 342,00 \\
\hline Total La Plata & 370,00 & 402,00 & 394,00 \\
\hline
\end{tabular}

(*) Promedio ponderado de las calificaciones de Docentes y Empresarios

A continuación se muestran las tablas jerárquicas del informe PISA 2009 a las que se les añadió la ubicación en ellas de La Plata.

\section{Matemática}

\begin{tabular}{|c|r|l|r|}
\hline Nivel & Jerarquía & \multicolumn{1}{|c|}{ Países } & Media \\
\hline \multirow{4}{*}{4} & 1 & Shanghái - China & 600 \\
\cline { 2 - 4 } & 2 & Singapur & 562 \\
\cline { 2 - 4 } & 3 & Hong Kong - China & 555 \\
\cline { 2 - 4 } & 4 & Corea del Sur & 546 \\
\hline 3 & 5 & Taipéi - China & 543 \\
\hline
\end{tabular}




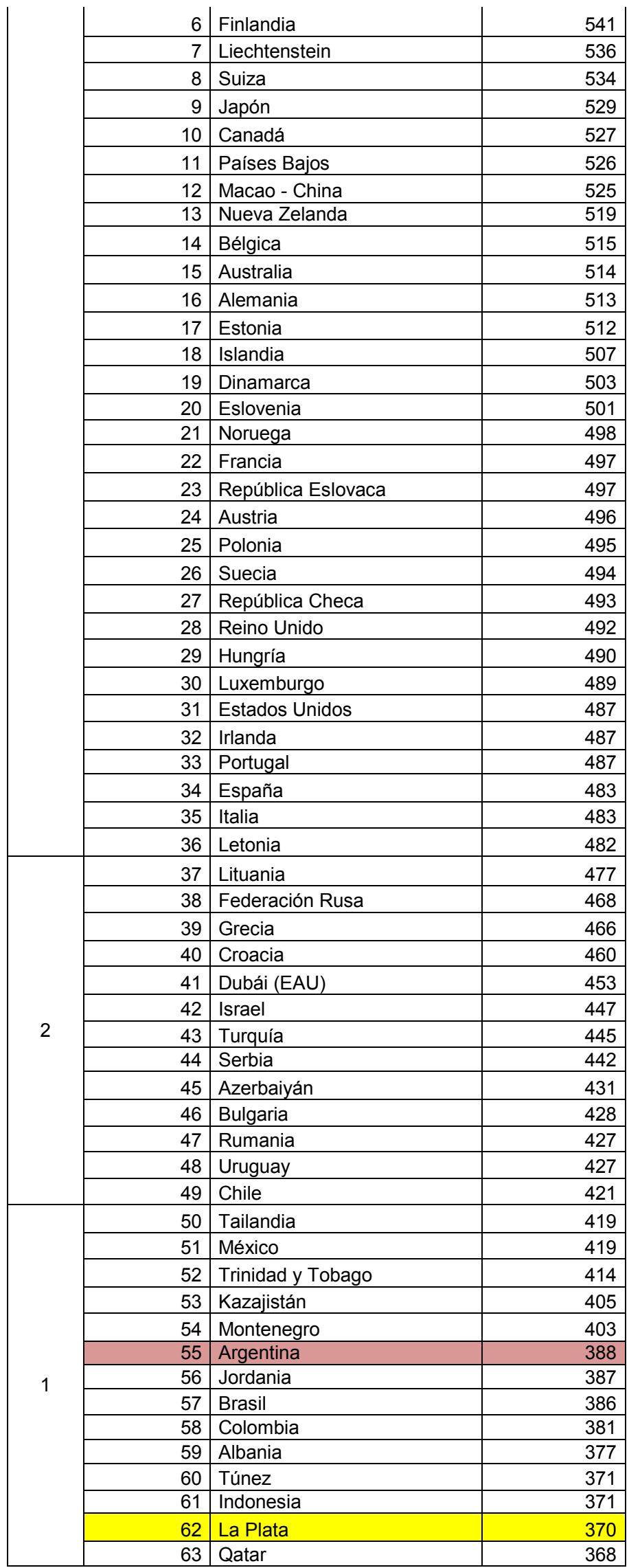




\begin{tabular}{|c|c|l|r|}
\multirow{2}{*}{} & 64 & Perú & 365 \\
\cline { 2 - 4 } & 65 & Panamá & 360 \\
\hline \multirow{2}{*}{-1} & 66 & Ensenada & 332 \\
\cline { 2 - 4 } & 67 & Kirguistán & 331 \\
\hline & & Promedio OCDE & 496 \\
\hline
\end{tabular}

\section{Lengua}

\begin{tabular}{|c|c|c|c|}
\hline Nivel & Jerarquía & Paises & Media \\
\hline 4 & 1 & Shanghái - China & 556 \\
\hline \multirow{32}{*}{3} & 2 & Corea del Sur & 539 \\
\hline & 3 & Finlandia & 536 \\
\hline & 4 & Hong Kong - China & 533 \\
\hline & 5 & Singapur & 526 \\
\hline & 6 & Canadá & 524 \\
\hline & 7 & Nueva Zelanda & 521 \\
\hline & 8 & Japón & 520 \\
\hline & 9 & Australia & 515 \\
\hline & 10 & Países Bajos & 508 \\
\hline & 11 & Bélgica & 506 \\
\hline & 12 & Noruega & 503 \\
\hline & 13 & Estonia & 501 \\
\hline & 14 & Suiza & 501 \\
\hline & 15 & Polonia & 500 \\
\hline & 16 & Islandia & 500 \\
\hline & 17 & Estados Unidos & 500 \\
\hline & 18 & Liechtenstein & 499 \\
\hline & 19 & Suecia & 497 \\
\hline & 20 & Alemania & 497 \\
\hline & 21 & Irlanda & 496 \\
\hline & 22 & Francia & 496 \\
\hline & 23 & Taipéi - China & 495 \\
\hline & 24 & Dinamarca & 495 \\
\hline & 25 & Reino Unido & 494 \\
\hline & 26 & Hungría & 494 \\
\hline & 27 & Portugal & 489 \\
\hline & 28 & Macao - China & 487 \\
\hline & 29 & Italia & 486 \\
\hline & 30 & Letonia & 484 \\
\hline & 31 & Eslovenia & 483 \\
\hline & 32 & Grecia & 483 \\
\hline & 33 & España & 481 \\
\hline \multirow{16}{*}{2} & 34 & República Checa & 478 \\
\hline & 35 & República Eslovaca & 477 \\
\hline & 36 & Croacia & 476 \\
\hline & 37 & Israel & 474 \\
\hline & 38 & Luxemburgo & 472 \\
\hline & 39 & Austria & 470 \\
\hline & 40 & Lituania & 468 \\
\hline & 41 & Turquía & 464 \\
\hline & 42 & Dubái (EAU) & 459 \\
\hline & 43 & Federación Rusa & 459 \\
\hline & 44 & Chile & 449 \\
\hline & 45 & Serbia & 442 \\
\hline & 46 & Bulgaria & 429 \\
\hline & 47 & Uruguay & 426 \\
\hline & 48 & México & 425 \\
\hline & 49 & Rumania & 424 \\
\hline
\end{tabular}




\begin{tabular}{|c|r|l|r|}
\multirow{4}{*}{} & 50 & Tailandia & 421 \\
\cline { 2 - 4 } & 51 & Trinidad y Tobago & 416 \\
\cline { 2 - 4 } & 52 & Colombia & 413 \\
\cline { 2 - 4 } & 53 & Brasil & 412 \\
\hline \multirow{4}{*}{ 1a } & 54 & Montenegro & 408 \\
\cline { 2 - 4 } & 55 & Jordania & 405 \\
\cline { 2 - 4 } & 56 & Túnez & 404 \\
\cline { 2 - 4 } & 57 & Indonesia & 402 \\
\cline { 2 - 4 } & 59 & La Plata & 402 \\
\cline { 2 - 4 } & 60 & Argentina & 398 \\
\cline { 2 - 4 } & 61 & Kazajistán & 390 \\
\cline { 2 - 4 } & 62 & Albania & 385 \\
\cline { 2 - 4 } & 63 & Qatar & 372 \\
\cline { 2 - 4 } & 64 & Panamá & 371 \\
\hline \multirow{4}{*}{ 1b } & 65 & Perú & 370 \\
\hline & 66 & Azerbaiyán & 362 \\
\hline & 67 & Kirguistán & 314 \\
\hline & 68 & Ensenada & 300 \\
\hline
\end{tabular}

\section{Ciencias}

\begin{tabular}{|c|c|c|c|}
\hline Nivel & Jerarquía & Países & Media \\
\hline 4 & 1 & Shanghái - China & 575 \\
\hline \multirow{25}{*}{3} & 2 & Finlandia & 554 \\
\hline & 3 & Hong Kong - China & 549 \\
\hline & 4 & Singapur & 542 \\
\hline & 5 & Japón & 539 \\
\hline & 6 & Corea del Sur & 538 \\
\hline & 7 & Nueva Zelanda & 532 \\
\hline & 8 & Canadá & 529 \\
\hline & 9 & Estonia & 528 \\
\hline & 10 & Australia & 527 \\
\hline & 11 & Países Bajos & 522 \\
\hline & 12 & Taipéi - China & 520 \\
\hline & 13 & Alemania & 520 \\
\hline & 14 & Liechtenstein & 520 \\
\hline & 15 & Suiza & 517 \\
\hline & 16 & Reino Unido & 514 \\
\hline & 17 & Eslovenia & 512 \\
\hline & 18 & Macao - China & 511 \\
\hline & 19 & Polonia & 508 \\
\hline & 20 & Irlanda & 508 \\
\hline & 21 & Bélgica & 507 \\
\hline & 22 & Hungría & 503 \\
\hline & 23 & Estados Unidos & 502 \\
\hline & 24 & República Checa & 500 \\
\hline & 25 & Noruega & 500 \\
\hline & 26 & Dinamarca & 499 \\
\hline
\end{tabular}




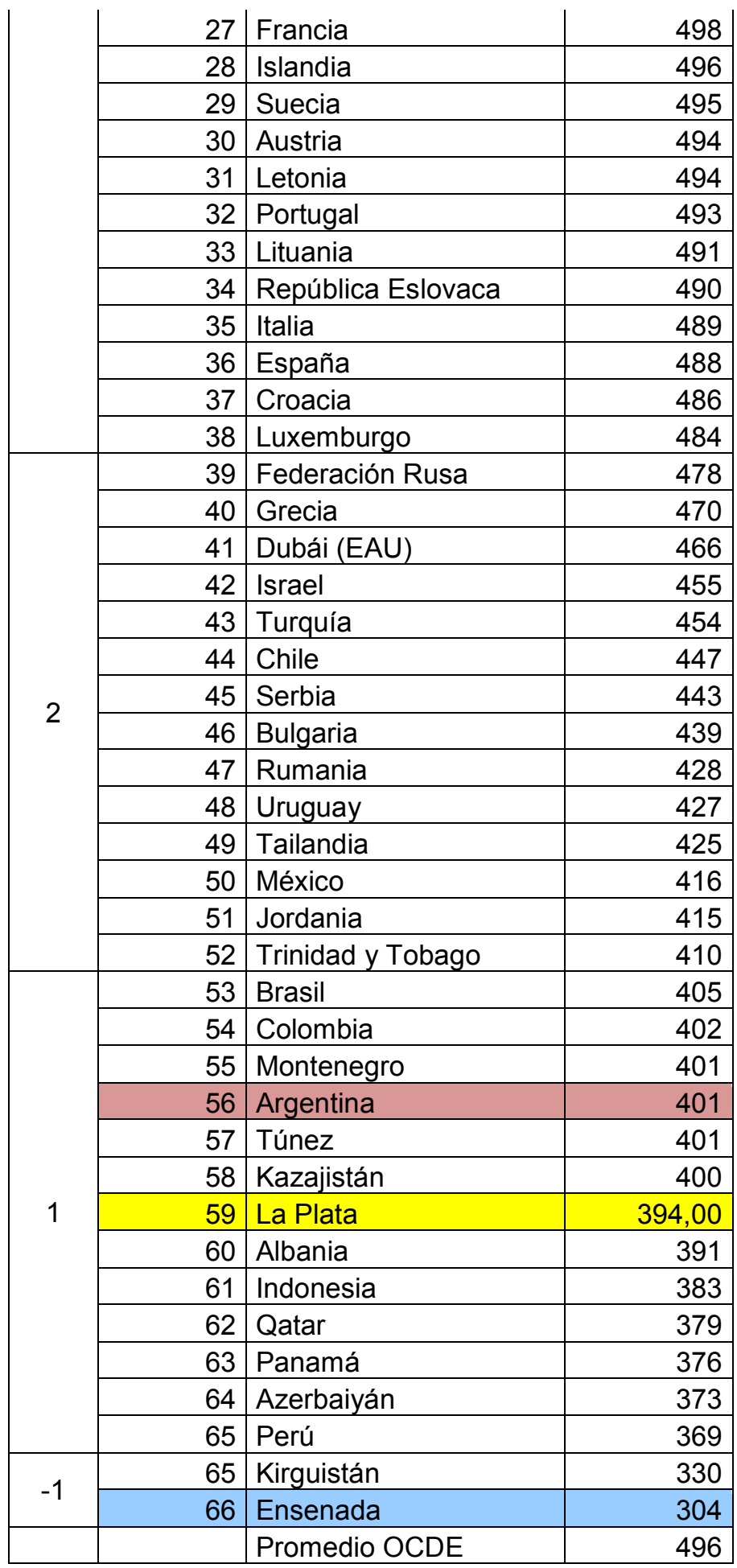




\section{Conclusiones}

Del análisis de los datos obtenidos es factible afirmar lo siguiente:

- Se observa que en todos los casos evaluados, los egresados de los colegios secundarios presentan un desempeño que fluctúa entre Bueno a Regular y un menor porcentaje en Muy Bien.

- El panel de expertos compuesto por empresarios tiene una mirada más crítica acerca de los conocimientos y aptitudes de los egresados, debido a que en las encuestas se puede observar que su valoración al respecto es menor que la de los docentes. Esto tiene sentido porque el empresario es el usuario directo del alumno al momento de trabajar y no tiene ningún tipo de compromiso sobre sus conocimientos.

- $\quad$ Cabe destacar que docentes y empresarios de la región tienen una mejor saldo de respuesta que los docentes y los empresarios de La Plata

- $\quad$ Según los el panel de expertos docentes, los saldos de respuestas en las áreas donde los egresados tienen mayor calificación respecto al panel de expertos empresarios son Matemáticas, Lengua y Ciencias, en cambio el panel de expertos compuesto por los empresarios, solo tuvo mejor calificación en Aptitudes personales esto se debe a que los empresarios tienen un control sobre sus empleados mayor que los docentes y con riesgo de perder su trabajo

- Ambos paneles de expertos coincidieron en que el área con mayor saldo de respuesta es el referido a las aptitudes personales.

- La Plata, en comparación con la región, muestra mayor nivel en la calidad educativa del secundario, ya que en ambos paneles de expertos el porcentaje en regular fue de $26 \%$ para la región igual a La Plata, pero en Bien La Plata tiene un $37 \%$ respecto a la región que tiene un $34 \%$ y en la respuesta muy bien los paneles de expertos le dan el $26 \%$ a La Plata y el $19 \%$ a la Región. 
- $\quad$ El saldo de respuesta global de la Regiòn en comparaciòn con La Plata, tanto de parte de los docentes como de los empresarios de la Regiòn otorgan un mejor saldo de respuesta que los docentes y empresarios de La Plata

- Con respecto al análisis de las tasas -datos de fuente secundaria-las comparaciones conducen a las siguientes conclusiones:

$\checkmark$ menor tasa de matriculación, en el 2010, pero en el año 2011 mejora e iguala a la región.

$\checkmark$ la tasa de sobre-edad tanto en la Región como en La plata disminuye en el 2011 respecto del 2010, pero en porcentaje en los dos años es muy similar, La plata mantiene el 78\% de sobre edad respecto a la región en 2010 y 2011.

$\checkmark$ el alfabetismo es menor tanto en la Región como en La Plata en el 2011 respecto del 2010 pero la relación en del 79 \% de La plata respecto a la Región se mantiene en el 2011 muy parecido al 2010.

$\checkmark$ Con respecto a los datos secundarios, La Plata en comparación con la región, presenta:

- En la a la comparación internacional, se ha observado que La Plata ha quedado en puestos más bajos que Argentina, excepto en Lengua que se encuentra por encima de Argentina.

- En matemáticas Argentina se encuentra en el puesto 55 y tiene 388 puntos, mientras que La Plata está en la ubicación 62 y con 370 puntos.

- En Lengua La Plata se encuentra por encima de la Argentina en el puesto 57 con 402 puntosy la Argentina se encuentra en el puesto 60 con 398 puntos.

- En Ciencias la Argentina se encuentra en el puesto 56 con 401 puntos y La Plata se encuentra en el puesto 59 con 394 puntos.

- Es importante tener presente que para PISA«Los estudiantes que alcanzan el nivel 2 , tienen las competencias mínimas para desenvolverse en el mundo e integrarse productivamente a la sociedad», en las tres áreas tanto Argentina como La Plata se ha ubicado por debajo de este nivel. Se encuentran en el nivel 1 con calificaciones muy bajas. 


\section{Referencias Bibliográficas}

- Binstock, G. \&Cerrutti, M. (2005) Carreras Truncadas-El Abandono Escolar en el Nivel Medio en Argentina. Unicef, Bs.As.

- Braslavsky, C. (año) Propuesta para el debate en torno a un propósito formativo organizador de nuevos diseños curriculares, desde la educación inicial hasta la polimodal: la formación de competencias. Editorial....

- Coll, C. et al. (año)Los contenidos en la reforma. Enseñanza y aprendizaje de conceptos, procedimientos y actitudes. Ed. Santillana, Bs.As.?

- Delors, J. (año)La educación encierra un tesoro .Ed,.......

- Heckman, J. (2000) ..........

- López Armegol, M. (2011) Hacia una Educación Superior de Calidad. Una Mirada de quienes gestionan las Universidades en Argentina, España y México. Ed.......

- La Educaciòn Secundaria en Argentina, (notas sobre la historia de un formato, por Myriam Southwell).

- Aproximaciones a la EducaciònSecndaria en la Argentina (2000-2010). (Coordinado por Horacio Ademan Ferreira)

- Hacia una educación superior de calidad (Edulp, varios autores, Editorial de la Universidad de La Plata)

- Los siete pilares de la educación (Edgar Morín)

- Democracia y educación (John Dewey)

- "Gestión educativa en América Latina. Construcción y reconstrucción del conocimiento". Benno Sander. Edit Troquel.

- "Gerencia de la calidad total". Hernando Mariño Navarrete. Tercer mundo editores.

- "La escuela vacía. Deberes del estado y responsabilidades de la sociedad." Emilio TentiFanfani. U.N.I.C.E.F.

- "Invertir en el futuro. Definir las prioridades educacionales en el mundo en desarrollo". Jacques Hallak. Edit Tecnos.

- ".

- "Algunos lineamientos e interrogantes para enmarcar la reflexión y el debate". Bibliografía de la cátedra. 
- "El concepto de calidad de la educación". Verónica Edwards. Instituto Fronesis. Libresa.

- "El nuevo pacto educativo. Educación, competitividad y ciudadanía en la sociedad moderna. "Juan C. Tedesco. Alauda Anaya.

- "Respuesta a la crisis educativa. Primer año del colegio secundario". Artículo de Daniel Filmus

- "La otra reforma. Desde la educación menemista al fín de siglo." Adriana Puiggros. Edit. Galerna.

- “La Obra. Revista de educación” N 920. Artículo: Calidad de la educación. Vilma Frattari.

- "El sistema educativo argentino. Características y problemas". Artículo de Silva Jauregui, María L. Lemos y Norma Paviglianiti.

- (La escuela vacía. TentiFanfani Emilio. UNICEF/Losada. Capítulo 3, Pág.89)

\section{0-Anexos}


Datos de Fuente Secundaria

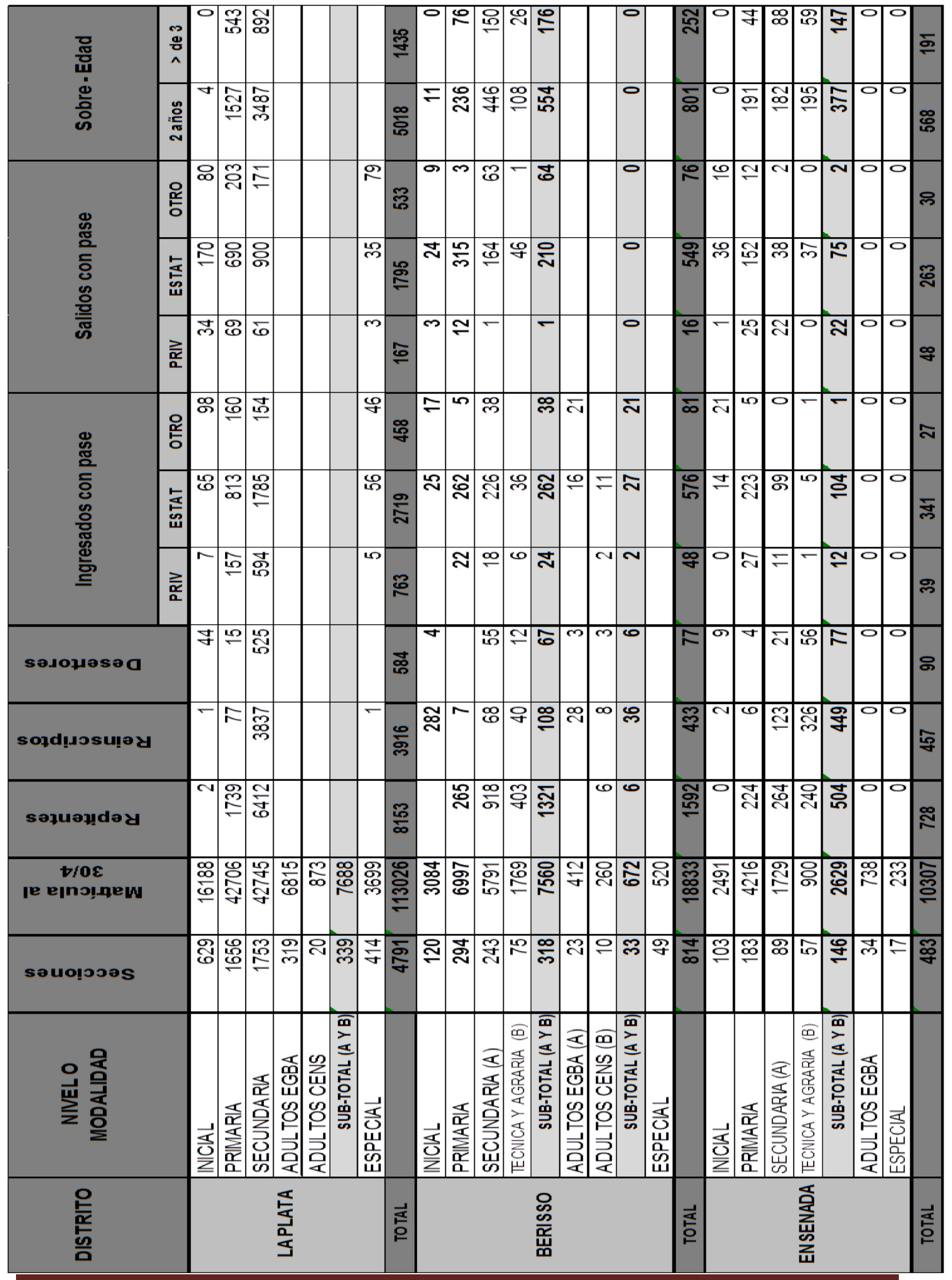




\section{Población}

\begin{tabular}{|l|l|c|l|}
\hline LA PLATA & Chicos entre 12 y 18 años & 67930 & Año 2010 \\
\cline { 2 - 4 } & Chicos entre 11 y 17 años & 66092 & Año 2011 \\
\hline
\end{tabular}

\begin{tabular}{|l|l|c|l|}
\hline BERISSO & Chicos entre 12 y 18 años & 10366 & Año 2010 \\
\cline { 2 - 4 } & Chicos entre 11 y 17 años & 10313 & Año 2011 \\
\hline
\end{tabular}

\begin{tabular}{|l|l|c|l|}
\hline ENSENADA & Chicos entre 12 y 18 años & 6590 & Año 2010 \\
\cline { 2 - 4 } & Chicos entre 11 y 17 años & 6517 & Año 2011 \\
\hline
\end{tabular}

Nota: la población total incluye a las personas viviendo en situación de calle.

El índice de masculinidad indica la cantidad de varones por cada 100 mujeres.

Fuente: INDEC. Censo Nacional de Población, Hogares y Viviendas 2010.

\section{Cantidad de personas que reportan leer y escribir}

\begin{tabular}{|c|c|c|}
\hline \multicolumn{3}{|c|}{2011} \\
\hline LA PLATA & BERISSO & ENSENADA \\
\hline 65302 & 10186 & 6435 \\
\hline
\end{tabular}

Datos suministrados por la Dirección de Información y Estadística de la Dirección Provincial de Planeamiento de la DGCyE

\section{Más resultados adversos en la universidad platense}

Aspirantes a Medicina reprobaron un examen de nivel primario. 


\section{La Nación 1998}

LA PLATA.- Un grupo de aspirantes a incorporarse en la Facultad de Ciencias Médicas de la Universidad Nacional de La Plata (UNLP), recientemente reprobados en una prueba de ingreso, no logró superar un examen de matemática elaborado sobre la base de conocimientos que se imparten en la escuela primaria.

A esta prueba optativa, la misma que se utiliza para evaluar a los alumnos de séptimo grado que desean ingresar en los colegios secundarios de la UNLP, se presentaron 217 jóvenes. El 89\% de ellos fue aplazado.

Estos resultados ahondan la preocupación por la deficiente preparación que los estudiantes obtienen en la enseñanza media. Como se recordará, 1727 aspirantes a estudiar la carrera de Medicina en la UNLP fueron reprobados en la evaluación diagnóstica que los hubiera eximido de realizar un curso introductorio a la carrera.

Ninguno de los que rindió la evaluación optativa logró responder correctamente la totalidad de las preguntas. Únicamente el $11 \%$ de ellos pudo aprobar.

Uno solo logró dar adecuada resolución a cinco de los seis ejercicios sobre matemática que integraban la prueba. Once lograron presentar cuatro bien resueltos; 46 hicieron correctamente dos o tres; 26 , solamente uno, y 16 , ninguno.

El examen constaba de tres problemas geométricos y tres aritméticos. Entre los primeros, los estudiantes debieron resolver, sin la ayuda de la calculadora, problemas de superficies y perímetros.

Uno de los ejercicios aritméticos interrogaba: "¿Cuántas decenas tiene el mayor número natural de tres cifras distintas?" Otro, de carácter incierto y gastronómico, enunciaba: "Paula va a preparar un sándwich y puede elegir entre tres tipos de pan (negro, lactal, francés) y cuatro de fiambre (jamón, salame, matambre y lomito). Si prepara el sándwich con un solo tipo de fiambre y un solo tipo de pan, ¿de cuántas maneras puede hacerlo?"

\section{Más resultados adversos}

La inquietud desatada por los resultados de la evaluación de los aspirantes a estudiar en la Facultad de Ciencias Médicas de esta ciudad fue incentivada por otros resultados adversos registrados en diferentes unidades académicas. 
En la Facultad de Ciencias Jurídicas y Sociales de la UNLP, el examen diagnóstico fue aprobado solamente por el $33 \%$ de los aspirantes, es decir, 600 alumnos sobre un total de 1800 .

Mucho peor fue el resultado obtenido en la sede de Ciencias Veterinarias, en la que se inscribieron 1700 estudiantes, de los cuales 540 (el 32\%) se presentaron a la prueba diagnóstica.

Cada alumno rindió tres exámenes y, del total de 1620 pruebas, fueron aprobadas solamente 125 , es decir, menos del $10 \%$ de los ejercicios presentados. Sólo cuatro alumnos completaron bien los tres cuestionarios.

No obstante, los reprobados tienen la oportunidad de realizar el curso de nivelación. Con el $80 \%$ de asistencia a las clases y aprobando un examen final, podrán finalmente ingresar a la carrera.

El decano de esa casa de altos estudios, doctor Eduardo Pons, comentó que esos resultados no son sorprendentes y admitió que las pruebas eran realmente complejas.

En Ciencias Exactas, el examen diagnóstico fue superado solamente por el $30 \%$ de los inscriptos, pero los aplazados gozarán también de otra oportunidad para ingresar a través del curso de nivelación.

La situación fue más alentadora en la Facultad de Odontología, donde aprobó alrededor del $70 \%$ de los inscriptos, que, de todas maneras, deberá realizar un curso teórico-práctico obligatorio.

En el resto de las unidades académicas los ingresantes deben efectuar cursos introductorios sin la opción de una prueba diagnóstica para eludirlo.

Consultado por La Nación, Horacio Sanguinetti, ex secretario de Educación porteño y, desde ayer, nuevamente rector del Colegio Nacional de Buenos Aires, opinó que las dificultades de los estudiantes secundarios para aprobar los exámenes de ingreso en la educación superior no es un fenómeno nuevo, aunque se ha acentuado en los últimos años.

"La enseñanza media vive una situación crítica y caótica desde hace 30 años comentó-. Pero, en la actualidad, la situación se agrava por la deserción de la familia en la faz educativa y, también, por la falta de lectura y de dominio del lenguaje de los jóvenes.". Víctor J. Gil 


\section{Revisarán un examen que nadie aprobó}

La Universidad evaluará si las pruebas tomadas por la facultad eran adecuadas para el nivel de conocimientos de los alumnos

LA PLATA.- Las autoridades de la Universidad Nacional de La Plata (UNLP) evaluarán si los exámenes diagnósticos no obligatorios, que reprobaron 1727 aspirantes a la carrera de Medicina, eran adecuados para su nivel de conocimientos adquiridos durante la escuela secundaria.

Los aspirantes habían rendido unas pruebas consistentes en dos ejercicios de matemática, dos de química y dos de física que, en caso de haber aprobado, les hubiera permitido el ingreso directo en la Facultad de Ciencias Médicas el mes próximo.

Llamativamente, ningún alumno aprobó. Sin embargo, no quedaron fuera de batalla. Durante cuatro meses asistirán a un curso de nivelación eliminatorio que concluye el 26 de junio y que, una vez superado, les permitirá ingresar en la carrera en el segundo semestre.

En diálogo con La Nación, el vicepresidente de la casa de estudios platense, Alberto Dibbern, confirmó la intervención de la secretaría académica en el entuerto.

Agregó luego: "Vamos a ser muy duros si del informe de la secretaría académica se desprende que las pruebas no eran adecuadas al nivel de conocimientos secundarios de los aspirantes".

La dureza aludida puede transformarse en la elaboración de un informe que contenga las condiciones que deben tener los exámenes diagnósticos en la geografía de la UNLP. Ello, a pesar de que por estatuto las unidades académicas tienen potestad para dictar sus respectivos cursos de ingreso.

El vicepresidente deslindó luego la responsabilidad institucional del Colegio Nacional de La Plata en la formulación de los contenidos de las pruebas. "Tal vez algún profesor intervino, pero a título personal", especuló.

Expresó que la secretaría académica emitirá un informe tras escuchar a un grupo de especialistas en educación media que tendrán a su cargo ese análisis.

\section{Duro de aprobar}

Por su parte, el vicedecano a cargo de la facultad, Rodolfo Hernández, atribuyó el resultado de los controvertidos exámenes a las deficiencias de la enseñanza secundaria y a una actitud poco responsable por parte de los alumnos. 
"Los resultados de este examen son una muestra de las falencias que tienen los chicos en su formación anterior. Lo que se les tomó en esta prueba lo vieron durante el secundario. Además, se presentaron a rendir sin haberse preparado previamente."

Dibbern (el presidente Luis Lima no pudo ser localizado en su despacho) tiene una opinión bien distinta. "Estamos muy preocupados. Sobre todo, porque estos chicos se preparan durante unos meses para ingresar. De modo que el nivel de sus estudios secundarios debe ser muy malo."

La prueba diagnóstica duró dos horas y consistía en temas incorporados a los programas de la escuela secundaria. El curso de nivelación, que harán tanto los que se presentaron al examen diagnóstico como los que eludieron la catástrofe académica, brinda la posibilidad de un examen recupera torio si reprueban la evaluación del período.

Como consecuencia de los resultados logrados, Hernández recomendó a los inscriptos "abocarse con toda dedicación a dicho curso, que se realizará justamente para cubrir las falencias formativas".

De los 1727 postulantes, sólo uno hizo bien tres de los seis ejercicios presentados a modo de opciones múltiples. Otros 23 realizaron bien dos ejercicios, 249, sólo uno, y 1454 no dieron bien ninguna respuesta. En algunos casos, las pruebas fueron entregadas en blanco.

El decano admitió que no era una prueba fácil y dijo que bien podían rendirla los alumnos que estudiaron matemática durante los cinco años del secundario.

Los únicos que quedaron exceptuados del curso fueron 22 alumnos que poseen antecedentes universitarios que, según lo establece una resolución firmada durante el anterior decano de la facultad -el fallecido José Fassi-, garantizan un nivel de conocimientos que les permite ingresar directamente en la carrera.

\section{Experiencia repetida}

El severo filtro para ingresar en Medicina en La Plata tiene antecedentes recientes: el año último se tomó una prueba similar que fue aprobada por 49 sobre 2100 alumnos que se presentaron a rendirla. Ala carrera ingresaron finalmente 552 estudiantes, al rendir bien el curso de admisibilidad.

De esos 49, había 36 bachilleres, 7 peritos mercantiles y 5 provenían de escuelas técnicas. En tanto, otros 24 habían cursado en escuelas públicas y otro número igual, en colegios privados. 
El vicepresidente de la Universidad expresó: "Me parece injusto que los chicos tengan dificultades para ingresar en la Universidad y esto es por muchas circunstancias".

"Si a esos alumnos uno les hubiera planteado circunstancias difíciles durante el secundario y la solución de diversos problemas -insistió el decano Hernández-, es probable que los ejercicios no fueran nuevos para ellos". Mientras conversaba con La Nación, el decano recibió una llamada del Ministerio de Educación y habló sobre los resultados de la prueba. En un tramo de la charla telefónica, el decano dijo: "Si a la UBA ingresa el $10 \%$ y acá el 30 , si nuestra prueba es difícil, la de la UBA debe ser peor".

Hernández dijo sentirse fracasado, "pero no como decano, sino como padre, porque por medio de la prueba se pudieron determinar las falencias de los jóvenes en su educación, que no provienen sólo de la escuela".

Al parecer, el nivel de conocimientos que los estudiantes adquieren durante la etapa de estudios secundarios es la gran piedra de la discordia.

Dibbern comentó que durante la prueba de nivelación no eliminatoria que los aspirantes rindieron en la Facultad de Veterinaria esta semana, sobre 720 sólo superaron la evaluación unas 28 personas. "No tengo dudas de que vienen mal de la escuela secundaria", concluyó el vicepresidente.

\section{Posible error}

En pedagogía hay una máxima que dice que cuando una evaluación es desaprobada en forma masiva hay que desconfiar de su elaboración.

"Estamos preocupados. Es probable que haya habido un error en el diseño de los contenidos de las pruebas diagnósticas", admitió a La Nación Alberto Dibbern, vicepresidente de la Universidad Nacional de La Plata.

"Mandamos a pedir los exámenes a la Facultad de Medicina para analizarlos", agregó.

\section{Culpan a la secundaria}

La ministra de Educación, Susana Decibe, atribuyó a fallas de la enseñanza media el sorprendente resultado del examen de ingreso en la Facultad de Medicina de La Plata, donde ninguno de los 1727 alumnos que se presentaron aprobó la prueba.

Decibe sostuvo que la solución a este problema debe venir de cada escuela del país e interpretó el resultado de la evaluación como un llamado de atención a los 
directivos y equipos docentes que se desempeñan en los colegios secundarios. "Es un tema que debe resolver la escuela, no la Universidad", precisó.

\section{Preocupación de Ferreira}

La Nación 2002

Consultado por La Nación, el decano de Medicina de la Universidad de Buenos Aires (UBA), Luis Ferreira, expresó su preocupación por el magro resultado de las pruebas.

Ferreira impulsa en la UBA una selección rigurosa de los aspirantes a Medicina, por medio del Curso Preuniversitario de Ingreso (CPI).

De los 12.000 estudiantes que en octubre último se inscribieron en el CPI para ingresar en 2002 en la UBA, sólo unos 1200 aprobaron el primero de los tres módulos en que se divide el curso, confirmó ayer el decano.

Frente a los 1727 alumnos reprobados en la Universidad de La Plata, Ferreira estimó que se trata de "una cifra alarmante y nos lleva a pensar sobre cómo vienen preparados los alumnos del secundario para entrar en la Universidad".

\section{Nuevosaplazo, nuevas frustraciones}

\section{Diario La Nación: 2008}

Son conocidas las dificultades que afrontan los alumnos que concluyen la escuela media y procuran continuar su formación en el tercer nivel. En los últimos días se ha registrado un nuevo capítulo de "bochazos" en dos facultades de la Universidad Nacional de La Plata (UNLP) y en la Universidad Tecnológica Nacional (UTN).

En el primer caso, apenas el 11,2\% de los alumnos -33 sobre un total de 294aprobó el examen para ingresar en la Facultad de Ingeniería. La prueba, que permitía evitar la instancia del curso nivelatorio, registró un resultado también preocupante: por cada uno de los que aprobaron hubo dos que sacaron cero. Fueron 60 los estudiantes que entregaron la hoja en blanco y obtuvieron la peor calificación. En tanto, hubo 206 inscriptos que ni siquiera se presentaron a rendir.

La de ahora fue la segunda oportunidad que los egresados del secundario tuvieron para ingresar en la facultad, tras el examen de diciembre. En total se inscribieron 956 
alumnos; de ellos, 456 rindieron sus exámenes en diciembre y sólo aprobaron 133. En el llamado de enero pasado se presentaron 294 y aprobaron 33. Así, sólo 166 aspirantes llegaron a la nota del seis, el puntaje mínimo para aprobar.

En segundo lugar, los "bochazos" siguieron sucediéndose entre los alumnos de la Facultad de Ciencias Astronómicas y Geofísica de la UNLP, donde sólo uno de los 35 aspirantes logró superar el examen de ingreso y, así, evitar el intensivo curso nivelatorio de admisibilidad. En efecto: una sola persona logró superar el examen de matemática, que consistía en 16 preguntas sobre geometría, logaritmos, trigonometría, polinomios y ecuaciones algebraicas, entre otros temas.

Cabe mencionar, asimismo, que en las evaluaciones de ingreso de la Facultad Regional de Mendoza de la UTN, en el primer examen de matemática, aprobaron sólo 22 de 1100 postulantes, apenas el $2 \%$. La mayoría de los aspirantes había asistido a un taller de orientación que la UTN realizó en noviembre del año último. En diciembre, aprobó el primer examen el $2 \%$ de los 1100 , y en un curso de recuperación aprobaron con más de 7 puntos 306 sobre 800 . En la tercera oportunidad, a fines de enero, rindieron satisfactoriamente 56 de los 556 estudiantes que se presentaron, es decir, un 10\%.

Durante los últimos años, el número de aplazos en los exámenes de ingreso en distintas universidades del país creció exponencialmente, sin que hasta el momento se haya encontrado la manera de revertir tan preocupante situación. En este sentido, resulta auspiciosa la iniciativa del Ministerio de Educación, que pondrá a disposición de las provincias un curso de apoyo para los alumnos diseñado especialmente para profundizar ejercitaciones intelectuales básicas, como práctica de lectura, expresión, comprensión y razonamiento.

El programa tuvo un primer ensayo, a través de una experiencia piloto, con alumnos de los últimos años de escuelas estatales de la ciudad de Buenos Aires, el conurbano, La Plata y Luján. Un $60 \%$ de los asistentes encontró al curso de apoyo diferente o muy diferente de su experiencia en la secundaria. Para el $72,3 \%$, la mayor utilidad del curso fue reforzar conocimientos, pero más de seis de cada diez afirmaron haber incorporado cosas que no sabían y el $66,3 \%$ dijo que había mejorado su forma de expresión. Las mayores dificultades se encontraron en matemática, donde el $47,1 \%$ admitió tener problemas (contra el $17,3 \%$ en literatura y el $14,3 \%$ en ciencia, cultura y sociedad).

Estos resultados revelan una de las debilidades del sistema educativo y corroboran que los contenidos de los programas de la escuela secundaria y del polimodal son inadecuados e insuficientes en la preparación y formación de los alumnos. Por 
consiguiente, es de esperar que las autoridades educativas encaren una amplia reformulación de dichos programas y contenidos y que, además, se profundicen los esfuerzos para lograr una mejor articulación entre el nivel medio de enseñanza y la universidad, de manera de poner fin a esta cadena de frustraciones. Cuanto se haga en esa dirección será de inestimable valor para el alumnado.

\section{El ingreso universitario ante los altos niveles de fracaso}

\section{Proponen un examen único en Medicina}

Los decanos de las facultades de todo el país estudian establecer una prueba nacional de ingreso y un cupo de admisión

La Nación 2004

Preocupados por el alto nivel de fracaso de los aspirantes y el creciente malestar de estudiantes y padres que denuncian la alta exigencia de las pruebas de admisión, los decanos de las facultades de Medicina de todo el país comenzarán a debatir hoy una reforma en el sistema de ingreso, que propone una prueba nacional común para todo el país, un cupo por facultad y un curso preparatorio voluntario que deben dictar las universidades y pagar los estudiantes.

La propuesta, elaborada por Carlos Fernández, médico y vicerrector de la Universidad Nacional de Tucumán (UNT), se presentará en la reunión mensual que realizan todos los primeros viernes de cada mes los integrantes de la Asociación de Facultades de Ciencias Médicas de la República Argentina (Afacimera), que reúne a más de 20 facultades de instituciones públicas y privadas.

El proyecto, al que tuvo acceso LA NACION, propone unificar el sistema de ingreso con un examen de admisión nacional idéntico, que se tome el mismo día y a la misma hora en todo el país. El examen, con contenidos y formato acordados entre las facultades, no tendrá recuperatorio y deberá aprobarse con 7 puntos. La nota se promediará con la calificación promedio alcanzada en la escuela media -lo que servirá para "valorizar los estudios secundarios"- y el resultado de una prueba de capacidad de razonamiento y resolución de problemas, aunque ambas calificaciones tendrán un peso menor. 
Con esa nota se elaboraría un listado general de méritos y los estudiantes ingresarían en las carreras hasta completar los cupos determinados en cada facultad, cuya suma establecería el número de postulantes que se pueden aceptar en todo el país.

La novedad es, además, el "cupo regional", que permitiría que si el número de alumnos en condiciones de ingresar supera el cupo en una institución se los pueda derivar a otra que tenga plazas disponibles.

"Tenemos que sincerar los problemas. Las facultades son incapaces de recibir la cantidad de alumnos que se inscriben. Hay que pensar en soluciones más abarcativas, de alcance nacional, y discutir esto con las autoridades de los ministerios de Educación y de Salud", dijo Fernández a LA NACION. De hecho, las autoridades de ambas carteras ya recibieron el proyecto y comenzaron a consultar a expertos.

\section{Consenso difícil}

Recientemente, los fracasos masivos de los aspirantes en las facultades de Medicina de Córdoba (90\%), La Plata (80\%) y Rosario (76\%) sacaron a la luz el problema del acceso, que estas carreras, con sus exigencias académicas, de prácticas e infraestructura, enfrentan con particular transparencia.

Para concretarse, la propuesta tiene un largo camino por recorrer: lograr consenso en las universidades es el primero y más difícil. Por ejemplo, la Facultad de Medicina de la UBA no forma parte de Afacimera desde abril de 2001, y, según pudo saber LA NACION, otras facultades no están muy dispuestas a apoyar la instalación de un único examen para todas.

La idea del cupo tiene más aceptación. De hecho, muchas lo tienen establecido y las únicas dos carreras de todo el país que recibieron la máxima acreditación de la CONEAU -por seis años- fueron las de las universidades nacionales de Cuyo y Tucumán, ambas con cupo y examen de ingreso. Según afirman sus autoridades, la relación docente-alumno resulta ideal, lo que hace que el índice de fracaso sea más bajo y los estudiantes se reciban en el tiempo establecido en mayor medida.

El proyecto también prevé que las facultades ofrezcan un curso preparatorio voluntario para la prueba de acceso, de tres a cuatro meses de duración, que sea pago a "un costo razonable" de $\$ 30$ a $\$ 40$ mensuales, con un número de becas que puede llegar al $10 \%$ de los inscriptos. Según dijo Fernández, el proyecto está pensado para las universidades públicas, pero "las privadas podrían sumarse". 
"Racionalizar el ingreso es imperativo y hay que afrontar este problema abiertamente. Es un tema fundamental para todas, públicas y privadas", dijo Abraham Sonis, de la Universidad Maimónides.

Por Raquel San Martín

De la Redacción de LA NACION. Domingo 23 de mayo de 2010

De la escuela a la universidad

\section{EI CBC, un monstruo que no es tan malo}

\section{Siete alumnos cuentan cómo es el temido primer bimestre en la UBA}

Silvina Premat

LA NACION

A dos meses de haber comenzado la universidad, Fabricio De Sa Torres, de 19 años, no se acostumbra: a los exámenes parciales sigue llamándolos "pruebas" y a la universidad misma, "el cole". Lucía Moltrasio, de 18, también intenta adaptarse al cambio más importante que implicó para ella el comienzo del Ciclo Básico Común ( $\mathrm{CBC}$ ) en la Universidad de Buenos Aires (UBA): tener que viajar todos los días casi una hora en tren.

Sin embargo, como muchos de los cerca de 60.000 jóvenes que cursan el CBC, Fabricio y Lucía están a gusto. Perciben que los primeros pasos en la vida universitaria los invitan a un mayor protagonismo en la toma de decisiones de su propia historia. $Y$ eso los entusiasma.

Después de la primera tanda de exámenes parciales del cuatrimestre, La Nación reunió a siete estudiantes del ciclo de ingreso en la UBA para distintas carreras, que, en estas ocho semanas de clases, confirmaron algunos de los mitos con los que se vincula a esa universidad y desecharon otros.

La masividad que caracteriza los pasillos de la mayoría de las trece facultades de la UBA puede provocar dificultades y retrasos a la hora de hacer un trámite, pero no impide que los alumnos se sientan bien tratados.

Si bien Lucía comparte en Ciudad Universitaria un taller de dibujo proyectual con otros 200 estudiantes, no encuentra dificultades porque, según cuenta, los docentes organizan grupos pequeños en las clases. El resultado es el mismo que percibe Belén Altamirano en los talleres de semiología, en la sede Montes de Oca, del CBC. "No noto que me traten como si fuera un legajo", cuenta Maximiliano Basegotte, de 20 años, y aspirante a ingresar en Arquitectura. 
"Si bien los profesores no saben mi nombre, y pedírselo es imposible porque hay algunos que tienen 500 alumnos, estoy bien porque hasta ahora tengo profesores delante de mí que aman dar clase." Y agrega: "Eso está bueno porque no me sirve que los profesores sólo sepan mi nombre y apellido, como me pasó en el secundario, sino que den la clase con vocación y hasta con amor".

Nicolás Correa, de 19 años, no coincide del todo con Maximiliano en cuanto a la calidad de los docentes. El comenzó el CBC a mediados de 2009, cuando cambió de idea sobre la carrera que quería estudiar. Después de haber aprobado tres de las cinco materias del primer cuatrimestre para Contador Público en una universidad privada se pasó a la UBA, para ingresar en Derecho. "Hasta ahora tuve profesores buenos y otros que se nota que van sólo para cobrar el sueldo", dice.

Muchos consideran que el CBC es un año perdido, y argumentan la necesidad de reformarlo e incluso de eliminarlo como sistema de ingreso. Quienes lo cursan, al menos los siete estudiantes consultados por La Nación, no piensan igual.

"El CBC está hecho para introducir al alumno a la vida de una facultad", dijo Ignacio Martínez Basanta, de 18 años, ingresantes de Derecho. "Además, un alumno de la UBA sale con la habilidad de resolver más problemas que cualquier otro porque van apareciendo trabas y se va haciendo difícil", agregó Ignacio.

"Sí, es como dice Ignacio, y esto sirve también para aprender a organizar los tiempos", dijo Pablo Sánchez Rey, de 18 años, que aspira a ser biólogo. "Además, si yo no hubiese tenido el CBC, no podría empezar con química orgánica, me despedazarían. Todo lo que vi en un año de química en el secundario acá lo vimos en una hora y media de clase", cuenta Pablo, quien ahora está "fascinado" con la química, pero que al principio del CBC le costó "horrores".

Quizá tanto como a Pablo con la química a los demás también les está costando adaptarse a un ritmo de estudio bien distinto del que conocían hasta ahora. "En la secundaria yo me preparaba dos días antes de la prueba; en cambio, acá tengo que prepararme con anticipación. Además, después de cada clase tengo que ir leyendo lo que se va dando para que no se me acumule y no llegar al último día con todo por estudiar. Eso me pasó justamente con el parcial que tuve esta mañana", dice Ignacio al referirse a un examen de economía.

¿Hubo algo de todo lo que se suele decir de la UBA que ellos hayan constatado hasta ahora como verídico? "Que hacer trámites es más engorroso", responden varios. Ya sea que se trate de gestionar la libreta como alumno regular, legalizar el título secundario o corregir un error administrativo. 
"Cuando me inscribí anotaron mal mi apellido y fue un problema porque no sabía adónde tenía que ir", cuenta Nicolás y continúa: "Si bien me quejé desde el primer día recién lo arreglaron dos semanas antes de que terminara el cuatrimestre. Un trámite así en la universidad privada, donde hice algunos meses, me lo arreglaron en cuestión de minutos. De todas formas estoy mejor en la UBA".

¿Qué los sorprendió al comenzar la universidad? "Ser la más chica del grupo", comenta Belén, de 18 años, que tiene compañeros "muy grandes; sobre todo en matemáticas, que curso a la tarde; todos son mayores de 21". En las materias para otras carreras, según los chicos, la edad de los ingresantes se eleva en el turno vespertino y nocturno. "Yo tengo dos compañeros de 40 años", dice Fabricio, y Maximiliano agrega: "Sí, yo he visto hombres grandes, más bien ancianos".

\section{Medicina y Abogacía son las preferidas}

Algo más de 59.000 estudiantes se inscribieron para comenzar el CBC en la UBA este año, un $7 \%$ más que en 2009. Las carreras tradicionales continúan siendo las más elegidas: medicina (5986 inscriptos) y abogacía (4723 inscriptos) encabezan las preferencias. Les siguen en cantidad de alumnos psicología (4251), contador público (3370), administración (2759), arquitectura (2652), diseño gráfico (2115), ciencias de la comunicación (1596), diseño de indumentaria y textil (1523), relaciones del trabajo (1048) y kinesiología (1045). Según cifras de la UBA, un $20 \%$ de estos alumnos abandonará el curso antes de fin de año.

\section{Nuevos aplazos masivos en el ingreso a Ingeniería}

\section{El 75\% de los aspirantes reprobó el examen en la Universidad de La Plata}

La Nación 2002

LA PLATA.- El examen de ingreso, que ayer desaprobó el 75\% de los aspirantes que pretenden estudiar en la Facultad de Ingeniería de la Universidad Nacional de La Plata (UNLP), volvió a generar duras críticas al polimodal, el ciclo que reúne a los últimos tres años del ex secundario.

Sobre un total de 1000 inscriptos habilitados para rendir el examen de ingreso que los podía eximir del curso de admisión que se prolongará por cuatro semanas, sólo se presentaron a rendir 335. De éstos, sólo 81 pudieron superar el examen, confirmó a LA NACION el decano de Ingeniería, Alberto Giovanbattista. 
Al analizar las causas del mal desempeño, las autoridades de la facultad advirtieron que los alumnos no llegan bien formados a la Universidad debido a que en el último año del polimodal no se dicta la asignatura matemática.

La falla fue admitida por las autoridades educativas. Al ser consultado por LA NACION, el subsecretario de Enseñanza Media del gobierno bonaerense, Alberto Sileoni, reconoció que "no dictar matemática en el último año del polimodal es un error. Estamos trabajando para incluir la asignatura".

Al respecto, agregó: "Quizás este año podremos dictarla en forma experimental y evaluar luego la evolución de los alumnos".

El decano de Ingeniería explicó que "de los 335 alumnos que creían que estaban capacitados para rendir la evaluación, unos 40 no pudieron responder ni un solo problema, por lo que su calificación fue cero".

El planteo de Giovanbattista sobre la deficiente preparación con que los alumnos llegan a la Universidad es compartido por los titulares de las facultades de Medicina y de Ciencias Jurídicas, que habían realizado similares descargos ante los reiterados aplazos en las pruebas de ingreso que se tomaron en los últimos tres años.

Pero el cuestionamiento del decano va más allá de la retórica. "La Facultad de Ingeniería prepara un curso a distancia que será emitido por el canal de la UNLP para que los alumnos del último año del polimodal puedan afianzar, en horario extracurricular, los conocimientos básicos de matemática", aseguró Giovanbattista.

Y aclaró: "Nosotros no intentamos reemplazar la educación básica. Sólo queremos que los chicos que estén interesados en estudiar ingeniería puedan tener elementos suficientes para ingresar en la facultad".

La Dirección General de Cultura y Educación afirmó que, efectivamente, en el último año del polimodal no se dicta la asignatura matemática. "Durante el $8^{\circ}$ y $9^{\circ}$ año de la educación general básica (EGB) y los dos primeros ciclos del polimodal hay una carga horaria equivalente a los cinco años de la vieja secundaria", explicó Sileoni.

El curso de ingreso a Ingeniería se modificó el año último ante los altos índices de deserción que tenía la unidad académica. "Durante los últimos seis años habíamos planteado un curso nivelatorio con examen final y que no era eliminatorio. Pero las estadísticas marcaron que el $90 \%$ de los alumnos que le iba mal en esa prueba después no tenía los suficientes conocimientos como para comenzar a cursar alguna de las asignaturas del primer año", explicó el decano.

Modalidad diferente 
Ahora, los aspirantes que pretenden ingresar en la carrera tienen que aprobar una evaluación de matemática que se puede rendir en diciembre o en febrero. Precisamente, en diciembre último se habían presentado 340 aspirantes de los 1000 inscriptos y en esa ocasión sólo aprobaron 46.

Entre el examen de diciembre y el que se tomó anteayer sólo ingresaron 127 alumnos que estarán en condiciones de cursar la carrera en marzo próximo. El 90\% de los ingresantes que fue desaprobado o que no se presentó a rendir tendrá que realizar un curso introductorio de cuatro semanas -y un examen final- que comenzará mañana.

\section{Antecedentes}

Ingeniería: en diciembre de 2001, de 1000 inscriptos rindieron sólo 316; de ellos, reprobó el 86 por ciento.

Medicina: en junio último, más del $70 \%$ de los 1600 inscriptos superaron el examen de ingreso y el recuperatorio. La cifra de reprobados en esta facultad superaba siempre el 65 por ciento.

Derecho: hace dos años, más de 2000 ingresantes reprobaron un polémico examen que incluía preguntas básicas de historia argentina.

Jesús A. Cornejo 


\section{Mala nota}

Los paises latinoamericanos siguen rezagados en ciertos aspectos en comparación a otros

Inversión en educación como \% del PIB

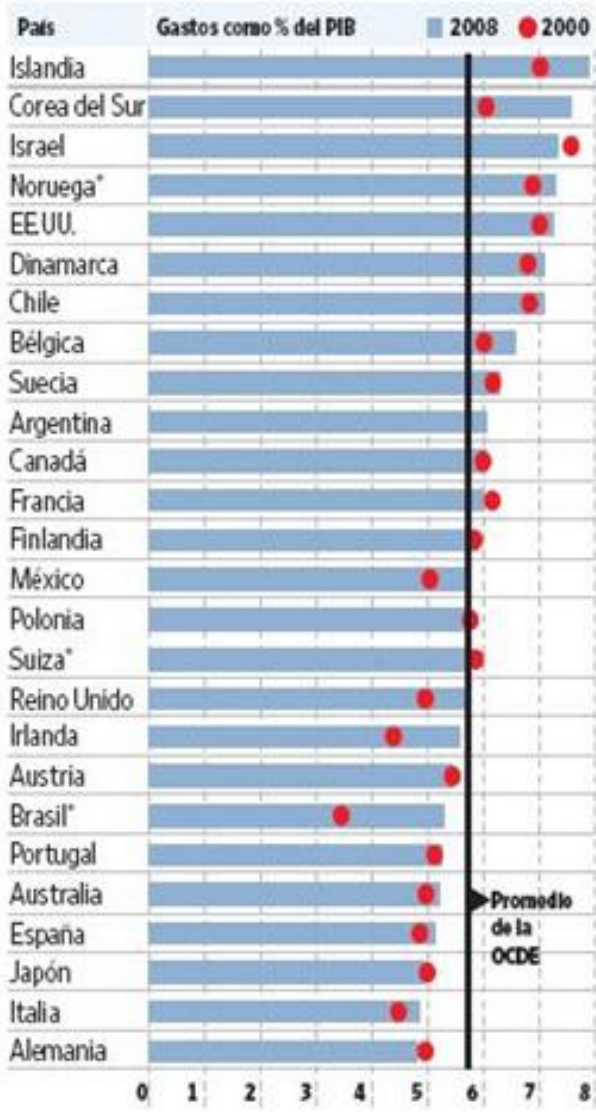

Nota: Para todes les niveles educativos $(2000$ y 2008$)$ y camble porcentual entre 2000 y $2008(2000=100$, en predos constames $x$ Solamente gastos pubilicos (para Sutza, wib en educacion supertor: para Argentria Indonesix irstatito Unesco para Estadisticas (World Education indicators Programme).
Inversión en educación en Brasil, 2000-09 en miles de mill. de reales

Prueba Pisa, matematica

Mandclpal Estatal Federal
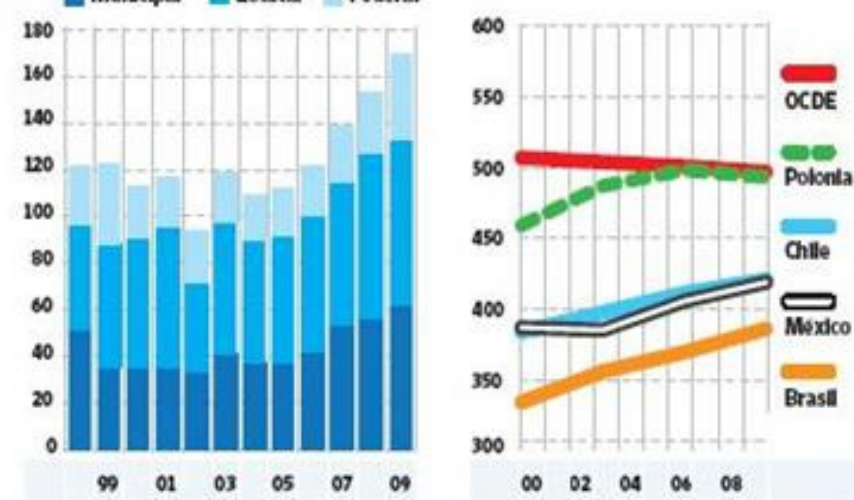

Fuentes: Tesomo Naxionat; OCDE (Ptsa), va el Banco Munetal

Afios de escolaridad en Brasil por renta familiar

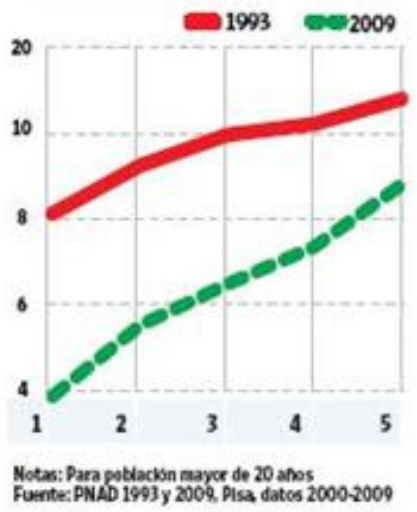

Prueba Pisa, matematica

Por quintil de renta en Brasil

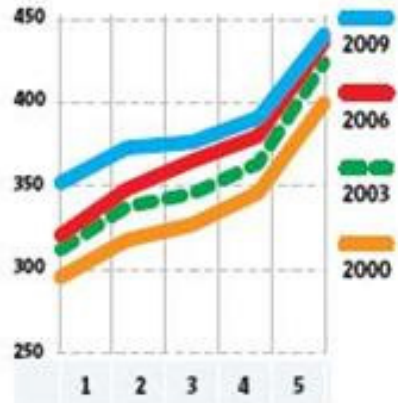

The Wall Street bural 